University of Louisville

ThinkIR: The University of Louisville's Institutional Repository

Electronic Theses and Dissertations

$12-2010$

\title{
How fares the selective tradition? : racial representation of characters in second grade classroom libraries.
}

Nancy Franklin Hulan

University of Louisville

Follow this and additional works at: https://ir.library.louisville.edu/etd

\section{Recommended Citation}

Hulan, Nancy Franklin, "How fares the selective tradition? : racial representation of characters in second grade classroom libraries." (2010). Electronic Theses and Dissertations. Paper 650.

https://doi.org/10.18297/etd/650

This Doctoral Dissertation is brought to you for free and open access by ThinkIR: The University of Louisville's Institutional Repository. It has been accepted for inclusion in Electronic Theses and Dissertations by an authorized administrator of ThinkIR: The University of Louisville's Institutional Repository. This title appears here courtesy of the author, who has retained all other copyrights. For more information, please contact thinkir@louisville.edu. 


\title{
HOW FARES THE SELECTIVE TRADITION? \\ RACIAL REPRESENTATION OF CHARACTERS IN SECOND GRADE CLASSROOM LIBRARIES
}

\author{
By \\ Nancy Franklin Hulan \\ B.A., University of Kentucky, 1999 \\ M.Ed., Vanderbilt University, 2003

\begin{abstract}
A Dissertation
Submitted to the Faculty of the

Graduate School of the University of Louisville

in Partial Fulfillment of the Requirements for the Degree of

Doctor of Philosophy
\end{abstract}

College of Education and Human Development

University of Louisville

Louisville, Kentucky

December 2010 



\title{
HOW FARES THE SELECTIVE TRADITION? \\ RACIAL REPRESENTATION OF CHARACTERS IN SECOND GRADE CLASSROOM LIBRARIES
}

\author{
By \\ Nancy Franklin Hulan \\ B.A., University of Kentucky, 1999 \\ M.Ed., Vanderbilt University, 2003
}

A Dissertation Approved on

November 9, 2010

By the Following Dissertation Committee

Dissertation Director 


\section{DEDICATION}

This dissertation is dedicated to

my grandparents, who encouraged me to

always keep learning,

my parents, who have provided me

with wonderful opportunities and encouragement, and to my husband and son, who support my efforts with love and patience. 


\section{ACKNOWLEDGEMENTS}

I have many people to thank for assistance and support through the research and writing of this dissertation. My advisor, Dr. Diane Kyle, has provided guidance, patience, and editorial help, as well as support in navigating the process of writing this dissertation. Dr. Ellen McIntyre has been a mentor throughout my doctoral studies, and has helped me through the research and writing process with valuable insights and constructive advice. Dr. Marco Muñoz has provided encouragement and useful information and ideas concerning the context of the study. Dr. Penny Howell and Dr. Bronwyn Williams have also provided useful feedback and insights to this work. In addition, Dr. Dena Dossett has provided helpful information concerning the context of this study. Many thanks! 


\section{ABSTRACT \\ REPRESENTATION WITHIN CLASSROOM LIBRARIES \\ Nancy F. Hulan}

November 9,2010

This study investigated teachers' inclusion of racially diverse literature within their classroom libraries, how the representations within the literature compared with the students in the classrooms, the inclusivity of students' book selections, and teacher thoughts concerning selection of literature. Individual classrooms were found to fall within categories of challenging, progressing against, or continuing the selective tradition, the tendency of teachers to favor literature that primarily features White, middle-class, male authors and subjects over works by and about women and other ethnicities or social classes (Luke, Cooke, \& Luke, 1986). Of 22 classroom libraries, three were challenging, three were progressing against, and 16 were continuing the selective tradition. This indicates that an underrepresentation of diverse characters within classroom libraries still exists, but offers hope that some teachers are making progress toward challenging the selective tradition and including more multicultural literature and diverse texts. Classroom libraries in more and less diverse schools were comparable in portrayal of different racial groups in texts. Thus, the children in more diverse schools are not represented within classroom libraries like the children in less diverse schools. Teachers expressed interest in obtaining more inclusive books for their classroom 
libraries and shared barriers to inclusion of literature within their libraries. Implications for teacher educators and ideas for future studies are shared. 


\section{TABLE OF CONTENTS}

PAGE

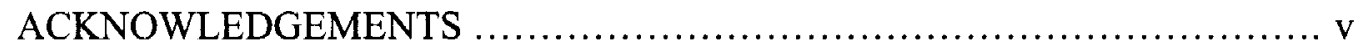

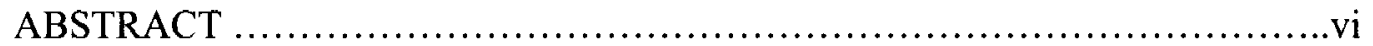

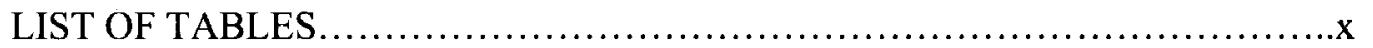

\section{CHAPTER}

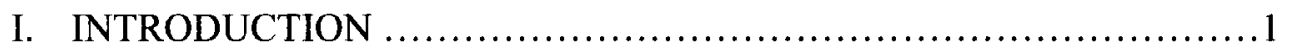

II. LITERATURE REVIEW ............................................... 11

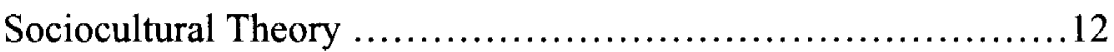

Publication of Multicultural Literature .........................24

Rationale for the use of Multicultural Literature ..................26

Teacher Selection of Literature ................................29

A History of Children's Books ................................32

Purpose of Study ................................................... 34

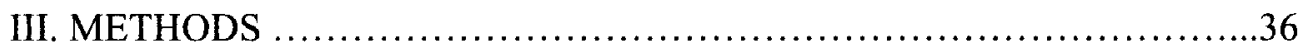

Population and Sample ..........................................

Research Design ...........................................42

Data Collection .............................................. 48

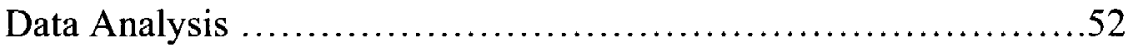

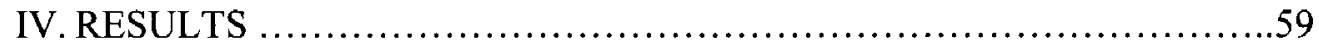

Racial Diversity within Texts in Second Grade Classrooms .........60

Diversity in Literature Compared to Diversity among Students ......67 
The Books Students Choose to Read .............................69

Teachers' Reflections on Selection of Classroom Literature ........72

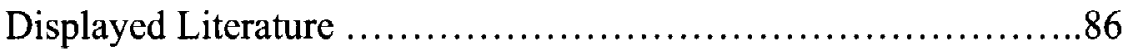

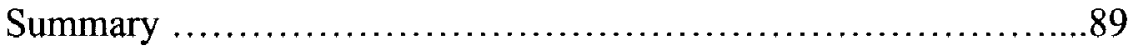

V. DISCUSSION .................................................... 94

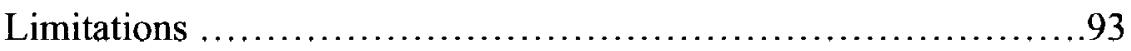

Racial Diversity in Text: Why Should Teachers Care? ............96

Why Teachers Choose the Books they Do: Patterns of

Racial Representation in Second Grade Classroom

Libraries ..........................................98

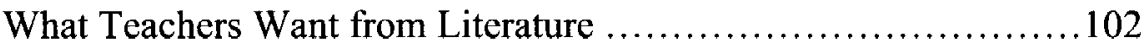

What the Children are Reading: Explaining Children's

Choices ................................................ 104

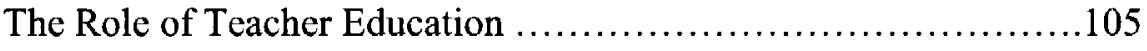

The Role of Schools: Professional Development on Topics

of Diversity .................................. 107

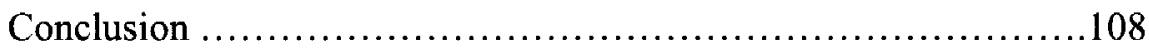

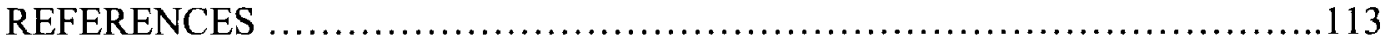

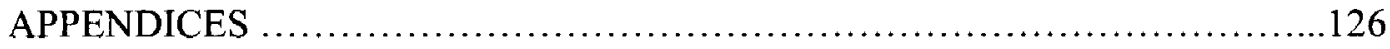

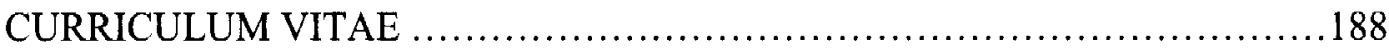




\section{LIST OF TABLES}

TABLE

PAGE

1. Teacher Status Regarding the Selective Tradition ....................62

2. Representation within Classroom Libraries by Teacher ...............63 Education Level

3. Representation within Classroom Libraries by Teacher Race ..........63

4. Diversity Within Literature and Students by School Group ............68

5. Diversity Within Classroom Libraries and Student-Selected Literature ..69

6. Prominent Themes among Student-selected Literature ................71

7. Sources of Classroom Library Books ............................73

8. Qualities Sought within Classroom Library Literature ...............74

9. What Teachers Hope Students will Learn from Classroom Libraries ...76

10. What Teachers Hope Students will Learn by School Group ..........77

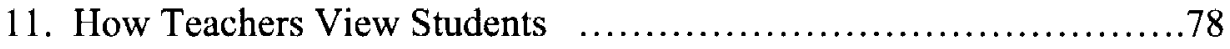

12. Teachers' Views of Students in A and B Schools ...................79

13. Teachers' Literature Wish Lists . .............................84

14. Influence of Information Sources by A and B Schools ...............85

15. Influence of Information Sources by Teacher Experience .............86 


\section{CHAPTER I}

\section{INTRODUCTION}

\section{Significance of the Problem}

In 1965, educator and researcher Nancy Larrick, attempted to answer a 5-year old African American girl's probing question. In looking at picture books in school, this young girl asked, "Why are they always white children?" (Larrick, 1965, p. 63). Upon investigation Larrick found that racial prejudice within society at large was limiting the publication of books depicting anyone other than White characters. More than forty years later publishing companies are putting out far more books that include and in some instances celebrate diverse families, individuals, and cultures. However, this change is not necessarily evident within our schools' classroom libraries.

As we experience an ever-increasing diversity in our schools, the need for crosscultural understanding (Norton, 2005) is amplified in our society. In $2005,33 \%$ of the U.S. population was a race other than White. Predictions point to this number rising to $39 \%$ by 2020 . Within our schools in 2004 , this group made up $42 \%$ of public prekindergarten through secondary school enrollment in the U.S. This percentage ranges dramatically from state to state, from $95 \%$ in Washington, D.C. to $4 \%$ in Vermont (National Center for Educational Statistics, 2008).

As the demographics of our society rapidly change, the students attending our public schools also reflect this change and are more diverse than in the past. However, 
the majority of teachers within our schools are White and middle-class, and curricular materials are predominantly geared toward that same demographic. This lack of representation is a problem for several reasons. Students try harder and feel more comfortable taking risks when they can see themselves as valued agents within the classroom setting. In addition, they learn best within supportive environments which are respectful of their identities (Darling-Hammond, French, \& Garcia-Lopez, 2002). The classroom is a microcosm of society at large, and it is important that all students have the opportunity to learn about themselves and others within and outside of the classroom.

The study described in this paper took place in a district that for years celebrated its diversity plan, in which students were bused from home neighborhoods to other locations with a goal of achieving racial diversity within schools. However, in 2007 , the U.S. Supreme Court declared that the district's placement plan relied too heavily on race and was thus unconstitutional. A new plan was created which continued the busing, but used household income, household education level, geography, and race to determine student placement in schools.

Many community members are outraged by this plan, which they say causes their children to sit on buses for overly-long amounts of time, to switch buses, and to go to school with people who are not from their own neighborhoods. Many want the old model of the neighborhood school back. But the school board and the majority of the community support the need for diversity in schools. They base these ideals on research that has shown that children who have experiences with people of various races are more likely to overcome prejudices and form positive relationships (Holme, Wells \& Revilla, 2005; Killen \& Stangor, 2001). Adults who went through desegregated schools report 
less racial prejudice and are more open to interacting with people of different racial backgrounds (Holmes, et al., 2005). In addition, students who attend desegregated schools and classrooms have higher quality educational experiences than students who attend segregated schools (Mickelson, 2001). The Executive Director for Student Assignment in the participating district has said that children from Area A (low-income and education levels, high minority population) who come from high-need areas do better academically when they are in schools with children who are more affluent and whose parents have rigorous and high expectations for them (Stemle, 2009). In fact, when children are in school with others who look, speak, and sometimes live differently than themselves they are more likely to be "more open-minded, less prejudiced and less fearful" (Holme, Wells \& Revilla, 2005, p. 15).

Like the controversial Student Assignment Plan, this study looked at race as an indicator, which is only one aspect of a child's identity. Others include culture, ethnicity, religion, and interests. Race is a societal construction, and through the years has been used to keep those in low status where they are, while allowing others privilege and power. It has been used as part of a strategy for "dividing, ranking, and controlling" (American Anthropological Association, 1998) people, guaranteeing that those of lowstatus races received less and those of high-status races received more.

The entire concept of race is disputed by many scholars. Traditional views of race assume that each racial group has significant amounts of uniqueness. There is, however, greater genetic variation within racial groups than there is between them (American Anthropological Association, 2007). The concept of race is viewed here as a folk category, used to classify people in societies (Herbst, 1997). 
This study tried to shed light on whether racially diverse students are indeed represented less within the classes they attend than White students. We now know that cultural knowledge is learned and is taught and conditioned into children from birth (American Anthropological Association, 1998). This cultural knowledge is always subject to change based on lived circumstances. Therefore, the representation of racial groups within curricular materials and classroom settings also help to construct that cultural knowledge. Students of all backgrounds should be encouraged to see themselves as valued and unique.

In order for all students to feel valued within the school setting, teachers and administrators must address what Gay (2002) calls the symbolic curriculum. Gay (2002) used this term to describe aspects of the physical environment of a classroom or school which include "images, symbols, icons, mottoes, awards, celebrations, and other artifacts that are used to teach students knowledge, skills, morals, and values" (p.108). These include bulletin boards, walls, books, and images that are advertised in the setting. Teachers and administrators relay their values about who they welcome and what they find important through the symbolic curriculum within their classrooms. The symbolic curriculum is apparent within classroom libraries as well.

Books which include diverse characters within meaningful settings and situations can be helpful in encouraging acceptance and understanding among different racial or ethnic groups (Norton, 1990). They can help students from non-White backgrounds see themselves as valued within the classroom setting, and can encourage respect for one's ethnic or racial heritage (Banks, 2007; Cai, 2008; Cox \& Galda, 1990; Kovarik, 2004; Steiner, Nash, \& Chase, 2008; Yokota, 1993). Such literature is often called 
multicultural literature. There are many reasons to include multicultural literature within a classroom library; however, this sort of literature is not as prevalent as other types of literature.

Recently a popular and prolific author of multicultural literature had an experience that highlights this point. It occurred on a visit to a College of Education where she discussed her work and the need for inclusive literature like multicultural literature within classrooms. Future and current teachers, administrators, and professors sang the praises of such causes, and acted as though they intended to include more multicultural literature within their classrooms. However, a different version of events was relayed from the author to a professor at that university following the experience.

Two teachers drove the author to the airport following her visit. On the way, the author closed her eyes to rest after the busy time at the school. The teachers in the front seats must have thought the author had dozed off because they whispered a conversation between themselves, saying they enjoyed the author's visit, and thought her books were interesting, but that they probably wouldn't use them in their teaching because they "wanted to stick with their old favorites" (McIntyre, personal communication, January 2, 2009).

This vignette points to what Luke and colleagues (1986) called the selective tradition. This is the choice by teachers, parents, and others to use and promote books from their childhoods, which were predominantly if not wholly written by and starring White males. While a rise in the publication of literature about and by women and people of diverse ethnicities and races has occurred, this selective tradition keeps such literature out of the hands of children. 


\section{Problem Statement}

As the faces within our classrooms become more diverse, so too must the faces within our curricular materials. One way that classroom teachers can work toward a more inclusive classroom is to include literature which portrays a diverse selection of characters and to advertise books with culturally inclusive agendas or themes.

Scholars, teachers, and other advocates have been backing the need for multicultural literature, literature that portrays students of diverse backgrounds, within our schools for years (Banks, 2007; Cai, 2008; Cox \& Galda, 1990; Kovarik, 2004; McIntyre, Hulan, \& Layne, 2010; Steiner, Nash, \& Chase, 2008; Yokota, 1993). Principals, administrators, scholars, and many teachers also support the need and importance of such literature within our classrooms. However, as an experienced classroom and reading resource teacher, I believe a dearth of such literature exists within our classrooms.

\section{Purpose Statement}

The purpose of this study was to describe what racial groups were represented within the literature in a sampling of 22 second grade classroom libraries, and how that representation compared with the racial population within those classrooms and the literature selected by students. It was also the purpose of this study to determine reasons behind teachers' selection of books for their classroom libraries and how the selection process may have affected the existence of books portraying racial groups within those libraries.

\section{Research Questions}

The goal of this study was to shed light on the following questions: 
1. What racial diversity (as delineated by the 2006 American Community Survey and the local school district) exists within the texts in classroom libraries in selected $2^{\text {nd }}$ grade classrooms?

2. How does the racial diversity in the literature compare to the racial representation of the students in those classrooms?

3. What books do students in those classrooms choose to read?

4. How do teachers choose the books for inclusion in their classroom libraries?

5. What books are purposefully displayed by the teacher and what themes do those books represent?

\section{Significance of the Study}

While many studies have touted the need for and benefits of multicultural literature in elementary settings (Banks, 2007; Cox \& Galda, 1990; Diamond \& Moore, 1995; Kovarik, 2004; Norton, 2005; Torres-Velasquez, 2000; Yokota, 1993), no one has conducted an examination of teachers' collections to see what is actually present in the classroom libraries. The findings from this study help to shed light on the state of literature within classrooms, ways teachers choose literature for their classrooms, and which books students choose to read. The study has implications for classroom teachers, teacher educators, school administrators, and publishers of children's literature.

\section{Delimitations}

This study took place during the Spring semester of 2009 in 22 selected second grade classrooms in a large Midwestern school district. Second grade classes were chosen based on that age level's (7-8 years) novel ability to have deeper insights into literature due to their more flexible thinking (Temple, Martinez, Yokota, \& Naylor, 
2002), and because second graders are typically reading independently. In addition, second grade students were chosen over students in kindergarten and first grade because the earlier grades generally focus on learning the mechanics of reading while students in second grade typically are learning to read for meaning. Children during this time period also learn to assume viewpoints which are different than their own (Patterson, 2008), which helps children to comprehend literature. Twenty-two teachers participated, two from each selected school. The school district has designated schools as "A" and "B" schools based on socioeconomic status, adult education level, and minority rate. The district is also broken into six geographic regions. Because this study focused on portrayals of race within children's literature, an attempt to collect data in the " $\mathrm{A}$ " schools with the highest minority rates and the "B" schools with the lowest minority rates was made to enhance the comparison. In the end, eleven schools took part in this study, five A schools and six B schools. Within each of those schools two teachers' classrooms were used for the sample. Therefore, the sample consisted of 22 classrooms.

\section{Assumptions}

In this study, the following assumptions were made: Teachers answered questionnaires accurately and honestly. Teachers placed only the books that were within students' desks on students' desks. It was also assumed that teachers did not alter their classrooms before observations.

\section{Definition of Terms}

Classroom Library: The books which students are allowed to read while in the classroom; these include fiction and nonfiction, but do not include reference 
books (encyclopedias, dictionaries), basal readers, or textbooks that are set apart from the classroom library

Multicultural Literature: Literature that focuses on populations other than White people

Race: A folk, not a scientific category used for classifying people in societies (Herbst, 1997); individual races identified within this study are White, Black or African American, Hispanic or Latino, Asian, American Indian or Alaska Native, Native Hawaiian or other Pacific Islander, and Other

Racial Diversity: The extent to which various races are represented within a classroom or book

Selective Tradition: The tendency of teachers to favor literature that primarily features White, middle-class, male authors and subjects over works by and about women and other ethnicities or social classes

Symbolic Curriculum: "Images, symbols, icons, mottoes, awards, celebrations, and other artifacts that are used to teach students knowledge, skills, morals, and values "(Gay, 2002, p.108).

\section{Organization of the Remaining Chapters}

The remainder of this dissertation is organized in four additional chapters, a bibliography, and appendices in the following way. Chapter two discusses the literature which is pertinent to and which describes the need for this study. This consists of an exploration of theory, publication trends, the need for incorporation of multicultural literature within classroom libraries, and teacher practices. Chapter three details the research design and methodology used in this study. The instruments used to collect 
data, procedures followed, sample selection, data collection, and methods of data analysis are also described. Chapter four reports the results of the study. Chapter five includes a summary of findings, conclusions, and recommendations for future work. A bibliography and appendices conclude the dissertation.

\section{Summary}

The growing racial diversity within American classrooms leads to the need for inclusion of literature that reflects this diversity. Studies have shown that while there has been an increase in the publication of multicultural literature (Cooperative Children's Book Center, 2008), there is still a tendency for teachers to choose literature that portrays and/or is written by White males-- literature they read as children (Jipson \& Paley, 1991; Luke, Cooke, \& Luke, 1986; Mosely, 1997). While the inclusion of multicultural literature has been seen to help children to value their cultural, racial, or ethnic backgrounds (McIntyre, Hulan, \& Layne, 2010; Steiner, 2001; Yokota, 1993), the selective tradition, or choice of teachers to exclude such books, could keep children from experiencing literature as a reinforcing agent for the development of pride in their

backgrounds. It also keeps children from learning about people different than themselves. This study investigates the racial diversity represented within the literature in selected second grade classrooms and teachers' limitations and successes in including such literature. 


\section{CHAPTER II}

\section{LITERATURE REVIEW}

As the faces within our classrooms become more diverse, so too must the faces within our curricular materials and the books that are available for students to read. One way teachers can work toward more inclusive classrooms is to select literature that portrays a diversity of characters for their classroom libraries. Teachers in public schools tend to work with limited resources and often struggle to find appropriate materials for the classroom. In an attempt to clarify the state of our classroom libraries, this study described the characters that populate the literature within classroom libraries and the books selected by children for personal reading in selected $2^{\text {nd }}$ grade classrooms in one school district in the Midwestern United States. An additional purpose of this study was to describe the intent and motivation surrounding teachers' literature selection and how these processes may affect the presence of books portraying diverse students within those libraries.

In second grade, children (generally between seven and eight years of age) are acquiring new information through learning activity, which is described as structured activity around specific content (Bodrova \& Leong, 1996). Within this time, students' thinking becomes more flexible, allowing them to have deeper insights into literature (Temple et al., 2002). One further accomplishment of this time period is that they learn 
to assume viewpoints that are different from their own (Patterson, 2008), which helps children to comprehend literature. For this study, second grade students were chosen over students in kindergarten and first grade because the earlier grades generally focus on learning the mechanics of reading while students in second grade typically are learning to read for meaning, which coincides with more independent reading.

Furthermore, by the age of eight, children begin to self-identify with an ethnic group (Aboud, 1987), which helps them to mold their own identities while being able to compare and contrast themselves with others in the world and in literature. These milestones point to the novel ability of second graders to see and understand people like and different from themselves within literature.

Positive literature can lead children to appreciate differences and uniqueness, leading to appreciation of others. With such results possible, this study sought to determine the level of representation of diverse populations within classroom libraries in selected second grade classrooms.

A review of pertinent literature is presented in this chapter. The major tenets of sociocultural and transactional theories are discussed in order to position the reader and the study within a theoretical framework. Next, a discussion of the symbolic curriculum, specifically in light of multicultural literature is presented. Finally, research on teacher selection of literature for the classroom and the "selective tradition" are shared within a historical frame.

\section{Sociocultural Theory}

Today's educational structures, assumptions, content, and operations were built upon European American cultural icons and ideals (Gay, 2000). The curriculum, 
materials, and pedagogical practices have focused on what works for White, middle-class children or teachers rather than what works for the diverse population which actually exists within the walls of a school. This imbalance between the curricular world and the world of students can interfere with academic achievement (Gay, 2000). The inconsistencies between the two can cause disturbances in children's learning and motivation. One reason for this is that formal education is not the first chance we have to learn. Children's education begins long before they reach school. As Vygotsky pointed out, "any learning a child encounters in school always has a past history" (1978, p. 84). This background knowledge can destructively intersect with school knowledge, because how children are accustomed to engaging in "intellectual processing, self-presentation, and task performance is different from the processes used in school" (Gay, 2000). This culture clash can cause students to drop out of school, figuratively and literally. As Williams states:

...people whose identities don't fit the scripts of the dominant culture's narratives often are silenced... it is part of our job as literacy educators to engage with such issues... Our literacy practices can help us to explore and understand issues of identity, both individually and as a culture (2003, p.181).

It is important that teachers respect the individual identities of their students (Nieto, 2000) and learn what they can about them (McIntyre \& Stone, 1998). Students learn best within supportive environments which are respectful of their identities (Darling-Hammond, et al., 2002). One way teachers can create such an environment is through connecting curriculum to students' lives and background knowledge by filtering content and teaching strategies through students" "cultural frames of reference" (Gay, 
2000, p. 24) or "funds of knowledge," which refer to the wealth of students' household and community knowledge (Moll, Armanti, Neff, \& Gonzalez, 1992). The incorporation of such knowledge can help to make content more meaningful and accessible "because all children have some experiences that can help them learn" (Nieto, 1999, p. 7).

The use of literature in classroom settings has the potential to tap into students' funds of knowledge. Literature serves as one venue for learning and sharing ideas. What a child reads helps her to interpret the world around her. Likewise, the past experiences and knowledge that a child holds help her to interpret literature. Reading is a social act. Because of this, "its use depends upon the needs of communities, families, and individuals, and thus, children come to school with different understandings of how literacy figures into their lives” (Dyson, 1990, p. 196).

Interpretations of literature are influenced by past experiences and understandings of the world, which are rooted in cultural and social histories. It is important that children have access to literature to which they can connect. This need to connect with text in order to read and comprehend leads to an examination of sociocultural theory. Vygotsky posited that we learn from our social interactions with more experienced peers and adults and that all knowledge is socially constructed (1978). This learning takes place within the zone of proximal development (ZPD)- "the distance between the actual developmental level as determined by independent problem solving and the level of potential development as determined through problem solving under adult guidance or in collaboration with more capable peers" (Vygotsky, 1978, p. 86). In order to learn things within the ZPD, a process called scaffolding can help to increase a learner's level of performance and understanding (Wood, Bruner, \& Ross, 1976). 
Scaffolding is, in essence, breaking tasks down into more manageable parts and leading children toward higher levels of functioning and understanding. A gradual release of responsibility from the more experienced to the less experienced participant occurs.

Literature which addresses a child's lifestyle, family, age, ethnicity, or hobby can serve as a scaffold or mediator toward new understandings. Children listening to or reading books that in some ways resemble their lives are more prone to understand the contents, character behaviors, and story structure than if they are unfamiliar with the contents of the story.

This phenomenon can be explained based on the ways children actively observe the events around them and gain knowledge by watching and listening to their surroundings. This process occurs long before school begins (Finn, 1999; Vygotsky, 1978) through involvement with elders and more experienced children. From their very earliest days, children build on skills and perspectives of their society with the help of others (Rogoff, 1990).

Identity. Our literacy practices and understandings of literature are connected to our identities (Williams, 2003). Identity refers to our understandings of who we are and to what groups we belong (Sheets, 2005). Self-concept and self-esteem are highly correlated to identity. For this reason, it is important to recognize that caregivers, parents, teachers and peers impact identity development. "In the classroom children need to be physically safe, emotionally nourished, intellectually challenged, and ethnically acknowledged to ensure positive development of self-concept and self-esteem" (p. 50). People develop their identities over time and across settings (Williams, 2003) through multiple experiences and dimensions of self based on who they are and how they are 
expected to act in various circumstances such as church, school, the basketball court, or step team practice. Various factors play into formation of our identities. These include ethnicity, race, gender, ability, sexual orientation, and religion (Sheets, 2005). In addition, "texts, and the literature practices that accompany them not only reflect but may also produce the self" (Moje \& Luke, 2009, p.416).

An important part of a person's identity is a sense of membership to an ethnic or racial group (Patterson, 2008; Sheets, 2005). For children who are part of a racial or ethnic minority group, "a strong ethnic identity is linked with positive mental health" (Patterson, 2008, p. 545). An understanding of racial and ethnic identity can be accelerated through racial socialization, a process through which parents and teachers instruct children about racial and ethnic culture, in ways to get along in mainstream society, and in ways to battle and cope with racism (Patterson, 2008).

An important role of a teacher is to provide children with the "symbolic material with which to understand and transact with the social environment" (Ferdman, 1990, p. 198). Teachers sometimes try to supply such material through children's books or teaching methods. These often do not reflect diverse faces or practices, and therefore can lead to cognitive dissonance, a disconnect between expected behavior and understandings or beliefs of what is expected or right (Sheets, 2005). Children confronted with this often have to internally rationalize their behavior as an attempt to fit in while they are violating their beliefs or values.

These issues of identity and curricular and cognitive dissonance are especially worrisome in light of the fact that most teachers are White, female, and from the middle class while society's and therefore schools' demographics become more diverse every 
year. The 2004 population brief (United States Census Bureau, 2005) found that $67.3 \%$ of the population was White and $32.7 \%$ of the population was of any other racial background or combination of backgrounds. These numbers are quite different from numbers from 1980 (United States Census Bureau, 1981) when $83.2 \%$ of the population was White and $16.8 \%$ was of any other racial description. In 1960 the population was $88.6 \%$ White with only $11.4 \%$ from any other racial group (United States Census Bureau, 1971). This quick and significant change in the population has led the census bureau and school districts to acknowledge and begin to service the needs represented within our diversity society.

The 2006 American Community Survey (United States Census Bureau, 2006a) collected data on White, Black or African American, American Indian and Alaska Native, Asian, Native Hawaiian and other Pacific Islander, and "Other" racial groups within the population of the United States. The American Anthropological Association (AAA) lists only African, European, and Asian as distinct "races" (American Anthropological Association, 2007). The district within which this study took place lists Black, American Indian, Asian, Hispanic, and White when collecting and reporting racial demographics of students. Race is complex, partially because it is not a biological construct, but a societal and cultural phenomenon. Because a part of identity formation is based on race (Sheets, 2005), this study utilized a combination of reports from the U.S. Census Bureau and the local school district's designations of race. These include Black or African American, American Indian or Alaska native, Asian, Native Hawaiian or Pacific Islander, Hispanic or Latino, White, and Other. 
It is important to point out that while race and the representation thereof was the focus of this study, traditional concepts of race give an inaccurate picture of human variation. These concepts assume that each race has significant amounts of uniqueness while, in fact, "the genetic variation in populations such as Europeans and Asians are actually subsets of the variation in the African population" (American Anthropological Association, 2007, para. 1) and greater genetic variation exists within racial groups than between them (American Anthropological Association, 1998). Race as an ideology is flawed, and has been used to overpower, dehumanize, and control people for centuries.

In this study, the use of race was meant to reflect a basic concept of self which children and teachers recognize daily. Race here was used in order to find out how one part of a student's identity was represented within a classroom. This study was limited to race in order to determine where we are now in our inclusive practices (in regards to book selection) in schools. Do children of diverse racial groups have the opportunities to see reflections of their racial selves within their classroom libraries?

In the years prior to school, children may be accustomed to seeing people who look like them, hearing voices that sound familiar, and interacting with stories in a particular way. When they reach school, many students experience disconnects between the curriculum and the world of school and their own backgrounds. They do not see themselves reflected in the school setting, and therefore may experience difficulty in learning. Without materials (here specifically books) that reflect a child's background knowledge and understandings a child is not likely to see him or herself as an important member of the school community, or as a learner. 
To illustrate the point expressed above, Rogoff (2003) describes studies that scholars conducted in examining peoples' "everyday cognition." They observed such events as people making complicated woven patterns and calculating costs in the market. One such study showed the differences in children's reproduction of patterns depending on their familiarity with the materials being used in that particular process. Children performed well when they were reproducing a pattern in a familiar medium and poorly if the medium was unfamiliar. This helps to illustrate the point that children must be allowed to utilize familiar materials and/or background knowledge in forming new products or understandings. To be successful in such a task, children must be allowed to access prior knowledge, and they must have a reason to do so. With literature that portrays familiar settings, characters, and situations, children have both the reason and the ability to use what they know to interpret stories and to create their own. One of the first ways that children learn to communicate is through telling stories.

Jerome Bruner (1990) argued that "one of the most ubiquitous and powerful forms in human communication is narrative" (p.77). Children learn to recount events using the specific narrative format that is preferred within their cultural communities. Caregivers work in partnership with children in telling stories and in guiding them in the local vernacular, which varies from one community to another (Rogoff, 2003 ). "It is a push to construct narrative that determines the order of priority in which grammatical forms are mastered by the young child" (Bruner, 1990, p. 77). This drive to construct narrative or stories is scaffolded and molded by the narratives within one's culture and upbringing. This again points to the premise that knowledge is socially constructed. 
The social construction of knowledge can occur while children are interacting with peers, adults, or texts. A character in a book or a reading tutor or friend can serve as a source of new information or viewpoints. While it is important that children read books that reflect their own identities and backgrounds, it is also important that children read about groups and people who are different from themselves. Literature serves as a launching point for broadened understandings of ourselves and others, within the intricate transaction between reader and text.

The reading transaction. When a child sits down with a book, neither the child nor the book is the pure creator of meaning. The transaction between the book and the child's background knowledge, likes, dislikes, abilities, and understandings more accurately defines the reading act. Per transactional theory, the reading act is a dialogue among the reader, the text, and the author (Rosenblatt, 1978). This is in contrast to a oneway interaction in which the reader unearths the author's intent or passively receives meaning from that text (Rosenblatt, 1978).

Since the reader and the text participate in a unique reading transaction, no book or reading event will be exactly the same for any two people (Rosenblatt, 1994). Meaning is what happens between reader and text (Rosenblatt, 1982), and that newlyformed, personal meaning depends on the understandings and background knowledge of the reader. Within transactional theory the reader is seen "as the interpreter of the author's cultural representation" (Rogers \& Christian, 2007, p. 26).

This view of reading as an active exchange between text and reader points to the need for students to see themselves sometimes within those texts and the daily narrative of school. Every reader comes to a text with unique ideas and past experiences, so their 
interpretations will be shaped by their identities and the identities represented within the pages. The construction of new knowledge is built upon a child's understandings-in this sense, concepts, characters, or situations that are recognized by the reader help to scaffold a child's integration of new concepts.

A narrative or text can create intense or limited reactions in children. When an experience or text creates intense emotions, the brain tends to label that experience in a child's memory as "important." Such reading experiences and information gleaned from them are more easily remembered in the future (Siegel, 1999). Further, children typically engage more deeply in stories and books that have characters, settings, and topics with which they can relate (Au, 1998; Dickinson \& Smith, 1994; Rosenblatt, 1994). When children engage with and in literature and with the act of reading itself they fare better in school. For this reason, it is important to examine the contents of classroom libraries, student book selections, and teachers' book selection processes to learn who is actually represented therein, and why.

Symbolic curriculum. Within literature, the characters, settings, and themes serve as symbols or signs to readers. The sign is the most basic unit of meaning and can be anything that stands for something to someone. We use signs to send and receive messages, and the person who receives that message gives it meaning based on background knowledge and experiences (Berghoff, 1998). For children to accurately interpret the pictures in children's books, they must have developed schemata or preexisting knowledge to help them to translate what they see as they develop theories of the world (Bettelheim, 1975; Lewis, 2001; Nodelman, 1996). 
Gay (2002) describes "the images, symbols, icons, mottoes, awards, celebrations, and other artifacts that are used to teach students knowledge, skills, morals, and values" (p.108) as the symbolic curriculum. What teachers choose to display in their classrooms, the books they choose to advertise or promote to students, and ultimately who they revere within the walls of the classroom are all part of this symbolic curriculum. All of the subtle decisions that teachers make contribute to education as a process of socialization (Jackson, 1994). After being exposed to a teacher's choice of images over time, students come to value what is portrayed on the walls and begin to devalue what is not (Gay, 2002). Research has shown that messages in books may shape children's behaviors and attitudes. In this way, "texts always act as a subtle kind of propaganda" (McNair, 2003, p. 46).

In describing the ways that attitudes and beliefs are passed from teachers to students, Dewey (1997) stated, Beliefs and aspirations cannot be physically extracted and inserted. How then are they communicated? Given the impossibility of direct contagion or literal inculcation, our problem is to discover the method by which the young assimilate the point of view of the old, or the older bring the young into like-mindedness with themselves. The answer, in general formulation, is: By means of the action of the environment in calling out certain responses. The required beliefs cannot be hammered in; the needed attitudes cannot be plastered on. But the particular medium in which an individual exists leads him to see and feel one thing rather than another; it leads him to have certain plans in order that he may act successfully with others; it strengthens some beliefs and weakens others as a 
condition of winning the approval of others. Thus it gradually produces in him a certain system of behavior, a certain disposition of action. (p.10)

What Dewey spoke of in this quote has been called the hidden curriculum by some researchers (Anyon, 1980; Apple, 1980; Giroux \& Penna, 1979; Snyder, 1973). This refers to the underlying and unspoken goals of education for specific groups of students. For example, Rist (2000) described how a teacher in 1970 formed expectations of students based largely on social class. She split her class into groups, one that was expected to succeed, which she called the "fast learners," and another that was expected to fail, which she called the "slow learners." The group she called "fast learners" received "the majority of the teaching time, reward-directed behavior, and attention from the teacher. Those designated as 'slow learners' were taught infrequently, subjected to more frequent control-oriented behavior, and received little if any supportive behavior from the teacher" (Rist, 2000, p.268).

He explained how this phenomenon mirrored the class system within society and contributed to the formation and perpetuation of it. Schools continue to do this by providing middle- and upper-class students with more ideal treatment and educations. They receive more freedom and choice in their education, and higher levels of information (Finn, 1999; Shannon, 1985) while students in lower-class populations receive basic skills practice within highly controlled and contrived lessons. This hidden curriculum persists in today's schools.

Teacher selection of literature, then, has the potential to be both curricular and political. When choosing literature because it emphasizes concepts in the curriculum in an understandable way, that is a curricular decision. When selecting literature because it 
illuminates themes of social justice, of equality, or the environment, that is a political or dogmatic decision. Some texts could be selected using both criteria. Multicultural literature can serve both functions within this false dichotomy. Many multicultural children's books have been written surrounding themes of social justice, equality, the environment, etc. while also providing rich story lines and character descriptions for use in literacy education. For instance, Stitchin' and Pullin' (McKissack, 2008) addresses the importance of knowing about one's heritage and overcoming struggles for freedom. $M y$ Name is Yoon (Recorvits \& Swiakowska, 2003) is about learning to live and write in a new culture and language. These are two examples of the multitude of multicultural literature that has been published which addresses the above themes. This study will seek to find out whether teachers are incorporating such titles into their classroom libraries.

\section{Publication of Multicultural Literature}

The majority of children's literature has served as a type of mirror for the ideals of the dominant culture in society. Multicultural literature is about nondominant cultures, "cultures which exist parallel to the dominant culture" (Martinez \& Nash, 1998, p. 13). Harris described multicultural literature as "... literature that focuses on people of color (such as African-Americans, Asian-Americans, Hispanic-Americans, and NativeAmericans) or religious minorities (such as Amish or Jewish) or regional cultures (such as Appalachian or Cajun), or the disabled, and on the aged" (1996, p. 145).

Interest in creating quality multicultural literature which accurately portrays parallel cultures is a relatively recent phenomenon. In the 1800 s children's magazines and serialized novels were the predominant form of reading material for children. In 1919 , the first editor of books for children was hired by Macmillan, which led to the 
creation of children's book editorial departments in many major publishing houses (Robinson, 2007).

The majority of the books published from the beginning of children's book publishing in the United States through World War II were based on mainstream, hegemonic lifestyles, portraying White middle class characters, settings, and values. Characters who were not of the dominant culture were often stereotyped (Martinez \& Nash, 1998). According to Broderick (reported in Martinez and Nash, 1998), African Americans within juvenile fiction between 1827 and 1967 were portrayed as "unattractive, musical, and dependent on 'whites"” (p.13).

As noted earlier, in the mid-sixties a young Black child looked at a children's book and asked her teacher, "Why are they all White children?" That question led the teacher, Nancy Larrick, to conduct a study of the phenomenon (Larrick,1965). She analyzed 5206 children's books published in 1962, 1963, and 1964. She found that only $6.7 \%$ of the books included one or more African American characters. She further discovered that the publishers with the largest lists of children's books at that time (Doubleday, Franklin Watts, Macmillan, and Harper \& Row) published 866 books in that same period with only $4.2 \%$ involving an African American character in text or illustration. Even more striking, eight publishers produced books exclusively with allWhite characters.

Chall, Radwin, French, and Hall (1985) replicated Larrick's study ten years later. They found that $14.4 \%$ of books published between 1973 and 1975 included African Americans in the text or an illustration. That was more than double the number from Larrick's study but was still an unrepresentative portion of the children's books published 
in that period. In another study of African American representation within children's books, Rollock (1984) found that among those published between 1979 and 1984 only $1.5 \%$ of the total represented African Americans in any way. This represented a decrease in publication of such works. There has been even less representation of groups such as Latinos, Asian Americans, and Native Americans (Temple et al., 2002).

These studies indicate a gross underrepresentation of African Americans and other diverse populations within children's literature. In recent years, however, these numbers have fluctuated. Since 1985 the Cooperative Children's Book Center (CCBC) at the University of Wisconsin has collected data on books written and/or illustrated by African Americans. In 1994 they began collecting statistics on the number of books "by and about American Indians, Asian/Pacific Americans, and Latinos" (2008, para. 2). Based on data from the CCBC (2008) 5\% of newly published books that they received in 2007 included African American characters. This figure increased to $10.7 \%$ of the 3,000 books reviewed by the CCBC when also including American Indians, Asian Pacific Americans, and Latinos in the analysis. This suggests that while the statistics still show an inequality in publishing, publishing companies are producing more books that include diverse faces, themes, and attitudes. There are several reasons why this is important.

\section{Rationale for the Use of Multicultural Literature}

Multicultural literature can be used to modify curriculum, instruction, and the learning climate to make a classroom more inclusive (McIntyre, Hulan, \& Layne, 2010; Young, Campbell, Oda, 1995). Our texts should reflect the diversity of the outside (real) world (Coatney, 2004; Kovarik, 2004; Young et al.,1995) the values and traditions (Cox \& Galda, 1990), and perspectives and knowledge (Torres-Velasquez, 2000) of diverse 
groups. Students who don't see their identities or cultures reflected anywhere but at home may begin to question their self-worth and acceptability in the world outside of that home (Henderson, 1991). In 1985 Eloise Greenfield wrote:

The books that reach children should: authentically depict and interpret their lives and their history; build self-respect and encourage the development of positive values; make children aware of their strength and leave them with a sense of hope and direction; teach them the skills necessary for the maintenance of health and for economic survival; broaden their knowledge of the world, past and present, and offer some insight into the future. These books will not be pap- the total range of human problems, struggles and accomplishments can be told in this context with no sacrifice of literary merit. (p. 21)

Multicultural literature can provide opportunities to view and learn about one's own culture. It can assist children in understanding and identifying with their culture more fully (Banks, 2007; Cai, 2008; Cox \& Galda, 1990; Kovarik, 2004), helping them to develop their identities (Al-Hazza \& Bucher, 2008). Reading about one's own culture can develop pride and a positive self-concept (Steiner, Nash, \& Chase, 2008; Yokota, 1993). Children can learn about their own uniqueness and see how their cultures relate to and interact with other cultures (Banks, 2007). It can be affirming for students to see stories like their own reflected in literature (Cox \& Galda, 1990; Steiner, Nash, \& Chase, 2008) and can "promote a feeling of belonging among immigrant and minority youth" (Agosto, 2007, p. 27), averting feelings of isolation (Steiner, et al., 2008). 
Multicultural literature can also teach us about other cultures. It can help us to see the similarities and differences among various cultures (Agosto, 2007; Norton, 1990), and can lead to social sensitivity to the needs of others (Norton, 1990), as well as an appreciation of our uniqueness (Rasinski \& Padak, 1998). Through literature about other cultures we see different perspectives (Cox \& Galda, 1990; Galda, 1998) and can experience cultures vicariously (Yokota, 1993). An introduction to characters who are different from ourselves can help to develop our understandings of other value and belief systems (Norton, 1990).

To help our students function within a diverse global society (Cox \& Galda, 1990) we must increase understandings of various forms of knowledge, attitudes, and skills (Bishop, 2003; Cai, 2008). These attitudes and skills can influence the way children see themselves within a culturally pluralistic society (Yokota, 1993), potentially leading to an appreciation of other cultures and increased understandings of cultural conflicts (Cai, 2008). Bishop (1990) discussed the utility of multicultural literature through the metaphor of mirrors and windows to explain two uses of the literature. As mirrors, multicultural literature allows readers to see reflections of their own lives while as windows lets readers visit the lives of others.

Positive multicultural literature has been used effectively to help readers identify cultural heritages, understand sociological change, respect the values of minority groups, raise aspirations, expand imagination and creativity, improve reading scores when linked to effective instruction and activities, and improve attitudes among students from varying cultures (Norton, 2005). It is for all of these reasons that the presence of multicultural literature is necessary within our schools. It is clear that students and teachers can benefit 
from inclusion of diverse literature within a classroom, but if these books are not making their way into classroom libraries the argument is null. If a child sits in a classroom wishing for a book that resembles him/herself but can't find it, will the child want to read? Will the child feel validated within the school setting? Will the child succeed to the heights she may have if that literature had been there?

\section{Teacher Selection of Literature}

While much research defends the use of multicultural literature, theory seems to be out-running practice (Gay, 1995). In several studies, preservice and inservice teachers have shown a tendency to select books with hegemonic themes, and lacking cultural diversity or sensitivity. In one such study Luke, Cooke, and Luke (1986) asked 54 preservice teachers to choose their favorite children's books that they thought elementary school students would like and would learn from. The majority of these respondents did not consider race or gender of author or character in their selections. In addition, the majority of their selections were written by and about White men, and the characterizations were very "conventional and stereotypical" (Luke, et al., 1986, p. 213). In their findings they noted the presence of unconscious gender and racial bias within preservice teachers' constructs of what is appropriate for kids to read. Younger preservice teachers chose books by drawing on their childhood memories and the background experiences they had with literature, stating that they chose "books I liked as a kid" (p. 216). The authors posed this as possible evidence of "cross-generational cultural reproduction (p. 216)," perpetuating the use of male and White-centric literature. Hunt (2001) called this preference of works from one's own background "commercial conservatism" (p. 9). Luke and colleagues borrowed Williams' (1978) idea of the 
selective tradition, which he used for the way society intentionally and selectively shapes the past and present, to describe the tendency of teachers to favor literature that primarily features White, middle-class male authors and subjects over works by and about women and other ethnicities or social classes (Luke, et al., 1986).

In an attempt to extend the findings of Luke and colleagues, Jipson and Paley (1991) surveyed 55 teachers in elementary schools to see if inservice and practicing teachers would continue following the selective tradition, as preservice teachers had done in the previous study. Surveys asked teachers to name the titles, authors, and main characters of three children's books they used in their instruction during the previous year and reasons for choosing each book for use in their classes. Results indicated that the selected books showed an extreme over-dependence on works that did not include nonWhite characters. Teachers' reasons for choosing books were broken into three categories:

... the appropriateness of the text within a larger instructional context, personal preference for the books because of the story, author, illustrations, or awardwinning status, and the recognition of gender, race, and ethnicity as important elements in (the) book selection process (Jipson \& Paley, 1991, p. 152).

These results indicate that teachers were at least beginning to include the identities of children in their thought processes when selecting books through the examination and inclusion of characters of different genders, races, and ethnicities.

Mosely (1997) inventoried books within the school library of one elementary school that served predominantly African American students. She found far fewer books 
with African American, Asian, Native American, and Hispanic characters than books representing White people.

In 1996 Hart and Rowley gave preservice teachers selections from various works of children's literature. Different pages represented Caucasian, African American, Asian, Hispanic, Native American, and Appalachian people. The future teachers were asked at the beginning and end of a course to select five pages from the packet that appealed to them as valuable resources within the elementary classroom. They gave instructional, personal, and production quality reasons for selections. Following a course on inclusive teaching practices more of the future teachers exhibited a willingness to select books that included groups that were "other than mainstream" (Hart \& Rowley, 1996, p. 214).

The willingness to move away from the selective tradition, the development of understandings that students need to see themselves within literature and the ability to find appropriate literature are hurdles that must be overcome by teachers. Small (2000) studied ways teachers choose materials for their classrooms, and found that the most influential sources for information on books for the classroom included other teachers, libraries and librarians, conferences, workshops, and book clubs. Less influential sources were journals and magazines, family members, and students' parents. The least influential source of information about books for the classroom at the time of the study was the Internet. To determine whether the teachers in the present study use similar or different resources as those within Small's study, teachers will be asked in the teacher questionnaire where they obtain the most influential information about children's books. In preparation for this study, a focus group of elementary school teachers from one school in the participating district was asked to share their sources of books for their 
classroom libraries. About 40 teachers participated, and all of their suggestions were included in a questionnaire used in this study. Based on this focus group, it became clear that many teachers acquire books for their classroom libraries from retiring teachers, yard sales, community library sales, book fairs and clubs, and their own homes. For this reason, the classroom library of a typical $2^{\text {nd }}$ grade is likely to include books from decades long gone as well as new works of literature. To understand complications and influence of age on literature within classroom libraries, it is important to learn about the historical purpose of children's literature through the years. Teachers could unknowingly harbor books within their classroom libraries that perpetuate sexist and racist ideologies.

One way that stereotypes are passed through generations is through children's books (Gillespie, Powell, Clements, \& Swearington, 1994). Teachers should read literature before sharing it with a class to make sure the characters are portrayed in a culturally conscious way (Gillespie et al., 1994), accurately depicting the language, history, values, and culture of any group. Materials should not include any racist themes or words (Jackson, 1994), loaded words with insulting undertones or sexist language (Kovarik, 2004), or stereotypes (Agosto, 2007). When including multicultural literature, Kovarik (2004) recommends that teachers check the copyright dates, stating that multiracial books that correctly represented multicultural realities did not appear until the early 1970s.

\section{A History of Children's Books}

Children's literature has developed over time through the desire of society to educate children in one way or another. The general chronology of this literature's hidden intentions went through religious ideology, then education, and finally toward 
pleasure reading for children (Hunt, 2001). The first picture books, beginning in the mid1600 's, were focused on religious doctrine, with the first widely-distributed works of this kind written by Puritan writers (MacLeod, 1995). These usually included an educational or folklore slant, and were intended for a child's moral instruction, with little focus on entertainment and more on modeling behavior and religious content (Hunt, 2001).

This began to change in the late Victorian era. During that time books evolved to include artistry meant to appeal to and delight children (Martinez \& Nash, 1998). A transformation from mere instruction to enjoyment had begun. As childhood became more valued, children's books "became more respectful towards the child and imagination, and less didactic" (Hunt, 2001, p. 11). Books continued in this way for many years.

In the 1940s and 1950s books portrayed a "single vision of a secure childhood and an abiding social order" (Egoff, 1981, p. 249). In these works diversity was nonexistent, and there was only one acceptable way to behave. Martinez and Nash (1998) explain that in the 1960 s books seemed to be continuing the trends of the earlier era until the publication of Where the Wild Things Are (Sendak, 1963). This work brought to light the idea that the young child "matures more by sharing in the real and emotional world around it than by being protected from it" (Egoff, 1981, p. 251). This rather sociocultural sentiment led writers and publishers to begin tackling real children's issues within literature. These included such themes as death, sibling rivalry, and moving. In the 1980s and 1990s more children's books were written to involve children, young adults, and adults. Themes within books of that time dealt with cultural diversity, 
social and environmental concerns, and war and its aftermath (Martinez \& Nash, 1998). The trends of the next era are still being forged.

As of 2002 there were more than 50,000 English language works for children in print (Temple, et al., 2002). Every year approximately 5,000 new titles are published in the United States. While excellent multicultural literature is published each year (CCBC, 2007), it represents a relatively small proportion of these new titles. Therefore, it is imperative that teachers work to incorporate literature that portrays diversity of peoples in their classrooms. While teachers and schools work to keep their libraries current, it is often difficult to reflect the relatively new appreciation of diversity within our classrooms.

\section{Purpose of Study}

More of the literature being written today reflects the realities and faces within our classrooms than in the past. The inclusion of such literature within our classroom libraries is important for the cognitive and affective development of our diverse population. Without such inclusion our diverse students become silenced (Williams, 2003). Therefore, this study sought to determine the extent to which racial diversity was present within second grade classroom libraries and students' selections from these libraries. Further, this study addressed teacher intentions, criteria, and resources used in obtaining books for their libraries.

Previous research has described the value of multicultural literature, criteria for appraising an individual work's merit, and ways to use the literature within the curriculum. One missing piece to this discussion is the level of inclusion of such literature within classroom libraries. As the faces within our classrooms become more 
diverse, so too must the faces within our curricular materials. One way that classroom teachers can work toward more inclusive classrooms is to include literature which portrays a diversity of characters. The purpose of this study was to describe who is represented within the literature in selected second grade classroom libraries in one large, urban district in the Midwestern United States. It was also a purpose of this study to determine the nature of teachers' book selection processes for their classroom libraries and how this process may affect the existence of books portraying diverse students within those libraries. 


\section{CHAPTER III}

\section{METHOD}

This chapter describes the methodology used in this study. A statement of the purpose and research questions will be followed by a description of the research design. The study's sample, population, and reasons for their selection will then be discussed. Instrumentation, data collection techniques, data analysis, and limitations are also described.

\section{Purpose}

This study looked into the world of the second grade classroom through inclusion or absence of racially diverse characters within books students are allowed to read and which are presented or advertised in that classroom. In addition, the perspectives of that classroom's teacher were retained and ciphered for intentions toward or aversions to inclusion of racially diverse populations within classroom literature, limitations to finding resources, and sources of information on children's literature. Through this study the following questions were addressed:

1. What racial diversity (as delineated by the 2006 American Community Survey and the local school district) exists within the texts in classroom libraries in selected 2nd grade classrooms?

2. How does the racial diversity in the literature compare to the racial representation of the students in those classrooms? 
3. What books do students choose to read?

4. How do teachers choose the books for inclusion in their classroom libraries?

5. What books are purposefully displayed by the teacher and what themes do those books represent?

I approached this study from a sociocultural perspective, seeing learning and the construction of identity as social. Both knowledge and identity are seen as ever-changing due to life experiences. Thus, experiences with text depend on the reader, the history of that reader, and the intent of the author. A transaction between all of these factors creates meaning, leading to the idea that a book will have a different meaning for different readers, depending on prior experiences and factors such as race, gender, religion, and others that help to construct identity.

\section{Population and Sample}

The sample for this study came from elementary schools in a large, Midwestern school district. Ninety elementary schools served 48,404 students in the district. The population of that student body was $48.8 \%$ White and $51.2 \%$ non-White. Of the elementary students $61.9 \%$ qualified to receive free or reduced lunch and 1,777 or $3.7 \%$ of students received services to address their limited English proficiency (Rodosky, 2008a).

Following a 2007 Supreme Court decision stating that this district could no longer use race in the assignment of students to schools, a new district map was drawn based on household socioeconomic status, education level of adults in the homes, and percentage of minority students attending the schools. Of the ninety elementary schools, 82 were 
placed within this new plan. Some schools were not part of the student assignment plan because they were either magnet schools or had another distinction, making adherence to the student assignment plan impractical (Muñoz, 2010). Data were collected on each of the previously listed demographic variables, and schools received an " $A$ " or " $B$ " distinction based on the findings.

The school district's Accountability, Research, and Planning Department performed an analysis of the areas surrounding each school. Based upon the socioeconomic status, education levels of adults, and percentage of minorities within the area of each school they assigned the "A" or "B" distinction. The "A" schools lie within geographic areas in which 1) the median household incomes are below the district average, 2) the educational attainment of people of age 25 or older is lower than the district mean, and 3) the number of minority families living in the area is above the district average. The " $\mathrm{B}$ " schools lie within a geographic area in which 1) the median household incomes are above the district average, 2) the educational attainment of people age 25 or older is higher than the district mean, or 3) the number of minority families living in the area is below the district average (Dossett, personal communication, June 19, 2008).

As it happens, no combinations of these sociocultural variables exist beyond the categories described here as A or B. That is, there are no geographic areas with a higher than average percentage of minority families who also have higher than average income or educational attainment. Thus, the categories used for this study are those used for the district: $\mathrm{A}=$ low income, low educational attainment, and high minority schools, and $\mathrm{B}=$ middle-high income, middle-high educational attainment, or high majority White schools. 
Furthermore, the district is broken into six geographic clusters. In its creation, the planners of this system ensured representation of " $A$ " and " $B$ " schools within each cluster. This was meant to allow students to transfer from one school to another within clusters regardless of socioeconomic status, race, or parent education level.

This study included 11 purposefully-sampled schools based on the percentage of minority students within the schools. Because this study focused on racial diversity in children's books within classrooms, it made sense to view these data in the context of a highly diverse student population as well as a homogenous White population. Therefore, the six " $A$ " schools with the highest percentages of minority students plus six " $B$ " schools with the lowest percentages of minority students were asked to participate first. When an A school or teacher chose not to participate, the A school with the next highest minority population was asked to participate, and so on. Likewise, when a B school or teacher chose not to participate, the B school with the next lowest minority population was asked to participate, and so on.

There are 2,805 full time elementary school teachers in this district. Of those teachers, at the time of the study, $82.6 \%$ held at least a Masters degree. Twenty-five elementary teachers in the district were certified by the National Board for Professional Teaching Standards (NBPTS), and 17 had earned doctorate degrees. Of the full time elementary teachers in the district $14.5 \%$ were African American while $85.5 \%$ were of any other ethnic origin (Rodosky, 2008b). Data on race and educational level of teachers were collected for the specific teachers that participated in this study.

A stratified purposeful sample (Miles \& \& Huberman, 1994; Patton, 2002) was used to select teachers for participation in this study. This helped to "illustrate subgroups 
and facilitate comparisons" (Miles \& \& Huberman, 1994, p. 28). After obtaining names of second grade teachers within the selected schools, two teachers were selected from each school. Since $14.5 \%$ of the teachers in this district are African American, a stratified purposeful sample was used so that some of the participating teachers would be African American. When there was an African American teacher or a teacher of another minority group within the group of teachers at a particular school, that person was asked to participate in the study rather than a White teacher, due to the disproportionately large number of White teachers and the lack of diversity among teachers in public schools. Thus, of the 22 teachers participating in this study, seven were Black and 15 were White. Pseudonyms were used to protect the identities of participants.

Rationale for the sample. There are several reasons why this study focused on second grade classrooms. First, while children are around the ages of seven or eight (and typically in the second grade) their thinking becomes more flexible. This enables them to form deeper understandings about literature (Temple, et al., 2002). Children also learn to assume viewpoints that differ from their own during this time (Patterson, 2008), and by the time children are in second grade they are generally reading for meaning while kindergartners and first graders are still learning the mechanics of reading. Also, by the age of eight, children begin to self-identify with an ethnic group (Aboud, 1987).

The previously listed issues point to the need for literature that provides opportunities to view cultures and races that are both familiar to and different from the readers. Second graders have the ability to see and understand people similar to and different from themselves. Positive literature has the potential to lead children to appreciate differences and uniqueness, leading to appreciation of others. Within the 
participating district, where diversity of the student body is a goal, students need opportunities to see characters who are familiar and those that are novel. Within both schools with more homogenously White populations and schools with more diverse student bodies, students should be able to see characters that look like themselves and characters that look differently than themselves to encourage an appreciation of others. While it is important for young children to experience literature that represents differences and similarities in culture, geography, ethnicity and language, this study was confined to looking at race in the literature as a way to begin to examine the kind of diverse perspectives afforded the students.

Criteria for selection. As previously stated, twelve schools were the goal of selection, based on high (A schools) and low (B schools) student minority populations. The principals of these schools received letters and emails concerning the study, including reasons for the investigation, assurances of confidentiality of the school and teachers, timeline of the study, and any specific requirements of the school for participation. A copy of the letter is included in Appendix A.

If a principal agreed to allow teachers to participate, the stratified purposeful sampling produced the names of teachers who received invitations to take part in the study. Teachers were contacted first by school-based email and then by phone. The correspondence included a description of the study, an invitation to participate, an assurance of their anonymity within the parameters of the study, and a description of what would be required of them if they agreed to participate. If teachers chose not to participate, another teacher in the school was randomly selected and asked to participate in the manner previously described. 
Consenting teachers were required to sign consent forms stating their agreement to participate. This consent form is illustrated in Appendix B. To prevent a situation in which teachers purposefully advertised multicultural literature, but also in an attempt to be honest about the purpose of the study, I gave teachers a description without full disclosure. Specifically, the consent form said the purpose of the study was to describe the types of literature found within second grade classroom libraries, student literature choices, and the ways teachers select and obtain these books. It went on to explain that teachers would be asked to complete a short questionnaire about where and how they select books for their classroom libraries, and that I would inventory the books within their classroom libraries and take photographs of the walls and use of space within the classroom after school hours. The consent form also informed teachers that they would be asked to put books from the classroom library that students had in their desks on top of their desks.

If a principal declined to participate, another school with similar minority demographics was chosen. That school's principal then received the correspondence and invitation to participate in the study. In the end, five A schools (10 A teachers) and six B schools (12 B teachers) participated in this study.

\section{Research Design}

This was a multi-site, qualitative study. This design was chosen specifically to lead to a description of the diversity within texts in classroom libraries and as advertised through the symbolic curriculum beyond the libraries. With the changing demographics in student population in U.S. schools, as stated in Chapters 1 and 2, it is critical that the literature represent the variety of children in the schools. Thus, by comparing the 
diversity represented within the texts in classrooms with the demographics of students in those classrooms, a finding of inequitable representation of children in schools might have been found. On the other hand, this investigation could have led to a realization that teachers were mindfully incorporating texts which portrayed diverse populations in their classroom libraries. The design of this study followed the collective case approach (Denzin \& Lincoln, 2000) with 22 cases (i.e, teachers). Data sources included descriptions of each classroom library, photographic data, teacher questionnaires, and follow-up interviews.

Instrumentation. Three instruments were utilized in the collection of data for this study. These included a chart for book descriptions within classroom libraries, displayed literature, and student-selected literature; photographs taken of books prominently displayed within classrooms and found on students' desks, and teacher questionnaires. Each instrument is described in detail here.

Books in the classroom libraries, left on student desks (upon the request of the researcher), and displayed in the classroom were inventoried using the chart in Appendix C. This chart was created according to guidelines of content analysis (Neuendorf, 2002). It was used to document representation of individual racial groups within each coded book.

Several sources were consulted to define racial groups for the chart used to code books. The Cooperative Children's Book Center (CCBC) (2008) at the University of Wisconsin records the racial representation and diversity of authors within newlypublished books each year. This organization uses the racial distinctions of African/African Americans, American Indians, Asian Pacifics/Asian Pacific Americans, 
and Latinos. The 2006 American Community Survey (from the U.S. Census Bureau) includes White alone, Black or African American alone, American Indian and Alaska Native alone, Asian alone, Native Hawaiian and other Pacific Islander alone, some other race alone, and two or more races in their racial categories (U.S. Census Bureau, 2006b). They included Hispanic or Latino within a question about ethnicity. The district where this study occurred lists Black, American Indian, Asian, Hispanic, and White as racial groups represented within the district (Rodosky, 2008a). Norton (2005) includes African American, Native American, Latino, Asian, Jewish, and Middle Eastern peoples in her description of people represented in multicultural literature.

Due to the discrepancies within these sources, the political and social nature of the subject of race, and the purpose of this study, a combination of the 2006 American Community Survey and the terms used by the school district were used in the data collection of this study to most-closely match the way teachers in the district may view racial groups in their work. The American Community Survey data adds more inclusive categories than the district's framework. Therefore, it allowed for a more inclusive description of books included in the classroom libraries. This allowed for more accurate documentation of teachers' attempts to include racial diversity within their classroom libraries. The groups included within the study's data collection were Black or African American, American Indian or Alaska Native, Asian, Native Hawaiian or Pacific Islander, Hispanic or Latino, White, and other. An additional category was called neutral to document books with non-human characters, such as animals. When I looked through books for racial representations, I looked at characters' skin tone, dress (traditional outfits such as saris, Andean hats, etc.), and book topic (e.g., Day of the Dead). This is an 
imperfect way to classify race, and forced me to make judgments. Sometimes the race of characters was obvious (as in the book about The Day of the Dead, due to the content, images of characters, etc.), and sometimes it was not.

In this study, every fifth book was examined for characters' races. Every fifth book was analyzed because this process has been shown effectively representative in a previous, award-winning study of the holdings of elementary classroom libraries (Duke, 2002). The recognized races/ethnicities or lack thereof (as in animal characters) were tallied on the chart (Appendix C). When marking the sheet for a book that included only Black characters, for instance, I marked 1 under Black/ African American. When documenting a work that portrays Asian, Black or African American, and White characters, I marked a 1 under each of the racial categories represented. When documenting the existence of a work that only portrayed non-human characters- through representation of characters as animals, for example, the neutral category was marked with 1 . The numbers of marks within each category was used to determine the level of racial diversity contained within the classroom libraries. Reference books such as dictionaries and encyclopedias, basal readers, and textbooks were not included within the description of the classroom libraries in this study except when they were obviously part of that library. For example, when a random encyclopedia was inserted within picture books it was included in the data collection (if it was the fifth book). When the encyclopedias were set off away from the classroom library and there was a complete set, it was clear that they were not part of the classroom library, per se, but were part of a specific reference section of the classroom. 
Photographs were taken of books that were "advertised" or prominently displayed within the classrooms. Books that were advertised were sometimes placed on chalkboard trays, on stands, sitting open on top of book cases, etc. Since the teacher actively creates the symbolic curriculum through these types of advertisements (Gay, 2000), these photographs helped me to see if patterns in the symbolic curriculum were evident. The photographs allowed for a more rich understanding of the setting (Bogdan \& Biklen, 1992) and were used to study detail within the classroom in "intense inspection" (p. 143) after the observation. Therefore, the content of these photographs was recorded onto an additional chart like the one in Appendix $\mathrm{C}$ in order to add weight to the classroom library data and to determine what types of characters were advertised within the classroom space. Importantly, the date of data collection was noted so that the advertised books were analyzed in context. That is, certain books are more likely to be advertised prior to Martin Luther King Day, etc.

In addition to photographing the prominently displayed books, photographs were taken of books that students left on their desks (see procedures section below). These data helped to create a full inventory of the classroom library, and indicated which books students actually chose to read from the classroom library. These data were documented separately from the classroom library data to ensure careful use and practicality of analysis of student preferences. In addition, the numbers from student book preferences, the symbolic curriculum photographs, and the classroom library were combined to create a complete picture of racial diversity representation within the classroom library.

Following data collection within each classroom, questionnaires were left for teachers to complete in order to obtain an insider's perspective. This questionnaire is 
shown in Appendix D. The questions were meant to determine how and why teachers chose the books for inclusion in their classroom libraries and who they were thinking of when they selected these books. Teachers were also asked for their dream list of books they would purchase if money was no object. This question was meant to check for interest in inclusion of multicultural literature or literature which represents characters that reflect the identities of their students. One question addressed student demographic data, specifically racial backgrounds. In addition, demographic information of the teachers such as years of experience and teaching degrees were included, and teachers were asked to indicate if they would be willing to answer follow-up questions (details below). Questionnaires were accompanied by self-addressed, stamped envelopes for easy response. These were returned to the researcher's home address and were opened and read by the researcher only. This ensured anonymity of teachers' responses.

Reliability/trustworthiness of the instruments. The instruments used in this study were tested in the field for usefulness and accuracy before the study began. Charts used for documentation of books in classroom libraries and books displayed in the symbolic curriculum were devised using guidelines for content analysis (Neuendorf, 2002). In addition, I analyzed my own use of the chart. A fellow teacher and I analyzed 20 books for character representations. This fellow teacher was an African American woman with 16 years of teaching experience, and she agreed to participate out of interest in the study. The teacher was instructed in how to document data found in the books using two books that were not included in the 20 used for the trustworthiness check. When the teacher and I had completed the analysis of the 20 books separately, we compared our findings. There was $92 \%$ agreement between the two analyses. We went 
back through the books and discussed the way we had coded each. We found that the differences we had existed mainly when one of us had coded a character using one code (for example Hispanic) while the other had coded that same character using more than one code (Hispanic and White). This demonstrates the complexity of dealing with race and ethnicity in research and especially our perceptions of race within texts.

One item on the teacher questionnaires was formulated using a focus group of teachers. This focus group was comprised of kindergarten through fifth grade teachers. Teachers were asked to list the places where they had obtained the books they used in their classroom libraries. A compilation of the responses was used to create the items in question one of the questionnaire, which asks respondents where the books in their classroom libraries came from. Question seven asks respondents to rate several sources of information on children's literature according to how helpful they are to them. This question was inspired by Small's (2000) investigation into teachers' use of resources in selecting literature for the classroom.

Procedures to increase response rates of questionnaires. To ensure a high response rate on questionnaires, stamped, self-addressed envelopes were included with the questionnaires for the teachers along with a gift of pencils for students. In addition, follow-up emails were sent one day after the observation and one week following the observation. Phone calls were placed to the teacher at school each week thereafter. If questionnaires were not received after two weeks, duplicate questionnaires were sent through the school district's mail system to those teachers. This occurred again after one month. Only one of the 22 teachers did not return the questionnaire. This teacher was contacted many times and insisted that she was mailing it on the last day of school, when 
on the phone with the researcher. That was her last day of school before retiring, and the questionnaire was never received.

\section{Data Collection}

Data collection took place in the spring semester of 2009. To limit disruption during the school day, data were collected after school hours (after 4:00 pm) and on days when school was not in session (Spring Break, holidays, professional development days). Data were collected in two second-grade classrooms in each of 11 elementary schools. In order to obtain entrée to the field, letters were sent and phone calls were made to principals of each selected school following IRB and the school district's approval. Those schools were selected based on high minority populations for " $\mathrm{A}$ " schools and low minority populations for " $\mathrm{B}$ " schools. The letters served as an introduction to the study and the researcher and provided a brief overview. Letters explained the study to principals and included requirements and reasons for selection and the investigator's contact information.

Once the sample teachers were selected, had agreed to participate, and had signed the consent forms, dates were arranged to visit classrooms for data collection. Teachers were asked not to change anything about their classrooms except to ask students to take the books from the classroom libraries that were in their desks and place them on top of individual desks. This allowed me to document those books used by students without invading their privacy.

During classroom visits, teacher presence was not required; however, teachers were welcome to work in their rooms while data collection occurred. If teachers did stay, they were asked not to assist with data collection in order to maintain consistent data 
collection procedures across the classrooms. Classroom library charts were used to document presence of books; photographs were taken of books placed in the classroom as part of the symbolic curriculum; photographs were taken of groups of books from the classroom library that were on the students' desks, and a teacher questionnaire was placed on the teacher's desk.

In documenting every fifth book in the classroom library, a paint stick was placed in the spot where a book was taken out in order to keep track of progress. After each book was documented, the paint stick was moved to the place where the next fifth book resided, and that book was checked for content and documented on the chart. This continued through the entire book collection. When books were placed in shelves like in a typical library with spines facing out, the order of data collection proceeded from left to right and top to bottom. When books were placed in "book boxes" with the covers facing forward, the data collection occurred from front to back.

However, when classroom libraries were separated into genres, such as nonfiction and fiction, multicultural, animals, or weather, one book was documented from each subcategory and then the fifth book within each of the sub-categories was documented, and so on. Teachers often placed these genres into distinctly labeled book boxes, and so a different style of sampling was needed to insure that important data were not missed due to the data collection process. This process insured representation of the books and not over-representation of one group over another.

In cases in which teachers had very small book collections (anything under 60 books), every $3^{\text {rd }}$ book was documented, in order to capture representation within that 
classroom library. This ensured that at least 20 tallies from each classroom were collected.

Teacher questionnaires (Appendix D) were left on teacher desks as previously noted. Follow-up emails and phone calls were used to ensure a high response rate. The final question on the questionnaire asked teachers if they were willing to answer followup questions. Teachers who agreed to this were contacted at a later date. Questions were crafted based on findings from the other data sources and using techniques described by Patton (2002) and McCracken (1988).

A question guide was formed for the follow-up interviews based on initial findings from other data sources. This guide helped to guarantee that the same basic questions and lines of inquiry were asked of each person interviewed, helped to maximize time, and made asking questions of several different people "systematic and comprehensive" (Patton, p. 343). The guide is shared in Appendix E. It was created to illuminate any questions about the data, to fill in gaps of understanding left from data analysis and classroom observations, and to share findings with teachers in order to perform member checks on the accuracy of the researcher's interpretations.

One misunderstanding from initial data analysis concerned teachers' response that they chose "quality literature" for their classroom libraries. This answer was unclear to me, and so I asked for clarification in the follow-up interviews. As part of the interviews, descriptions from individual teachers' classrooms (shared in Appendices G-AB) were read to the teachers. I hoped to use this as a member check and as a venue for cointerpretation from participating teachers (Newkirk, 1996). I asked teachers to stop me if they disagreed with anything I read or if they wanted to add anything. Questions were 
asked after I read the description of the classroom about whether they would like information on multicultural literature and if they would change anything based on the information I had shared. Hence, they were given the opportunity to agree that the interpretations were accurate, inaccurate, or otherwise.

Reliability/ trustworthiness of the data. The trustworthiness of the data was increased through several strategies used in data collection. First, the use of multiplecase sampling "adds confidence to findings" (Miles \& \& Huberman, 1994, p. 29). In addition, purposeful sampling of schools and stratified purposeful sampling of teachers increased the chance of finding teachers and classrooms which represented schools with high and low minority rates, as well as leading toward inclusion of a representative sample of minority teachers. Interviews served as member checks of the data collected within the classrooms.

In addition, data triangulation (Patton, 2002) strengthened the trustworthiness of this study with four different sources of data: classroom library data, symbolic curriculum photography data, student book choice data, and data from teacher questionnaires. When viewed together, classroom library data, photographs, and student book choices helped to show a more complete picture of the classroom library and the books in the classroom. Teacher questionnaires helped to explain why and how the books in the classroom library got there. Follow-up interviews helped to answer any unresolved questions, served as a member check, and helped to complete the picture of the classrooms and teachers. Follow-up questioning of teachers helped to answer any unresolved issues and questions within the data. The use of data collection charts led to uniformity and consistency of data collection that also increased trustworthiness. Also, 
trustworthiness was increased through the use of a focus group in creating and perfecting a question for the teacher questionnaire. Each mode of data collection was used in the investigator's classroom preceding this study to guarantee usefulness, precision, and practicality.

\section{Data Analysis}

Data reduction. Following each classroom visit a contact summary sheet was completed by the investigator. This was a "single sheet with some focusing or summarizing questions" (Miles \& \& Huberman, 1994, p. 51) about that field contact. This helped to condense the main concepts or issues that arose during the classroom visit. This contact summary sheet is included in Appendix F. A process of data reduction (Miles \& \& Huberman, 1994) took place in which the investigator could "select, focus, simplify, abstract, and transform the data" (p. 10). This occurred through the use of descriptive statistics, the Constant Comparison Method (Glaser \& Strauss, 1967), and Content Analysis (Givan, 2008). These methods are further described below.

To answer the first research question, What racial diversity (as delineated by the 2006 American Community Survey and the local school district) exists within the texts in classroom libraries in selected 2 nd grade classrooms? three sources were added together. These sources were the numbers of different racial representations within classroom library data, student-selected literature, and displayed literature. Together these three data sources represented the classroom library as a whole. Specifically, the racial groups represented in the literature in each classroom (White, Black, Asian, etc.) were recorded in percentages of the total number of literature selections in the classroom. 
After the initial analyses, I separated classrooms into groups of those aligning with or against the selective tradition based on observations of classroom libraries, displayed literature, and student-selected literature. Following this initial grouping, I found that the classrooms I had categorized as challenging the selective tradition have at the most a difference of five percentage points between the number of White representations and all other character representations. Classrooms I had categorized as making progress against the selective tradition had between a $5 \%$ and $10 \%$ difference between the number of White character representations and all other group representations. Classrooms I had categorized as continuing the selective tradition had a greater than $10 \%$ difference between White character representations and all other character representations (with the number of White representations always larger).

The choice to use $5 \%$ and $10 \%$ is arbitrary. Simply by having a $5 \%$ or $10 \%$ discrepancy does not necessarily mean that a collection is more representative of the children in the classroom or of society at large. However, it is a way to make sense of the data and to help to narrow the lens to get a clearer understanding of what is actually in the libraries in terms of racial representation. In addition, collapsing all racial groups other than White into a category and comparing it to the representation of White characters is simply a way to help contextualize the data. Data were analyzed based on "A" and "B" distinctions, teacher years of experience, teacher race, and teacher education level.

In order to answer the second question, "How does the racial diversity in the literature compare to the racial populations of the students in those classrooms? descriptive statistics from question one were used in conjunction with demographic information from each classroom. The racial representation of students within the 
sampled classrooms was compared with the racial representation within the literature in the classrooms. The averages of the data for "A" schools and "B" schools were determined.

It is important to note that a classroom with a strong relationship between the race of characters in the children's literature and the race of the children themselves is not necessarily a determining factor for "goodness" and could not be interpreted as such without the entire data set of the classroom library, teacher survey, books students favor, and responses from follow-up questions with teachers. Indeed, as explained previously, research has shown that all children benefit from reading and being exposed to literature with characters from varied racial groups. Thus, in some respects a strong relationship between inclusion in books and populations can be a negative thing. Of course, it could be interpreted as negative in any classroom if children of particular racial groups are not represented, or represented only minimally, in the books in their classroom.

To answer the third question, What books do students favor? the racial representations within the books left on the students' desks was tallied. I compared the classroom library as a whole with student-selected literature. For example, in Ms. Ingram's classroom $47.5 \%$ of the representations within classroom library books were White, while $62.1 \%$ of the representations within student-selected books were White. The diversity within characters in books chosen by students was compared with the diversity within that classroom library. Based on this comparison, I assigned one of the following distinctions to the student-selected literature within a classroom: 1) more inclusive than teachers' selection criteria, 2) less inclusive than teachers' selection criteria, or 3) a mixture of more and less inclusive than teachers based on race categories. In the case of 
previously mentioned Ms. Ingram, her classroom library was more inclusive than the literature selected by her students at the time of observation.

The fourth question, "How do teachers choose the books for inclusion in their classroom libraries?" was answered using the constant comparative method (Glaser \& Strauss, 1967) of content analysis (Patton, 2002) and descriptive statistics to analyze answers to the teacher questionnaire. Answers to question one, in which teachers placed checks next to sources they use for obtaining books, were analyzed by adding the number of checks for each resource to determine which were most used. This was done for all teachers, broken down by A and B teachers, and by years of experience.

Questions two through six of the questionnaire invited teachers to reflect on qualities they look for in children's literature, what they hope students will learn from that literature, how they envision their students, and what books they would buy if money was no object. The answers to these questions were analyzed using the constant comparative method of content analysis. This process was based on Bogdan and Biklen's (1992) recommended steps, with additional focus on the themes of this study. The answers to each individual question were read several times to look for trends and patterns. Chunks of texts that expressed individual themes served as the units of analysis (Zhang \& Wildemuth, 2009). Repeated reading allowed patterns across various teachers' answers to emerge. From these patterns, themes were created which were then given codes. For example, question four asked teachers to describe the typical student in their classroom. The themes that arose from the data were Family/Home Life, Likes/Dislikes, Behavior, and Learner/Reader. 
Themes were continuously altered and tweaked in order to reduce data into the most meaningful themes. Through this process memos were written to document momentary thoughts and ideas concerning categories and themes of the study. The categories were used in comparison with results from other data sources to cull deeper understandings of the relationships between teacher selection processes, literature, the symbolic curriculum, and student choices.

Question seven on the questionnaire asked teachers to rank order from most to least influential resources they use for their knowledge of children's literature. Since the most influential was the highest number and the least influential was the lowest number, I was able to calculate the most influential to all teachers by adding the numbers assigned to each of the options by the teachers. For instance, for Formal classes, I added up all numerical rankings given by the teachers, which added up to 112 . These numbers indicated which resources were most to least influential.

The fifth research question of this study, What books are purposefully displayed by the teacher and what themes do those books represent? was analyzed using content analysis. This was performed on the photographs of the symbolic curriculum beyond the literature in the classroom libraries. It involved photographing books that teachers displayed within the classroom for students to see. I originally planned to analyze the displayed literature by diversity among characters. However, after data collection and studying the contents of the classroom photographs, it became clear that diversity among characters was not overtly or covertly shared through the texts. There was no pattern among or within classrooms' displayed literature relating to diversity of characters. 
Therefore, analysis was based on themes that came to light upon analysis rather than being predetermined. 


\section{CHAPTER IV}

\section{RESULTS}

Ms. "Ingram" (pseudonym) taught in a B school (low minority population) in a second grade classroom. Ms. Ingram is African American, holds a Masters degree, and at the time of this study, had five years of teaching experience. During the study year, her classroom was comprised of five Black or African American students, 18 White students, and one Hispanic or Latino student. The children's books in her classroom library were hand-me-downs from former teachers or bought by Ms. Ingram. When looking for literature for her classroom library she reported that she looks for "books that will allow students to make a connection socially, environmentally, and academically." She rated sources of information concerning children's literature from most to least influential in the following way: formal classes, in-services, other teachers, bookstores, libraries/librarians, book clubs, Internet resources, and parents. Ms. Ingram hoped her students would gain insights from the books in her room. She described the typical student in her classroom as "bright, energetic, with an extremely short attention span!' She explained that when buying or checking out books for her classroom library she envisioned her students helping to "mold the minds of the next generation." Her wish list of books included picture books, and books that reflect social studies and science content. 
Ms. Ingram arranged her classroom using five round tables, with one student desk set apart from the others. There was a book box in the center of each table for students to store their selected books. The books in Ms. Ingram's classroom library were arranged in several ways; some were in labeled boxes on bookshelves, and others were in crates with no apparent order. Many texts focused on famous African Americans, and much of the displayed literature depicted racially diverse characters. Overall, texts within this classroom included more non-White characters than White characters.

This description of Ms. Ingram's classroom represents one of three categories of classroom types with respect to the nature of racial representation of characters in the classroom literature in second grades in an urban school district in the Midwest, the topic of this dissertation. Ms. Ingrams's classroom was categorized as one that challenges the selective tradition. This chapter will illustrate the patterns of racial representation in 22 second grade classrooms in Ms. Ingram's school district.

The purpose of this study was to investigate the diversity of character representation within classroom libraries, the demographics of the children in the selected classrooms, the texts students choose to read, the selection process employed by teachers when building their classroom libraries, and the relationships among the diversity of texts, children, and literature selection processes. This chapter is organized in order of findings from each of the five research questions: What racial diversity exists within the texts in classroom libraries in selected $2^{\text {nd }}$ grade classrooms? How does the racial diversity in the literature compare to the racial representation of students in those classrooms? What books do students choose to read? How do teachers choose the books 
for inclusion in their classroom libraries? What books are purposefully displayed by the teachers and what themes do those books represent?

Classroom libraries, displayed literature, and student-selected literature of 22 classrooms were inventoried for racial representation. In addition, 21 participating teachers completed questionnaires about the literature in their classroom libraries, their selection processes, and their thoughts concerning literature.

\section{Racial Diversity within Texts in Second Grade Classrooms}

As discussed in Chapter 2, teachers tend to favor literature that features White, middle-class, male authors and subjects more than works by and about women, other ethnicities, or social classes. This tendency is called the selective tradition (Luke et.al., 1986). I used the data collected from classroom libraries on character representation to further understand teachers' subconscious alignment with the selective tradition, as it applies to race. Results from each individual classroom library are shared in Appendices G through AB. A compilation of all classroom library data is shared in Appendix AC.

The diversity of character representation within the literature found in the 22 classrooms assessed in this study varied greatly. There appeared to be no patterns of difference by school grouping (racially diverse A schools or less diverse B schools); however, the differences fell strongly into three categories: those that challenged the selective tradition, those that were progressing against the selective tradition, and those that continued the selective tradition. Using this analysis, of the 22 classroom libraries sampled in this study, three were challenging the selective tradition (one from Group A and two from Group B); three were progressing against the selective tradition (one from 
Group A and two from Group B); 16 were continuing the selective tradition (eight from Group A and eight from Group B).

I looked at the questionnaire responses of the six "challenging" and "progressing" teachers for patterns across responses. Two of those six teachers who were challenging or progressing were in the more diverse school settings, based upon the A and B distinction. The six teachers who were challenging or progressing were made up of five females and one male; two African American, four White. Professional teaching experience among these teachers ranged from one year to 25 years. All of these six "challenging" and "progressing" teachers had their Masters or Rank 1 (30 hours beyond Masters) distinction.

Table 1 shows the frequencies and percentages of character representations of each of the 22 participating teachers, and then categorizes them as "challenging," "progressing," or "continuing" the selective tradition. Schools are broken into A and B groups. All teachers defined as challenging or progressing against the selective tradition had degrees beyond their bachelor's degree. However, as displayed in Table 2, further education does not always coincide with more diversity within classroom libraries. Table 2 addresses the educational level of all participating study teachers and the diversity within their classroom libraries.

Table 1

Teacher Status Regarding the Selective Tradition 


\begin{tabular}{|c|c|c|c|c|c|}
\hline \multirow[b]{2}{*}{ Classrooms } & \multicolumn{2}{|c|}{$\begin{array}{c}\text { Frequency of Character } \\
\text { Representation }\end{array}$} & \multicolumn{2}{|c|}{$\begin{array}{l}\% \text { of Character } \\
\text { Representations }\end{array}$} & \multirow{2}{*}{$\begin{array}{c}\text { Selective } \\
\text { Tradition } \\
\text { Status }\end{array}$} \\
\hline & White & Non-White & White & Non- White & \\
\hline \multicolumn{6}{|l|}{ A schools } \\
\hline Evans & 170 & 102 & $62.50 \%$ & $37.50 \%$ & Continuing \\
\hline Franklin & 128 & 80 & $61.54 \%$ & $38.46 \%$ & Continuing \\
\hline Klink & 67 & 46 & $59.29 \%$ & $40.71 \%$ & Continuing \\
\hline Lee & 89 & 50 & $64.03 \%$ & $35.97 \%$ & Continuing \\
\hline Quinn & 132 & 113 & $53.88 \%$ & $46.12 \%$ & Progressing \\
\hline Robin & 56 & 35 & $61.54 \%$ & $38.46 \%$ & Continuing \\
\hline Smith & 53 & 32 & $62.35 \%$ & $37.65 \%$ & Continuing \\
\hline Turner & 93 & 95 & $49.47 \%$ & $50.53 \%$ & Challenging \\
\hline Usher & 120 & 61 & $66.30 \%$ & $33.70 \%$ & Continuing \\
\hline Vogel & 82 & 58 & $58.57 \%$ & $41.43 \%$ & Continuing \\
\hline \multicolumn{6}{|l|}{ B schools } \\
\hline Adams & 98 & 81 & $54.75 \%$ & $45.25 \%$ & Progressing \\
\hline Burns & 112 & 47 & $70.44 \%$ & $29.56 \%$ & Continuing \\
\hline Caudill & 92 & 93 & $49.73 \%$ & $50.27 \%$ & Challenging \\
\hline Dauphin & 66 & 36 & $64.70 \%$ & 35.30 & Continuing \\
\hline Greene & 95 & 69 & $57.93 \%$ & $42.07 \%$ & Continuing \\
\hline Harper & 172 & 111 & $60.78 \%$ & $39.22 \%$ & Continuing \\
\hline Ingram & 58 & 64 & $47.54 \%$ & $52.46 \%$ & Challenging \\
\hline Jones & 68 & 33 & $67.33 \%$ & $32.67 \%$ & Continuing \\
\hline Mimms & 155 & 85 & $64.58 \%$ & $35.42 \%$ & Continuing \\
\hline Napier & 170 & 104 & $62.04 \%$ & $37.96 \%$ & Continuing \\
\hline Osborne & 226 & 150 & $60.11 \%$ & $39.89 \%$ & Continuing \\
\hline Preston & 100 & 83 & $54.64 \%$ & $45.36 \%$ & Progressing \\
\hline
\end{tabular}


Note. Teacher adherence to the selective tradition defined as Continuing (a difference of greater than $10 \%$ difference between percentage of White and all other character representations); Progressing (a difference of between $5 \%$ and $10 \%$ in that same comparison); and Challenging (with less than or equal to $5 \%$ difference in the comparison.

Table 2

Representation within Classroom Libraries by Teacher Education Level

\begin{tabular}{llll}
\hline $\begin{array}{l}\text { Racial Category } \\
\text { Of Characters }\end{array}$ & $\begin{array}{l}\text { Bachelor } \\
(\mathrm{n}=3)\end{array}$ & $\begin{array}{l}\text { Master } \\
(\mathrm{n}=11)\end{array}$ & $\begin{array}{l}\text { Rank 1 } \\
(\mathrm{n}=7)\end{array}$
\end{tabular}

White

$60.1 \%$

$58.5 \%$

$61.5 \%$

Black or

$23.9 \%$

$21.8 \%$

$20 \%$

African American

Hispanic or

$3.7 \%$

$6.7 \%$

$5.9 \%$

Latino

Asian

$8.9 \%$

$8.1 \%$

$9 \%$

Note. Rank 1 indicates 30 hours past a Masters degree. $\mathrm{N}=21$ because one teacher did not return the questionnaire.

One might assume that Black or African American teachers would have more inclusive classroom libraries than White or European American teachers. The following table addresses and exposes the fallacy of this assumption. While the numbers indicate that Black or African American teachers have slightly higher percentages of books with non-White characters, it is a very small difference.

Table 3

Representation within Classroom Libraries by Teacher Race

Racial Category Teacher Race


White

Black or

African American

Hispanic

Asian
$60.5 \%$

$20.9 \%$

$58 \%$

$23.5 \%$

$5.7 \%$

$6.1 \%$

$8.5 \%$
$9 \%$

Figures 1 and 2 show the total frequency of character representations within displayed literature, student selected literature and classroom libraries across the twentytwo classrooms and a comparison of non-White and White character representations. An over-abundance of White character representations over all others is clear in both figures. 


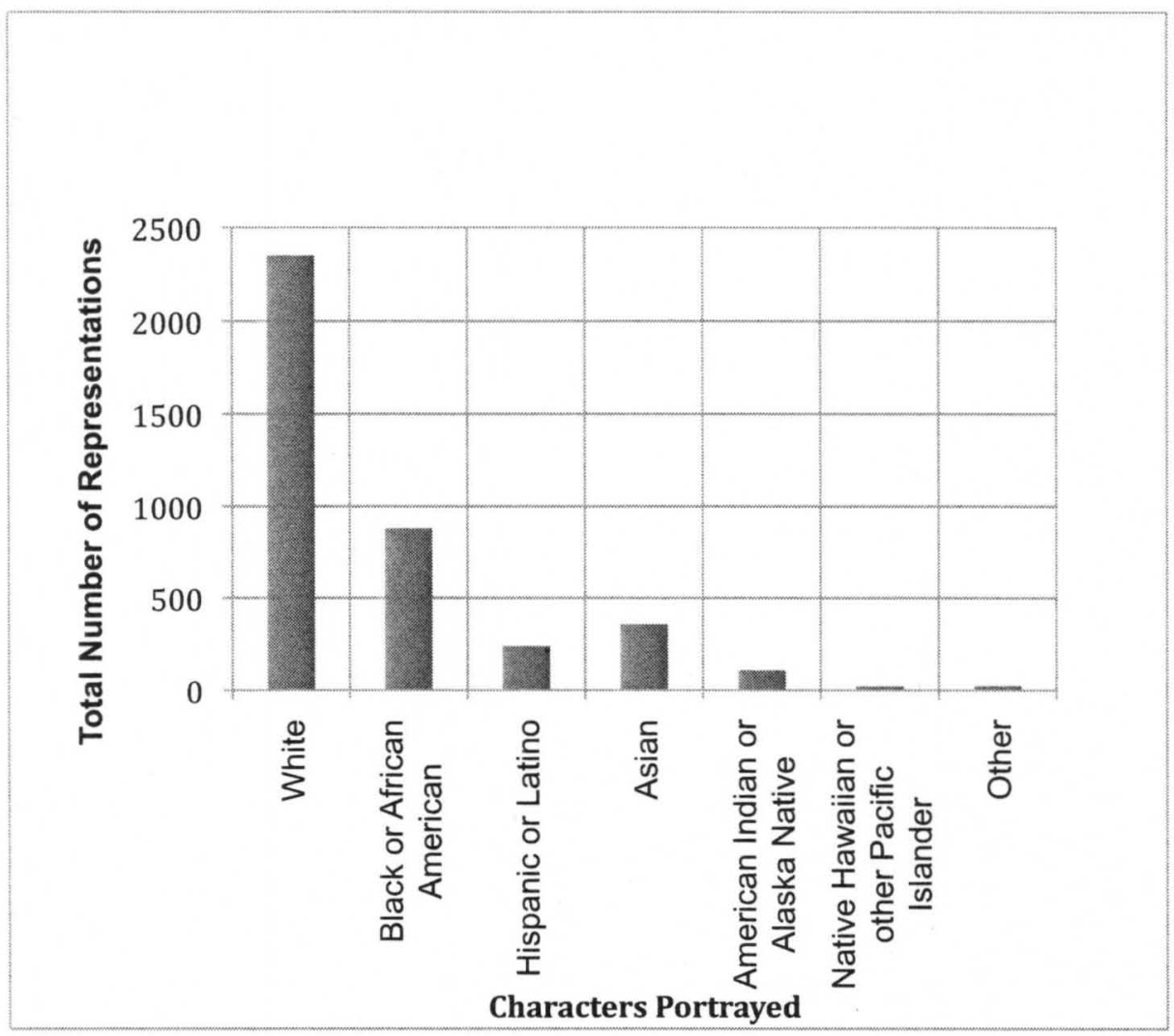

Figure 1. Representations of all groups within classroom literature of all 22 classroom libraries. 


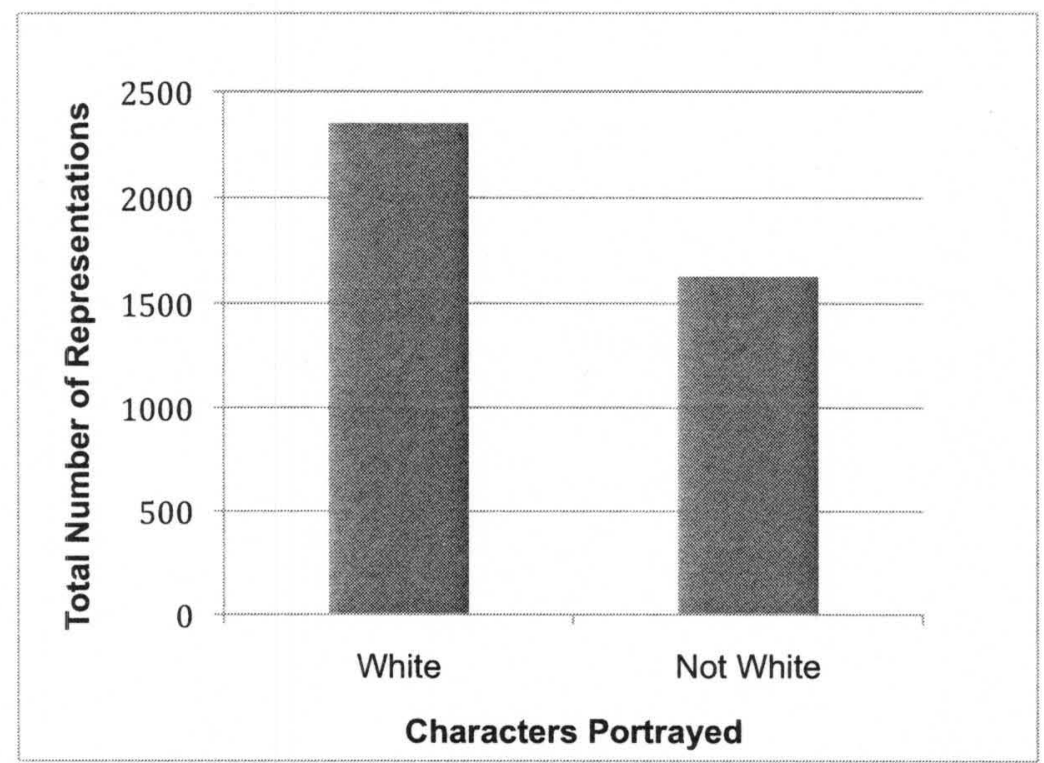

Figure 2. Representations of White and Non-White characters within classroom literature of all 22 classroom libraries. 


\section{Diversity in Literature Compared to Diversity among Students}

The literature within classroom libraries and among students seemed related in B classrooms, but not in A classrooms. In A classrooms, which are more diverse, the literature did not reflect the students' diversity. A large majority of literature represented White characters while the majority of students were non-White. In fact, A and B classroom libraries were surprisingly similar in diversity of character representations. The literature in B classrooms more closely represented students within those classrooms than did literature in A classrooms because more of the student population in B schools is White.

I analyzed this relationship by comparing classroom literature holdings with student populations. Many classroom libraries proved to be inversely related to the populations within their classrooms. For instance, in Ms. Evans' classroom library $62.5 \%$ of character representations were White while only $13 \%$ of the students in her classroom were White. This demonstrates an inverse relationship. In contrast, in Ms. Turner's classroom library $49.47 \%$ of character representations were White while $46 \%$ of students in her classroom were White. This demonstrates a corresponding relationship.

Not all classrooms fell into one of the two categories, but the majority did. Of classrooms with corresponding classroom libraries and student populations five were B classrooms: Harper, Mimms, Napier, Osbourne, and Preston, and one A classroom: Turner. This highlights the notion that B schools reflect their students within literature more often, because the literature has more White characters and the majority of their students are White. Ms. Turner's classroom library positively reflects the diversity of her classroom library, and is one of the libraries labeled as challenging the selective tradition. 
Of classrooms with inverse relationships between classroom literature and student populations seven were A schools: Evans, Franklin, Lee, Quinn, Robin, Smith, and Vogel, and one B classroom: Dauphin. This again reflects the lack of diverse texts within our most diverse classrooms. Appendix AC shares data from all classroom libraries and the corresponding student populations.

To find out how the diversity within texts related to the diversity among students in participating classrooms as a whole, I tabulated the percentages of representations of the different racial groups within classroom libraries, student-selected literature, and displayed literature. I divided the number of times a group was represented by the total number of all representations of the racial groups in the classroom libraries. In Table 4, those percentages are shared for A and B schools compared to the percentages of the various racial groups represented by the students in each classroom. These percentages echo previously discussed findings, that classroom libraries within A schools are less reflective of their students than are B schools. This also reflects the continuation of the selective tradition.

Table 4

Diversity Within Literature and Students by School Group

\begin{tabular}{lllll}
\hline & \multicolumn{2}{c}{ A Schools $(\mathrm{n}=9)$} & & B Schools \\
\cline { 5 - 5 } & $\begin{array}{l}\text { Classroom } \\
\text { Library }\end{array}$ & $\begin{array}{l}\text { Student } \\
\text { Population }\end{array}$ & $\begin{array}{l}\text { Classroom } \\
\text { Library }\end{array}$ & $\begin{array}{l}\text { Student } \\
\text { Population }\end{array}$ \\
\hline White & $60 \%$ & $27 \%$ & $59.5 \%$ & $63.1 \%$ \\
Black or & $21.6 \%$ & $51.3 \%$ & $21.4 \%$ & $30.3 \%$
\end{tabular}

African American 
Latino

Asian

$9.21 \%$

$2.8 \%$

$8.9 \%$

$2.3 \%$

Note. One A school teacher did not return the questionnaire, so data from only 9 of the $10 \mathrm{~A}$ classrooms is included in these figures.

\section{The Books Students Choose to Read}

In general, the students in the classrooms in this study more often chose literature with more White characters than literature with more non-White characters, despite the demographic make-up of the students in those classrooms. However, the teachers included literature with more non-White characters than what students selected (at the time of observations) in both A and B schools in the majority of classrooms. Table 5 illustrates these findings.

A few individual classrooms do not follow the pattern shared in Table 5 of teachers having more inclusive literature than students. One B classroom and four A classrooms had student-selected literature choices that were comparable to their corresponding classroom libraries. These included Burns, Franklin, Klink, Turner, and Vogel. Ms. Preston's students (in a B school) were more inclusive than her classroom library, choosing to read books that depicted various racial groups rather than predominantly White characters. On the contrary, students in Ms. Mimms' classroom (a B school) selected literature that included only White characters. Results from individual classrooms including a critique of that classroom's inclusiveness are shared in Appendix AD.

Table 5

Diversity within Classroom Libraries and Student-Selected Literature 


\begin{tabular}{|c|c|c|c|c|}
\hline & \multicolumn{2}{|c|}{ A Schools $(n=10)$} & \multicolumn{2}{|c|}{ B Schools $(n=11)$} \\
\hline & Classroom & Student & Classroom & Student \\
\hline Group represented & Library & Selected & Library & Selected \\
\hline White & $59.9 \%$ & $73 \%$ & $58.8 \%$ & $75.3 \%$ \\
\hline Black or & $22 \%$ & $16.4 \%$ & $21.9 \%$ & $13.3 \%$ \\
\hline \multicolumn{5}{|l|}{ African American } \\
\hline Hispanic or & $5.6 \%$ & $3.2 \%$ & $6.4 \%$ & $2.9 \%$ \\
\hline \multicolumn{5}{|l|}{ Latino } \\
\hline Asian & $8.3 \%$ & $5.9 \%$ & $9.1 \%$ & $6.1 \%$ \\
\hline
\end{tabular}

Students chose literature from a variety of genre, as displayed in Table 6 . While much is covered in this list, it is also quite specific to the interests of this age group. In question six of the teacher questionnaire teachers were asked to tell what books they would like to have if money was no object. Some of the categories included in Table 6 are represented within teachers' responses, but most are not. Ms. Evans, the teacher who asked her students to help answer the question came closest to mirroring what students had selected from the classroom library. Her students told her they wanted more books that tell how to do things, joke books, chapter books, I Spy books, and books about or based on Presidents, movies, sports and animals. The following table displays patterns and themes found among the student-selected literature in the 21 classrooms that had it available (one of the original classrooms did not have student-selected literature 
available). The thematic categories were determined after reviewing the student-selected literature several times for patterns.

Table 6

Prominent Themes among Student-Selected Literature

Thematic Category Characteristic or Example

Animals

Award winners

Class-made

Dictionaries

Dinosaurs

Environmental

Fairy tales and folk tales

Favorite authors

Funny

Holidays

Wordless books
Fiction and Nonfiction

Caldecott, Newberry, etc.

Based on class experiences

Bilingual (e.g. Spanish/English) and Monolingual

Fiction and Nonfiction

Fiction and Nonfiction

Fractured and Traditional

Patricia Polacco, Leo Lionni, Mo Willems, Mary

Hoffman, Frank Ash, Tomie de Paola, Gail

Gibbons, Cynthia Rylant, Beverly Cleary, Arnold

Lobel, Laura Numeroff, Roald Dahl, Judy Blume, Maurice Sendak, Eloise Greenfield, Eric Carle, Kevin Henkes, Stephen Kellogg

Silly situations and Joke books 
Leveled and phonics readers

Mysteries

Nonfiction

Dinosaurs

Popular media-based

Princesses and fairies

Relationships

Series characters

Sports and adventure

Word play
Step into Reading, Ready to Read, An I Can Read

Book, old Basal readers

Magic Tree House, Boxcar Children, The Secrets of

Droon, Magic School Bus, Bailey School Kids, Cam

Jansen, Horrible Harry

Linked to content areas, How to..., Question and

Answer, If you lived.... (historical), atlases,

magazines (e.g., Sports Illustrated for Kids, Time

for Kids)

Fiction and Nonfiction

TV shows, movies, comics, video games

Family, friendship, coming of age

David (Shannon), Junie B. Jones, Berenstein Bears, Nate the Great, Amelia Bedelia, Frog and Toad, Arthur, Henry and Mudge, Frances, Wimpy Kid, Little Bill, Grace, Curious George, Clifford, Olivia, Miss Nelson, Jamaica

Wrestling, Football, Sled-dogging, etc.

Tongue twisters, poetry

Note. Thematic categories are listed alphabetically.

\section{Teachers' Reflections on Selection of Classroom Literature}


Twenty-one of the 22 participating teachers responded to a questionnaire about the literature in their classroom libraries, their selection processes, and their thoughts concerning literature. The responses provided and the findings culled from them follow.

Sources of classroom library literature. Teachers were asked where the literature in their classroom libraries came from. Responses included a variety of sources for their classroom library holdings. Most teachers reported that they received books from former teachers and all teachers stated that they buy books for their classroom libraries with their own money. More teachers from A schools versus B schools received books from their schools, while more B schools than A schools receive books from parental support (of students) of some kind. The following table shows the percentage of teachers out of the group of 21 reporting, who claimed to use particular sources for obtaining literature for their classroom libraries.

Table 7

Sources of Classroom Library Books
A Schools $(\mathrm{n}=9)$
B Schools $(n=12)$

Source

$\mathrm{n}$

$\%$

n $\quad \%$

Hand-me-downs

$9 \quad 100 \%$

$11 \quad 91.7 \%$

from former teachers

Purchased by teacher

$9 \quad 100 \%$

$12 \quad 100 \%$

Purchased by school

$7 \quad 77.8 \%$

$5 \quad 41.7 \%$

Public library

$4 \quad 44.4 \%$

$3 \quad 25 \%$ 


$\begin{array}{lllll}\text { Grants } & 3 & 33.3 \% & 0 & 0 \% \\ \text { Free: book club point } & 0 & 0 \% & 3 & 25 \% \\ \text { School library } & 1 & 11.1 \% & 2 & 16.7 \% \\ \text { School bookroom } & 1 & 11.1 \% & 0 & 0 \% \\ \text { Parent contributions } & 0 & 0 \% & 1 & 8.3 \% \\ \text { PTA money } & 0 & 0 \% & 1 & 1 \% \\ \text { Friends } & 1 & 11.1 \% & 0 & 0 \% \\ \text { Total from parental support } & 0 & 0 \% & 5 & 41.7 \% \\ \text { (parents, PTA, book clubs) } & & & & \end{array}$

Note. One A teacher did not return the questionnaire

Qualities teachers look for when selecting books. Teachers from both A and B schools use similar criteria when selecting literature. The most frequently used response was that teachers looked for books that would be interesting to kids. Readability, popularity, variety, the ability to make curricular connections, character familiarity, aesthetics, and availability were among the other teacher responses. More teachers from A schools used variety as an important criterion, while teachers from B schools did not consider it as much in their selection process. One teacher from both A and B schools stated that they choose "quality literature" when selecting texts. In follow-up interviews these teachers clarified that quality literature has a good story and is valuable in some way.

Table 8

Qualities Sought within Classroom Library Literature 
Quality

Example

What are they checking out

13

life connections

Readability

Popularity

Variety

Curricular

connections

Character

familiarity/ at the library?

Age level; skill;

11

Illustrations to support text;

Meaningful text; storyline

Award-winning;

9

Based on TV shows;

Well-known authors/ illustrators

Of genre or level;

8

Nonfiction/fiction

Reading Counts or

7

Accelerated Reader books

that allow students to use

different strategies

Chapter book sets;

3

Character repetition/ familiarity 
Series books

Aesthetically

Color;

pleasing to

Writing/illustrations stimulate

teachers

A desire to read;

Teachers appreciate writing

Access/availability

Price;

to teachers or

Students have limited exposure

students

Note. Qualities are listed in order of teacher reliance.

What teachers hope students will learn from classroom libraries. More than anything else, teachers in this study wanted their students to gain a love of reading and of books from the literature in their classroom libraries. Teachers also wanted students to practice skills within the books in their libraries. They wanted them to learn the usefulness of reading; to see reading as a life skill. In addition, teachers wanted students to gain knowledge from reading the books within their classroom libraries. Table 9 shares these findings based on all 22 classrooms, while Table 10 breaks findings down by school group. There is no obvious difference in terms of what teachers in the two school types hoped students would glean from books in their classroom libraries.

Table 9

What Teachers Hope Students will Learn from Classroom Libraries

Quality

Examples

Number 
Pleasure in reading

and books

Skill practice

Gain knowledge

Learn the usefulness
Love for reading and various

17

genre

Affinity for reading

Reading and Writing

7

Comprehension

Fluency

Find new interests

7

Learn lessons

Find relatable situations

Reading as a life skill

3

Purpose of reading

How reading can help

Table 10

What Teachers in A and B Schools Hope Students will Learn by School Group

\begin{tabular}{lcc}
\hline \multicolumn{1}{c}{ Quality } & A schools $(\mathrm{n}=9)$ & B Schools $(\mathrm{n}=12)$ \\
\hline See the pleasure of reading & $54 \%$ & $48 \%$ \\
Skill practice & $15 \%$ & $24 \%$ \\
Gain knowledge & $23 \%$ & $19 \%$
\end{tabular}


Teachers' views of their students. Four themes emerged from teaches' descriptions of the typical student in their classrooms. One of these was Family/ Home Life, which included statements concerning parents, caregivers, and home experiences. This theme of family/ home life includes the theme of diversity, because the racial, ethnic, cultural, socioeconomic and linguistic background of students reflects the family and/or home life. Another theme was Affinity, which included statements relating to students' interests, likes, or dislikes. A third theme was Behavior and was assigned to statements referring to students' positive, negative, or neutral behavior. The theme of Learner/Reader was assigned to statements describing students as learners and/or readers. These statements included topics of students' inabilities and abilities. Some statements pointed out students' ages, which was redundant in the context of this study due to the exclusively second grade sample of teachers. Themes and statements are categorized by A and B schools in Table 12 .

\section{Table 11}

How Teachers View Students

Thematic Category Examples n
n

Learner, Reader

Eager to learn

Reading levels from low first grade to end of $3^{\text {rd }}$ upwards.

Limited vocabulary 
Most are great readers

Need a little extra push to read on their own

Family, Home Life

Both parents working

16

Limited experiences

Has books at home

Minority

Parents are supportive

Likes, Dislikes,

They love to read

11

Affinities

They love fiction books

Interested in a variety of subjects

Enjoys computer

Behavior

Majority are talkative

Energetic

Usually on task

Easily distractable

Note. 61 total clauses, excluding those describing students' ages.

Table 12

Teacher Views of Students in A and B Schools 
Learner, Reader

A

Excited about learning

Desire to learn

Sometimes hard to engage

They read right at grade level

From non-readers to $4^{\text {th }}$ grade level

My students are basically average

second graders

Average to lower intelligence

Bager to learn
Quizzical
Average to above average
reading ability
Reading levels from low first
grade to end of $3^{\text {rd }}$
upwards

Good reader (2)

On reading level

Gets excited when they find books related to any content that we are studying

Bright

Limited vocabulary

Knows how to read silently

Basic math skills

Family, Home life

\section{A}

All my students are free and/or reduced lunch

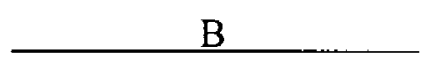

Both parents are working Average to slightly below average 
All backgrounds

Low socioeconomic

level (2)

Minority

One parent in jail

Split household

Child living with foster parent or

other family member

Some support from home for income families

Average or below socioeconomic

level

Great home support (2)

Limited experiences

Has books at home

Likes/ Dislikes

A

Love fiction picture books

They are interested in a variety

of subjects from dinosaurs

to volcanoes to dancing

Loves to read
B

They love to read

They enjoy shared reading

Self selected reading

Loves to read books

Enjoys computer

Enjoys AR (Accelerated

Reader)

Behavior

A B 
They are very active

The typical is usually on task
Majority are talkative (2)

Easily distractable

Most of the children are well behaved

Work hard on their studies

Energetic (2)

An extremely short attention span!

Shares books with others

Who teachers envision when selecting literature. Many teachers did not directly answer the question, "Who do you envision when selecting books for your classroom library?" Possibly this question made some teachers feel uncomfortable, or perhaps the question was misunderstood. Ms. Osborne, for example, answered what seemed like a different question altogether when she wrote, "The variety of reading materials will help my students become better readers, improve comprehension skills and better writers."

Those who did answer the question did so by addressing a wide variety of ideas, suggesting that teachers consider many different factors when selecting literature. Teachers think of students' reading level, their interests and what will excite students, and sometimes they think of themselves and what they would like to read. Many of the teachers looked at books for the potential they offered students to make connections to their own worlds and understandings, and to grow or be challenged in various ways. 
When selecting literature teachers sometimes selected texts based on content and then thought of the students in their classes, making the selection content-driven. Other times teachers thought of their students and their lives, needs, and interests before choosing the texts, making the selection student-driven. Ms. Evans reported that she thinks of her "hardest to reach students and what would grab their interests and encourage them to read. I also think of my most advanced student and try to get books that push them just past their reading to keep their reading level improving." Ms. Dauphin answered this question by stating "I do not have a stereotype at all."

Teachers' literature wish lists. Teachers were asked to list the children's literature they would want if money was no object. Some teachers listed specific titles or authors. Others could be subdivided into three categories of genre, form, and other attributes. Specific authors listed by teachers included Patricia Polacco, Nikki Giovanni, Nikki Grimes, and Shel Silverstein. One teacher wrote, "Books by my favorite author." Specific titles, characters, or series listed by teachers included Junie B. Jones (Park \& Brunkus, 1998), I Spy (Marzollo \& Wick, 2003), American Girl books (Adler, Tripp, \& Grace, 1986), “Time for Kids” magazine, books about Hannah Montana, and books based on the movies Monsters vs. Aliens and Karate Kid.

Of nonfiction, teachers said they would want more texts addressing concepts of science, social studies, exploration, biographies, sports, animals, and "how to" books. Of fictional books, teachers indicated that they would like more historical fiction, such as the "If I grew up" series, folktales, books based on movies, and what some called "classic literature." Teachers also want to include more cultural diversity and real world topics in 
their classroom libraries. The most popular answers were: chapter books (4), nonfiction (6), multiple copies to create book sets (3), and greater variety (2).

Table 13

Teachers' Literature Wish Lists

\begin{tabular}{lll}
\hline Genre & Form & Other \\
& & Attributes \\
\hline Nonfiction & Chapter books & Cultural diversity \\
Fiction & Series books & Real world subjects \\
Poetry & Periodicals & More variety \\
Classic literature & Picture books & \\
Joke books & Leveled readers & \\
Animal & Multiple copies & \\
& Newer versions & \\
& Big/oversized books & \\
& Hardback books & \\
& Picture books & \\
& &
\end{tabular}

Teacher sources of information on literature. The contents of a classroom library are ultimately chosen by the teacher. Hence, where teachers learn about children's literature is important. Teachers rated resources from the most to the least influential on their current personal knowledge of children's literature. Of the 21 
reporting teachers, sources of information were ranked from most to least influential in the following order: formal classes, libraries/ librarians, bookstores, other teachers, inservices, book clubs, Internet resources, parents.

The following table shares teachers' most to least influential sources of information on children's literature in A and B schools.

Table 14

Influence of Information Source by $A$ and B Classrooms

\begin{tabular}{cc}
\hline A Classrooms & B Classrooms \\
\hline Bookstores & Formal classes \\
Internet resources & Libraries/ librarians \\
Libraries/ librarians & Book clubs \\
Formal classes & Other teachers \\
In-services & Bookstores \\
Parents & In-services \\
Book clubs & Internet resources \\
Other teachers & Parents
\end{tabular}

Note. Resources are listed from most to least influential to teachers.

I also analyzed these data based on teachers' experience, because I wondered if younger teachers would refer more often to the Internet and their formal classes (because classes would be more fresh in their memories) for their literature knowledge. My assumption was accurate, as teachers with less experience relied most on formal classes for information on literature and relied more on the Internet for that information than did the more experienced teachers. In contrast to the less-experienced teachers, those with 
16-30 years of experience used book clubs and other teachers as the most influential resource for knowledge of children's literature.

Table 15

Influence of Information Source by Teacher Experience

\begin{tabular}{cc}
\hline \multicolumn{2}{c}{ Years of Experience } \\
\hline $1-15$ & $16-30$ \\
\hline Formal classes & Book clubs \\
Parents & Other teachers \\
Internet resources & Libraries/ Librarians \\
Libraries/ Librarians & \\
In-services & In-services and Internet resources \\
Book clubs & \\
Other teachers & Parents
\end{tabular}

Note. Resources are listed from most to least influential to teachers.

\section{Displayed Literature}

Teachers displayed a wide variety of literature across the 22 classrooms. Some teachers did not display any literature. Others were very conscientious about the titles they displayed, whether choosing based on curriculum (rocks and minerals; community; Shared Reading books from the basal series), or their own favorites (Goosebumps; Junie B. Jones). Still others seemed to have books haphazardly crammed in all corners of the room, with little overt attention to how they were displayed. While not all teachers were concerned with their displayed literature or even have any, the following analysis 
includes titles from classrooms where the teachers did display literature (or the book jackets) on chalkboard trays, on bulletin boards, in front-facing bookshelves, on top of bookshelves, etc.

Some teachers displayed books that they personally found appealing in their classrooms. Mr. Adams and Ms. Burns both fit this description. Mr. Adams said that the student he imagined when he picked out books was himself, and of the books he displayed, Puff the Magic Dragon (Yarrow \& Lipton, 2007), Calvin and Hobbes (Watterson, 1990), Don't let the Pigeon Drive the Bus (Willems, 2003) and Hooray for Diffendoofer Day (Seuss, Prelutsky, \& Smith, 1998) all are funny or from the time of his childhood except for Yeh Shen (Rigby, 2000), which is part of the second grade reading series in this district. Ms. Burns didn't display any books, but did have a Junie B. Jones poster in her classroom. In response to the question of the books she would want if money was no object she included, "I have all the Junie B. books, but I realize there are more out there...."

Ms. Evans asked her students to help her answer the question on the survey about what books they would like if money was no object. While this changes the results of the study somewhat because other teachers responded without the assistance of their students, Ms. Evans' connection and awareness of her students' needs came through in her questionnaire as well as in the books she had displayed in her classroom. While it was not evident that she was trying to display a diversity of ethnicities in the literature, many of the chapter books that were displayed were about adventures in $3^{\text {rd }}$ grade, which her students would soon be entering. Another one of the books included in the displayed literature was a self-made book called We Got Caught on Field Day! which included 
pictures of students playing and what appeared to be class-written text to accompany each picture. Displayed books about the presidential candidates (Obama and McCain) showed a connection to current events.

Several teachers displayed books directly connected to the current curricular topics. Second grade classrooms visited within the same district displayed many books about rocks and minerals, phonics or Shared Reading texts, insects, biographies, mathematics concepts, and life cycles.

Some teachers were obviously proactive in displaying diverse literature. Five of the 22 classrooms visited displayed many titles of literature with non-White characters. One of these classrooms only included diverse characters in biographies, as they seemed to be doing a biography study. With reference to the data on the status of these teachers' on continuing, challenging, or making progress against the selective tradition within their classroom libraries (Research question 1), Ms. Caudill and Ms. Ingram were challenging the selective tradition within their classroom libraries as well as their symbolic curricula of displayed literature. Ms. Jones was continuing the selective tradition within the classroom library, and while she displayed books with diverse "characters," they were all biographies. The majority of her fiction and other literature didn't portray diverse populations, which led to the conclusion that the class was doing a biography study. Ms. Klink was continuing the selective tradition in the classroom library and the displayed literature, while Ms. Quinn was making progress against the selective tradition in the classroom library and in the displayed literature.

Many teachers' answers on the questionnaires conflicted with the actual books in their classrooms. For instance, in her survey, Ms. Usher, who taught in a highly diverse 
classroom and school, said that she chooses books that will offer her students relatable situations and lessons in life. This was not evident in the investigation of her classroom. Most of her books were old (portraying all White characters); many were based on old Disney characters (Scrooge McDuck, for instance), and there was very little diversity within. In fact, while many books were displayed, the only non-White characters were portrayed in the popular Amazing Grace (Hoffman, 1991) and a book about tattling (Berry, 2008). One portrays a positive African American character; the other shows a negative one, a tattler.

\section{Summary}

While the majority of teachers in this study had classroom libraries that continued the selective tradition, the situation appears to have improved since Nancy Larrick (1965) first inquired about inclusiveness in children's literature. Publishers are printing more literature depicting authentically represented diverse populations, and in this study six of the 22 classroom libraries were challenging or progressing away from the selective tradition.

Classroom libraries in more (A) and less diverse (B) schools had comparable representation of racial groups within children's literature. This, then, means that many students within more diverse classrooms are less likely to see diversity within the literature in their classrooms. Students in more diverse (A) schools see less diversity in the books in their classrooms, so they mainly read about people who look different from themselves. Students in less diverse (B) schools get to see representations of people who look different from themselves and who look similar to them. 
While I had predicted that students would be more inclusive than teachers in their literature selections, the opposite was typical in this study. Students selected a much higher percentage of literature with White characters than existed naturally in the classroom library. With a few exceptions, teachers set the pace for inclusivity in literature selection.

Teachers in schools serving less diverse and more affluent students depended more on parental support for books than did teachers in more diverse, less affluent schools. All of the teachers reported purchasing books for their classroom libraries with their own money, and when buying these books, the majority of teachers think of students' interests and life connections, as well as readability of texts. The most important thing most teachers hope their students will glean from their classroom libraries is a love of reading.

When describing students in their classrooms, teachers in this study addressed a few key aspects of their students' identities. Some described students as learners, readers, and ability-holders. Others described students as they relate to their family or home life, their family's socioeconomic status, or their race. Some teachers described students in terms of their likes and dislikes; still others described students in terms of behavior. Perhaps surprisingly, teachers in less diverse, more affluent schools (B) focused on students' behavior more than teachers in other schools. Views of students as deficient in some way were evident in both A and B schools, as in teacher responses that described students" "limited vocabulary" and "lower intelligence."

Teachers were given the chance to describe their children's literature wish lists. The most popular answers given were chapter books, nonfiction, multiple copies of books 
to create book sets, and larger variety of books. One teacher asked her students what books they would like added to their classroom library.

The study's findings brought varied responses from teachers in follow-up interviews. Of the teachers whose classroom libraries continued the selective tradition, some seemed bothered by the realization while others did not seem concerned. After sharing the description of her classroom, Ms. Napier agreed that the account was accurate. I explained the true intent of the study; that I was looking at the diversity within classroom libraries and teachers' alignment with what is called the selective tradition and apologized for being a bit deceptive to learn from her library (My deception is addressed in Chapter 5). She explained that she understood and upon hearing that her library was one of many that continued the selective tradition she responded: That has never occurred to me. I never considered diversity. I am ashamed. I was ignorant on that thought. I shouldn't... I have several Black students but I just go and get good literature... I never thought about having more books that are more diverse. I'm very interested in adding some books to my collection."

Other teachers seemed unbothered by the lack of diversity within their classroom libraries. Ms. Mimms explained that she tries to include diverse texts, but blamed the lack of diversity within Scholastic book club's offerings as the reason for the absence of much diversity within her library. She went on to say, "I do look for them [texts portraying diverse populations]... it's whatever's offered during those months." I did not press this issue, but assume she meant months that are themed for specific racial and ethnic group awareness or appreciation, such as February for Black History Month. Banks might consider this an example of the most basic form of integration of 
multicultural literature into the classroom, which he has called the "heroes and holidays approach" (1988, p.1). Many see this type of inclusion of multicultural literature as tokenism (Gillespie, Powell, Clements, \& Swearington, 1994).

Ms. Ingram, an African American teacher, was pleased to learn that her classroom library challenged the selective tradition. This realization led her to tell me about her past.

I'm 46 years old and grew up in New York City in a very diverse environment. I was very unaware of racism and was very protected. At the end of the year I would celebrate Hanukkah with my friend along with Christmas. I had friends from Asia... so all of these cultures are so relevant. These kids [her students] are totally oblivious to everything and I really try to expand their minds. It's so important to me that they have a respect for others... I want them to grow. All teachers involved in the follow-up interview expressed interest in receiving information about inclusion of multicultural literature within their libraries.

Clearly teacher attitude, interest in, and commitment to the diversity within texts and society have an important role in the selection of texts. While as a whole, the data from this study indicate that classroom libraries are more diverse than in the past, teachers' decision-making concerning who is represented within the literature in their classrooms is crucial. 


\section{CHAPTER V}

\section{DISCUSSION}

This study of the racial representation of characters in the literature in 22 second grade classrooms illustrates both promising and distressing news in elementary education today. Without a doubt, classroom libraries are more multicultural than 50 or even 20 years ago. Much more exciting, well-written, racially accurate and respectful children's literature exists today, and many teachers are taking advantage of these new texts. However, it is also worrisome that many classrooms still do not fully represent the availability of this literature, and much classroom literature does not reflect the demographic population of students in the classroom. Further, what children choose to read continues to be books with predominately White characters, even for non-White students. These findings and others will be discussed in this Chapter, followed by specific recommendations for teachers and teacher educators. First, however, I describe the limitations of the study.

\section{Limitations}

Several limitations exist within this study. The short time frame and the single visit to each classroom are among these limitations. Future studies could involve multiple visits to each classroom over an extended time period. This would help to alleviate some of the bias that may have occurred due to inclusion of certain texts because of holidays (e.g. Martin Luther King Day), time of the year, or curriculum. 
In addition, this study focuses on race as a factor in identity and as a presence within children's literature, which limits its scope. Because race is a social or folk construction (Herbst, 1997), labeling a character's race is not a perfect science. With this in mind, another limitation of this study lies in the fact that the race represented was not always known or obvious. A best guess was made in these situations based on context, illustrations, and background knowledge. The more salient point here is that it is important to acknowledge when teachers have literature portraying characters that are clearly White to the exclusion or limitation of those that are not. This exercise was an attempt to grasp the teachers' inclusivity in their classroom libraries.

In reality, many factors contribute to our identities, with many influences on their formation and evolution. The term selective tradition, in fact, was originally used by Williams (1978) in his description of the way society intentionally and selectively shapes the past and present, leading to "social and cultural definition and identification" (p.115) based on ideals of the dominant and hegemonic pressures within society. As discussed previously, Luke and colleagues (1986) used Williams' term selective tradition to describe the specific tendency of teachers to favor literature that features primarily White, male, middle-class characters and authors over literature that is written by or written about females, people of diverse ethnicities and races, or characters from other social classes. So to combat the selective tradition in its original definition we need to include not only more racially diverse characters, but also more female characters and writers, more ethnic diversity among characters and authors, more characters with disabilities, characters who are from diverse socioeconomic groups, characters with disabilities; indeed any character, situation, and setting that does not represent a hegemonic and 
overrepresented group. Future studies could investigate the presence of characters of different ethnicities, cultures, disabilities, and from various geographic regions.

A further limitation of this study involves the depth of analysis of the literature itself. Future investigations must address the quality of multicultural literature within classroom libraries, teachers' use of such literature, students' interest in this literature and responses to it when present and when read.

As stated previously, in order to keep teachers from altering their classrooms before data collection, the specific intent of the study was not explicitly described. Teachers knew that the books would be inventoried, but did not know the purpose or intent of the exercise. While it is common for researchers to provide generic purposes to research participants (in this case, teachers) in order to avoid affecting the outcome of the study, a tension exists with luring participants into a study under circumstances in which the researcher does not fully disclose the research agenda. Newkirk (1986) has written about the ethical dilemmas in "seducing" teachers into allowing researchers in their classrooms with promises that they will never be "exposed" for problematic practices. He wrote that more often than not, teachers are "betrayed" when their practices are found wanting.

The teachers who eventually learned of my real purpose in this study appeared friendly, and a few seemed unconcerned when they learned that the study focused on examining the racial representations in the classroom libraries. These teachers may have had complicated feelings they could not articulate. They may have wondered whether I viewed them as racist in some way or, at minimum, irresponsible. Some teachers admitted that they had not considered the diversity within the texts in their libraries. 
While they appeared comfortable enough to speak with me about the lack of diversity in their classrooms, as a researcher and teacher myself, I felt uncomfortable confronting them with my deception. I struggled to word things in ways that would not offend or hurt teachers' feelings, and as I confronted this I realized that as a researcher I prefer working alongside teachers to make instructional practices better, rather than covertly observing and then pointing out good and bad practices. Of course, even when being open with teachers in any study, imperfect instruction and practices can happen, and difficult discussions can occur as a result. However in those instances teachers have signed up for the feedback and are more knowledgeable about the circumstances.

Despite the lack of diversity I saw in the literature in these classrooms, I recognized the problem as one more of teacher education and school-based professional development than with the teachers themselves. The teachers in this study, like the many teachers with whom I have worked for so many years, work hard to do what they believe is right for their students. The conditions for elementary teaching are such that they may not have the time, money, or specific knowledge to provide the kind of literature expected by "experts" today. To try to resolve some of my concerns, I will send to the teachers who participated in this study information on incorporating multicultural literature into their classroom libraries and instructional practices.

\section{Racial Representation in Text: Why Should Teachers Care?}

While the present investigation did not address the importance of teachers using racially diverse literature, it is important to reiterate why this literature is so essential in elementary classrooms in order to situate the findings of the present study. Several reasons follow. 
A classroom can be made more inclusive and accepting with the use of multicultural literature to modify curriculum, instruction, and the learning climate (Young, Campbell, \& Oda, 1995). When students do not see that their identities are reflected in the school world, they may begin to doubt their self-worth and acceptability there (Henderson, 1991). Therefore, multicultural literature can be affirming for students to see stories like their own reflected in literature (Cox \& Galda, 1990; Steiner, Nash, \& Chase, 2008), can "promote a feeling of belonging among immigrant and minority youth" (Agosto, 2007, p. 27), and avert feelings of isolation (Steiner, et al., 2008). These ideas are expressed by Rochman, "The best books break down borders. They surprise uswhether they are set close to home or abroad. They change our view of ourselves; they extend that phrase 'like me' to include what we thought was foreign and strange." (1993, p. 9)

With this in mind, teachers can help students to see that they are valued within the school setting by positively and purposefully incorporating literature and resources that reflect their students' races, ethnicities, cultures, and living situations. A teacher's goal might be to obtain texts for his/her classroom that reflect the diversity of the outside (real) world (Coatney, 2004; Kovarik, 2004; Young et al.,1995) including the values and traditions (Cox \& Galda, 1990), and perspectives and knowledge (Torres-Velasquez, 2000) of diverse groups.

Children can view and learn about their own cultures through multicultural literature. It can serve to scaffold children's understandings, can help them identify with their identities more fully (Al-Hazzaa \& Bucher, 2008; Banks, 2007; Cai, 2008; Cox \& Galda, 1990; Kovarik, 2004), and can foster pride, and positive self-concepts (Steiner, 
Nash, \& Chase, 2008; Yokota, 1993). Multicultural literature can also teach us about the similarities and differences among various cultures (Agosto, 2007; Norton, 1990).

Learning about how people are the same and different can lead to social sensitivity to the needs of others (Norton, 1990) and an appreciation of our uniqueness (Rasinski \& Padak, 1998). Through literature about other cultures we see different perspectives (Cox \& Galda, 1990; Galda, 1998) and can experience cultures vicariously (Yokota, 1993). An introduction to characters that are different from ourselves can help to develop our understandings of other value and belief systems (Norton, 1990). Indeed, just as the school district within which this study took place has a goal of school desegregation, classroom teachers also need to make desegregation a goal within their classroom libraries.

\section{Why Teachers Choose the Books They Do: Patterns of Racial Representation in}

\section{Second Grade Libraries}

As illustrated in Chapter 4, great variance existed in the diversity of character representation within the literature found in the 22 classrooms assessed in this study. There appeared to be no patterns of difference by school grouping. That is, the racial representation in the literature in classrooms in the A schools, which were highly diverse demographically, was no different than the racial representation in the literature in classrooms in the B schools, which were less diverse demographically. Instead, differences fell into three categories: those that challenged the selective tradition, those that were progressing against the selective tradition, and those that continued the selective tradition. Under these classifications, only six of the 22 classrooms had classroom libraries that might be expected today with the rich, multicultural literature that 
is available. Much research supports the use of multicultural literature, yet theory is outrunning practice (Gay, 1995). Why might this be?

The selective tradition is passed down as a result of unexamined assumptions developed over time. Research shows that preservice and inservice teachers tend to continue the selective tradition in part due to unconscious gender and racial bias about what students should read (Luke, Cooke, \& Luke, 1986). This will happen unless somehow interrupted by peers, teacher education programs, parents of students, or the teacher's personal experiences. Some teachers may simply use books in their classroom libraries that they know about from their own childhoods, a tendency that has been demonstrated in previous research, as discussed in Chapter Two (Jipson \& Paley, 1991). These books would be older and could include less accurate portrayals of diverse populations.

The selective tradition is also passed down via hand-me-down books from former teachers. Twenty of the 21 teachers who answered the questionnaire said they obtained books from former teachers. This is a tradition of its own within schools, and I do not wish to disparage this generous and often much needed practice. However, teachers need to take a critical look at the books they receive from yesterday's classrooms to be sure that they are appropriate for today's students.

Several teachers who continued the selective tradition indicated in their questionnaire responses that they chose "quality literature" for their classroom libraries. When pressed to explain this, the same teachers appeared flustered in the follow-up interview, having difficulty explaining what they meant by quality literature. This difficulty may have existed because their ideas of quality literature were so entrenched in 
tradition, what Raymond Williams (1978) calls "the most evident expression of dominant and hegemonic pressures and limits" (p.115). One teacher illustrated this in describing her idea of quality literature as, "I think of some of the oldies."

Teachers can face several challenges in choosing multicultural literature. They must be willing to move away from the selective tradition, hold an understanding that students need to see themselves within literature, and be able to find appropriate literature. Small (2000) studied ways teachers choose materials for their classrooms, and found that the most influential sources for information on books for the classroom include other teachers, libraries and librarians, conferences, workshops, and book clubs. She found that less influential sources included journals and magazines, family members, and students' parents. The least influential source of information about books for the classroom at the time of Small's study was the Internet.

In this study, the 21 reporting teachers ranked sources of information on literature as well. These teachers ranked formal classes, libraries and librarians, bookstores, and other teachers as most influential. They listed book clubs, Internet resources, and parents as least influential. Clearly, in both studies, Internet resources and parents or family members were not influential for most teachers while other teachers and libraries or librarians were.

In addition, teachers who were challenging or making progress against the selective tradition seemed to make diversity a goal in their literature selections. When speaking with some of them in follow-up interviews these teachers recounted stories of growing up in diverse settings, appreciating the experiences they had had within diverse 
contexts, and wanting to broaden the awareness of their students beyond their own neighborhoods.

The six teachers whose classroom libraries challenged or were progressing against the selective tradition all had degrees beyond the bachelor's level. This suggests that teacher education has a valuable and important role in encouraging the use of multicultural literature in classrooms. In addition, newer teachers listed formal classes as their main resource for information on children's literature. Bookstores and Internet resources were their next most reliable sources of information on the topic. Teachers in this study with 15 or fewer years of experience used other teachers the least as resources on information about literature. The fact that newer teachers use information from formal classes, bookstores, and Internet resources makes sense. The information from formal classes is still fresh in their memories, and in some cases is current to recently published literature. In addition, bookstores are very good at advertising, and few teachers can walk into a bookstore without buying or at least wanting a book for his/her classroom. I assume here that teachers with more than 15 years of experience have built their classroom libraries, and are buying fewer books than the less-experienced teachers. Through book clubs, teachers can acquire books for free (if their students participate and buy books from the clubs, which we saw in question 1 works in the more affluent B schools but not the A schools). Other teachers are often willing to lend books for individual lessons or units, as well. With these inferences in mind, one would think that teachers with more experience would have older (and therefore less inclusive of diverse populations) books in their classroom libraries. This, however, was not the case. When 
analyzing the quantitative data from the classroom library observation, it is clear that the teacher's age did not have an obvious effect on the inclusivity within classroom literature.

Teachers reported choosing books for their classroom libraries based on readability, popularity, variety, curricular connections, character familiarity, aesthetics, and availability. Any of these qualities could be matched with a goal of choosing books with diverse characters. While teachers did not list the inclusion of diverse characters as a criterion for selecting literature, books representing greater cultural diversity were listed within some of the teachers' wish lists. Perhaps this disconnect between teachers' selection processes and their wish lists illustrates the teachers' need for information on finding and selecting literature that includes diverse characters. Two of the three teachers who wrote that they would like books with more multicultural and diverse characters had classroom libraries that continued the selective tradition. One of the teachers who wrote that he would like more literature with diverse characters was progressing against the selective tradition. Clearly some of the participating teachers desired more inclusive and diverse literature. However, while this desire exists, teachers need explicit help in finding texts. We cannot assume teachers will learn about new literature and the possibilities within without explicit teaching in the area.

The majority of teachers had classroom libraries that continued the selective tradition, as it applies to race. While this is a disappointing finding, it is important to remember that the exclusion of diverse populations from classroom literature was much more prevalent and extreme in the past. In this study, as shared in Table 3, three teachers' classroom libraries were making progress against the selective tradition, and three were challenging the selective tradition, as it applies to race. In the past, literature 
depicting diverse groups of characters was not frequently published. More diverse literature is being published currently; therefore, teachers have the option to purposefully select literature depicting diverse characters.

\section{What Teachers Want From Literature}

This study was an investigation of not only the literature in second grade classrooms but, also, the teachers' views on the purposes of the literature. What do teachers use it for? What goals do they have that the literature can help them achieve? This study illustrated that most of the teachers wanted children to love to read, a highly laudable goal. They also wanted students to practice skills, probably decoding or word recognition, as they read the books. These are both common and important goals for elementary teachers. However, at times, the skill practice can get in the way of teachers providing high-quality literature. In their attempts to teach specific skills, teachers sometimes lean on texts that are created specifically for such practice (i.e., traditional workbooks, worksheets, and basal reading series) that contain controlled vocabulary and limit the types of books they display or read aloud to kids. Skill practice can take place within a shared reading or guided reading group using authentic literature, and such practice can be encouraged within teacher education programs and professional development.

When teachers choose literature for their classrooms they use as criteria for selection such factors as students' reading levels and interests, what they (the teachers) would like to read, and the potential for students to make connections as criteria for selection. Sometimes teachers select literature according to the content taught in the 
classroom. The findings of this study indicate that at times teachers select literature with a student-focus (i.e., interests, needs, possible connections) and at times teachers select literature based on content (i.e., science or social studies curriculum).

Clearly, the majority of the 22 teachers were not thinking of using literature as a tool for teaching students about social justice topics such as inclusion, anti-racism, antibullying, or celebration of differences. Yet, this literature can be one of the most powerful tools for teaching on such topics. Further, literature can serve as props for teachers who are still uncomfortable with teaching about race or differences. For instance, in the powerful book, Amazing Grace (Hoffman, 1991), the mother learns that Grace was told by another child that she could not play Peter Pan in the school play because she is Black. The mother grows dark and scowls. Grace's grandmother smooths things over by encouraging Grace to audition anyway (and Grace does go on to play Peter Pan). But this one moment in the book-when the mother scowls - can be a wonderful teaching moment for young children, if teachers simply ask the question and guide a discussion on, "Why would Grace's mom be so angry?" Many teachers may in fact use this book in this way. Yet, the teachers in this study did not indicate that this was the case. It may be that they have not learned how such books can teach important ideas. Or it may be because I did not directly ask them if and how they might use the books in their classrooms to teach about themes of inclusion.

\section{What The Children Are Reading: Explaining Children's Choices}

Despite the diverse student population in the classrooms in this study (especially classrooms in the A Group), the children shockingly chose to read considerably more 
books with predominately White characters than books that reflected themselves or their classmates. Why might this be the case? The one teacher who asked her students what sorts of books they wanted may help explain the students' voices. The children in that classroom said they wanted more books on how to do things, joke books, chapter books, I-Spy books, and books about or based on presidents, movies, sports and animals. This list helps explain why children choose books with mostly White characters. Most books, of course, have mostly White characters. Students in the participating classrooms seem more interested in the experiences described within the text or playing with text in a way (joke books, I-Spy) than in making overt connections to their racial or ethnic identities.

In an action research study performed with my own second grade class (Hulan, 2010), I found that while many students favored books that reflected their own races, ethnicities, or native languages, students also liked and chose to read books that reflected familiar experiences regardless of other factors that might reflect a child's identity (ethnicity, race, language, religion, etc.) For instance many students, regardless of race or ethnicity, listed My Name is Yoon (Recorvits, 2003) as one they could relate to and that they liked the best (of a group of multicultural books I read aloud) because it made them think of their own struggles learning to write or moving to another place. One student who spoke Turkish in my class expressed that she favored a book that was written in Turkish and English because of the use of her native language. Her preference reflected her identity in terms of her linguistic background.

Children in this study may have mixed criteria when selecting or favoring books, just as my second grade class had. Clearly many favored more interactive books such as 
I-Spy, joke books, and how-to books. A future step in this line of research may look more closely in students' choices of literature.

\section{The Role of Teacher Education}

While much research defends the use of multicultural literature, classroom practice is not keeping up with theory (Gay, 1995). The majority of classrooms in this study held few titles of literature portraying non-White characters. Teacher education programs can do a great deal to further the inclusion of such literature in future teachers' classroom libraries. Teacher educators should work to battle the selective tradition in teacher candidates' assumptions and practices beginning at the bachelor's level and continuing throughout teacher preparation programs. Incorporation of topics of diversity, multicultural literature, selection of literature, sources for finding good diverse literature, and further topics can take place within classes focused on methods as well as theory.

Future teachers should also have experiences within their preparation programs in diverse school settings. Many teachers have no history of working within multicultural or multiracial workplaces. In order to limit or stop the continuation of such patterns as the selective tradition, bias and labeling of kids as deficient, and the "savior" mentality of many teachers, teacher education programs need to give teacher education students the opportunity to learn about and with students from backgrounds that are different from their own.

According to the teachers involved in this study, teacher educators have a strong influence on future teachers' book selections for their classrooms. With this in mind, teacher educators need to be proactive and purposeful in the literature they share and promote in their classes. Hart and Rowley (1996) found that preservice teachers' 
selections of classroom literature may be influenced by instruction on the use of multicultural literature. If future teachers are exposed to inclusive, meaningful, and multicultural literature in their training and shown how to incorporate it into their instruction and curriculum, they are probably more likely to use those types of books in their classrooms. People need to be made aware of the variety of literature currently available or they will go back to the literature they were exposed to as children.

In addition to the selective tradition, future teachers often find themselves fulfilling what Lortie (1975) called the "apprenticeship of observation." This refers to the way prospective teachers form conceptions of teaching based on their own experiences as students. Many teachers regress to teaching as they were taught rather than enacting the instructional practices they learned in teacher preparation programs. This points to the need for continuing education and professional development for practicing teachers.

Presently social justice and work with diverse populations are tenets of many teacher education programs. While many colleges of education have added such direction and training to their curricula and goals, these programs still struggle to prepare teachers to work in diverse settings (Cochran-Smith \& Zeichner, 2005). Cochran-Smith has written, "Efficacious teachers committed to social justice do not come out of racist institutions and teacher education programs" (2004, p. xiii). To mold teachers who question their own stereotypes, and truly value social justice, the entire institution must adopt the mindset, as well. It is hoped that such a direction would help to encourage the incorporation and use of multicultural literature and other inclusive practices.

\section{The Role of Schools: Professional Development on Topics of Diversity}


It is important that teachers receive continuing education about serving diverse student populations (Banks, 2001). Professional development for continuing teachers should incorporate topics of diversity for the more experienced teachers. Once they are in the field, many experienced teachers have seen a vast demographic shift in the students they serve since the beginnings of their careers. In addition, many of these same teachers never received training on working with children from poverty, children for whom English is not their native language, and children who are not White and from the middle class.

Professional development within schools and school districts can foster teachers' understandings of working within a diverse and dynamic school population. The National Reading Panel (2000) found that professional development can change teachers' attitudes and practices, as well as improving student outcomes. In addition, they reported that to be effective, professional development should involve extensive support and prolonged periods of training.

Within the participating district, elementary students are bused to schools around the district with the goal of racial and economic diversity within schools. For this approach to desegregation to be effective, teachers must be armed with knowledge of effective practices for working with diverse populations. Professional development on topics of diversity should include use of multicultural literature. Grants should also be pursued in order to purchase multicultural literature for classrooms, and for professional development on ways to incorporate it into the curriculum.

Librarians and libraries were listed by teachers in this study as strong influences on their selections of literature. This is positive, especially if the library and librarian are 
up-to-date on available books and have a drive to choose inclusive and multicultural literature for their libraries. Professional development could be led by school or community librarians to introduce new titles available within the library and could include ways to incorporate such titles within the curriculum to enhance instruction and student engagement.

Effective professional development on the use of multicultural literature within the classroom and curriculum should focus on sharing many examples of the literature and ways to use it. Grants or school funding could be used to purchase multicultural literature for teachers or book rooms, with the promise of providing professional development on its use. Professional development should address the context of the school (Gambrell, Morrow, \& Pressley, 2007), introducing literature that both reflects children within a school setting and children who are not members of the school community.

Professional development can also address the variety of levels at which teachers adhere to the selective tradition. One way this could be achieved is through a professional development approach consisting of several sessions. The first session could address the definition and usefulness of multicultural literature while introducing the idea of the selective tradition. Teachers could be provided with positive examples of multicultural literature to be incorporated into their teaching. Further trainings could involve sessions that would focus on various subjects dealing with the use of multicultural literature and specific grade levels. Teachers could select sessions that most strongly fit their needs, their levels of implementation, and use of multicultural literature in the classroom. This type of training would protect teachers from being exposed as 
continuing the selective tradition while instructing them in ways to begin using multicultural literature, reasons for its use, and resources for immediate implementation.

In addition to the previously discussed training, professional development could be a venue for discussion on the social construction of identity. The idea that identity is not a fixed and innate concept, but that our experiences, surroundings, and social interactions help to construct an ever-evolving identity could help many teachers see the value in many instructional practices such as discussion, varied grouping patterns, and the use of multicultural literature. Such training could ask participants to deconstruct their own identities by completing graphic organizers, for example, which would help them to break down their various roles, or aspects of their identities. A teacher participating in such a training might write down the following items for herself: church member, mother, boy scout troop den mother, teacher, team leader, environmentalist, Asian American, graduate student, etc. The teachers would then either share in small groups or write reflections on the various items in their lives that contribute to their identity formations. Modeling and discussion of this exercise would be valuable in guiding participants to new understandings of the complexities of identity and the need to address it in the classroom.

\section{Conclusion}

Ultimately, what a teacher includes within a classroom library constitutes a political decision, even when made subconsciously. In most of the classrooms that participated in this study, racially diverse students were represented less within classroom libraries than White students. This was true in more and less diverse schools. However, 
a few teachers' classroom libraries did have a substantial number of books that portrayed diverse characters, and several teachers indicated that they wished to obtain more inclusive children's literature for their classrooms. While the selective tradition is still alive and well in our public elementary schools, there are signs here that some teachers are trying to incorporate more literature portraying diverse characters. Future studies must investigate the quality of multicultural literature within classrooms, the way it is used pedagogically, and how children respond to inclusive texts.

Studies have found that children who attend diverse schools are more likely to overcome prejudices and have positive relationships later in life (Holme, Wells, \& Revilla, 2005). Likewise, some teachers in this study whose classroom libraries were diverse indicated that they had positive experiences within diverse settings in their childhoods. Perhaps this sheds light on a cycle of attitudes toward diversity. The student assignment plan, which tries to keep students integrated and schools diverse is meant to produce children, teens, and thus adults who overcome prejudices, and have positive feelings toward and relationships with people of various races and ethnicities. Some teachers' inclusion of multicultural and diverse literature spawns from early experiences within positive diverse settings. Thus, to begin the cycle of inclusion, we must proactively end the cycle of exclusion and segregation within our schools and classroom libraries. 


\section{REFERENCES}

Aboud, F. E. (1987). The development of ethnic self-identification and attitudes. In J. S. Phinney \& M.J. Rutherman. (Ed.), Children's Ethnic Socialization. London: Sage Publications.

Adler, S.S., Tripp, V., Grace, R. (1986). Meet Samantha. Middletown, WI: Pleasant Company Publications.

Agosto, D. E. (2007). Building a multicultural school library: Issues and challenges. Teacher Librarian, 34(3), 27-31.

Al-Hazza, T. C., \& Bucher, K. T. (2008). Building Arab Americans' cultural identity and acceptance with children's literature. The Reading Teacher, 62(3), 210-219.

American Anthropological Association. (1998). American Anthropological Association Statement on "Race". Retrieved January 10, 2009 from http://www.understandingrace.org/about/statement.html

American Anthropological Association. (2007). Race and Human Variation. Retrieved on January 10,2009 , from http://www.understandingrace.org/humvar/race_humvar.html

Anyon, J. (1980). Social class and the hidden curriculum of work. Journal of Education, $162(1), 67-92$.

Apple, M. (1980). The other side of the hidden curriculum: Correspondence theories and the labor process. Journal of Education, 162(1), 47-66. 
Au, K. (1998). Social constructivism and the school literacy learning of students of diverse backgrounds. Journal of Literacy Research, 20, 297-319.

Banks, J.A. (1988). Approaches to multicultural curriculum reform. Multicultural Leader, $1(2), 1-3$.

Banks, J. A. (2007). Multicultural education: Issues and perspectives (6th ed.). New York: Wiley.

Berghoff, B. (1998). Multiple sign systems and reading. The Reading Teacher, 51(6), $520-523$

Berry, J. (2008). A Help Me Be Good Book about Tattling. New York: Joy Berry Enterprises.

Bettelheim, B. (1975). The uses of enchantment: The meaning and importance of fairy tales. New York: Knopf, Inc.

Bishop, R. B. (1990). Mirrors, Windows, and Sliding Glass Doors. Perspectives, 6, ix-xi.

Bishop, R.B. (2003). Making multicultural literature meaningful. Knowledge Quest, $32(1), 27-28$.

Bodrova, E., \& Leong, D. J. (1996). Tools of the mind: The Vygotskian approach to early childhood education. Columbus: Prentice-Hall, Inc.

Bogdan, R. C., \& Biklen, S. K. (1992). Qualitative research for education: An introduction to theory and methods. Boston: Allyn \& Bacon.

Bruner, J. (1990). Acts of meaning. Cambridge: Harvard University Press.

Cai, M. (2008). Transactional theory and the study of multicultural literature. Language Arts, 85(3), 212-220. 
Chall, J. S., Radwin, E., French, V. W., \& , \& Hall, C. (1985). Blacks in the world of children's books. In C. M. G. Woodward (Ed.), The Black American in books for children: Readings in racism (2 ed., pp. 211-221). Matuchen, NJ: Scarecrow.

Coatney, S. (2004). What about the collection? Teacher Librarian, 32(2), 47.

Cochran-Smith, M. (2004). Walking the Road: Race, diversity, and social justice in teacher education. New York: Teachers College Press.

Cochran-Smith, M., \& Zeichner, K. (2005). Studying teacher education: The report of the AERA Panel on Research and Teacher Education. Mahwah, NJ: Lawrence Erlbaum Associates, Publishers.

Cooperative Children's Book Center. (2008). Children's Books by and about People of Color Published in the United States. Retrieved October 15, 2008, from http://www.education.wisc.edu/ccbc

Cox, S., \& Galda, L. (1990). Multicultural literature: Mirrors and windows on a global community. The Reading Teacher, 43(8), 582-589.

Darling-Hammond, L., French, J., \& Garcia-Lopez, S. P. (2002). Learning to Teach for Social Justice. New York: Teachers College Press.

Denzin, N., \& Lincoln, Y. (Eds.). (2000). Handbook of Qualitative Research. Thousand Oaks: Sage Publications.

Dewey, J. (1997). Democracy and Education. New York: Free Press.

Diamond, B. J., \& Moore, M. A. (1995). Multicultural Literacy. White Plains, New York: Longman Publishers. 
Dickinson, D., \& Smith, M. (1994). Long-term effects of preschool teachers' book reading on low-income children's vocabulary and story comprehension. Reading Research Quarterly, 29, 104-122.

Dossett, D. (personal communication, June 19, 2008).

Duke, N. K. (1999). Print environments and experiences offered to first grade students in very low- and very high-SES school districts. Unpublished Dissertation, Harvard University, Boston.

Dyson, A. H. (1990). Research currents: Diversity, Social responsibility, and the story of literacy development. Language Arts, 67(2), 192-205.

Egoff, S. A. (1981). Thursday's child: Trends and patterns in contemporary children's literature. Chicago: American Library Association.

Ferdman, B. M. (1990). Literacy and cultural identity. Harvard Educational Review, 60(2), 181-204.

Finn, P. (1999). Literacy with an attitude: Educating working-class children in their own self-interest. Albany, NY: State University of New York Press.

Galda, L. (1998). An Annotated bibliography of multicultural children's literature. In M. F. Opitz (Ed.), Literacy instruction for culturally and linguistically diverse students. Newark, DE: International Reading Association.

Gambrell, L, Morrow, L., \& Pressley, M. (2007). Best Practices in Literacy Instruction. New York: Guilford Press.

Gay, G. (1995). Bridging multicultural theory and practice. Multicultural Education, $3(1), 4-9$.

Gay, G. (2000). Culturally Responsive Teaching. New York: Teachers College Press. 
Gay, G. (2002). Preparing for culturally responsive teaching. Journal of teacher education, 53(2), 106-116.

Gillespie, C. S., Powell, J. L., Clements, N. E., \& Swearington, R. A. (1994). A look at the Newbery Medal books from a multicultural perspective. In M. F. Opitz (Ed.), Literacy instruction for culturally and linguistically diverse students (pp. 229240). Newark, DE: International Reading Association.

Giroux, H., \& Penna, A. N. (1979). Social education in the classroom: the dynamics of the hidden curriculum. Theory and Research in Social Education, 7(1), 21-42.

Givan, L.M. (Ed.) (2008). The Sage Encyclopedia of Qualitative Research Methods. Thousand Oaks: Sage Publications.

Glaser, B., \& Strauss, A. L. (1967). The discovery of grounded theory: Strategies for qualitative research. Chicago: Aldine.

Greenfield, E. (1985). Writing for Children: A Joy and a Responsibility. In D. MacCann \& G. Woodard (Eds.), The Black American in Books for Children: Readings in Racism. Metuchen, New Jersey: Scarecrow Press.

Hart, P., \& Rowley, J. (1996). Different, but alike: An exploration of preservice teacher decision making with regard to the selection of children's literature for classroom use. Reading Research and Instruction, 35(3), 209-222.

Henderson, V. M. (1991). The development of self-esteem in children of color. In M. V. Lindgren (Ed.), The multicolored mirror: Cultural substance in literature for children and young adults. Fort Atkinson, Wisconsin: Highsmith Press.

Herbst, P. (1997). The Color of Words. Yarmouth, Maine: Intercultural Press.

Hoffman, M. (1991). Amazing Grace. New York: Dial Books. 
Holme, J.J., Wells, A.S. Revilla, A.T. (2005). Learning through experience: What graduates gained by attending desegregated High Schools. Equality \& Excellence in Education, 38(1), 14-24.

Hulan, N. (2010). Finding similarities in experiences through multicultural literature: An investigation of second graders' views toward literature from around the world. Unpublished manuscript.

Hunt, P. (2001). Children's Literature. Oxford: Blackwell Publishers.

Jackson, F. R. (1994). Seven strategies to support a culturally responsive pedagogy. Journal of Reading, 37(4), 298-303.

Jipson, J., \& Paley, N. (1991). The selective tradition in teachers' choices of children's literature: Does it exist in the elementary classroom? English Education, 23, 148 159.

Killen, M., \& Stangor, C. (2001). Children's reasoning about social inclusion and exclusion in gender and race peer group contexts. Child Development, 72, 174186.

Kovarik, M. (2004). Selecting children's books for a multiracial audience. Florida Libraries, 47 (1), 10-11.

Larrick, N. (1965). The all-white world of children's books. Saturday Review (September 11), 63-65, 84-85.

Lewis, D. (2001). Reading contemporary picturebooks: Picturing texts. New York: Routledge Falmer.

Lortie, D.C. (1975). Schoolteacher; a sociological study. Chicago: University of Chicago Press. 
Luke, A., Cooke, J., \& Luke, C. (1986). The selective tradition in action: Gender bias in student teachers' selections of children's literature. English Education, 18(4), 209-218.

MacLeod, A. S. (1995). Children's Literature in America. In P. Hunt (Ed.), Children's Literature: An Illustrated History. Oxford: Oxford University Press.

Martinez, M., \& Nash, M. (1998). Children's books: A look at how we evaluate and select them. Journal of Children's Literature, 24(1), 6-19.

Marzollo, J. \& Wick, W. (2003). I Spy a Dinosaur's Eye. New York: Scholastic Readers.

McCracken, G. (1988). The Long Interview. Thousand Oaks: Sage Publications.

McIntyre, E. (personal communication, January 2, 2009).

McIntyre, E., Hulan, N., \& Layne, V. (2010). Reading Instruction for Diverse Classrooms: Research-Based, Culturally Responsive Practice. New York: Guilford Press.

McIntyre, E., \& Stone, N. (1998). Culturally contextualized instruction in Appalachiandescent and African-American classrooms. National Reading Conference Yearbook, 47, 209-221.

McKissack, P. (2008). Stitchin' and Pullin'. New York: Random House.

McNair, J. C. (2003). "But the Five Chinese Brothers is one of my favorite books!" Conducting Sociopolitical critiques of children's literature with preservice teachers. Journal of Children's Literature, 29(1), 46-54.

Mickelson, R.A. (2001). Subverting Swann: First- and second-generation segregation in Charlotte, North Carolina. American Educational Research Journal, 38(2), 215252. 
Miles, M. B., \& \& Huberman, A. M. (1994). Qualitative Data Analysis (2nd ed.). Thousand Oaks: Sage Publications.

Moje, E.B. \& Luke, A. (2009). Literacy and identity: Examining the metaphors in history and contemporary research. Reading Research Quarterly, 44 (4), 415-437. doi: 10.15198/RRQ.44.4.7

Moll, L., Armanti, C., Neff, D., \& Gonzalez, N. (1992). Funds of knowledge for teaching: Using a qualitative approach to connect homes and classrooms. Theory into Practice, 31, 131-141.

Mosely, J. J. (1997). Multicultural diversity of children's picture books: Robert Fulton Elementary School library. Unpublished Master's Research Paper, Kent State University.

Muñoz, M. (personal communication, August 19, 2010).

National Center for Educational Statistics. (2008). Status and Trends in the Education of Racial and Ethnic Minorities, Retrieved October 11, 2008, from http://nces.ed.gov/pubs2007/minoritytrends/\#1

National Institute of Child Health and Human Development. (2000). Report of the National Reading Panel. Teaching children to read: An evidence-based assessment of the scientific research literature on reading and its implications for reading instruction (NIH Publication No. 00-4769). Washington, DC: U.S. Government Printing Office.

Neuendorf, K. A. (2002). The Content Analysis Guidebook. Thousand Oaks: Sage. 
Newkirk, T. (1996). Seduction and betrayal in qualitative research. In Ethics and representation in qualitative studies of literacy, p.3-16. Urbana, Illinois: National Council of Teachers of English.

Nieto, S. (1999). The light in their eyes. New York: Teachers College Press.

Nieto, S. (2000). Language, literacy, and culture: Intersections and implications.

National Reading Conference Yearbook, 49, 41-60.

Nodelman, P. (1996). The pleasures of children's literature (2nd ed.). White Plains, NY: Longman Publishers.

Norton, D.E. (1990). Teaching multicultural literature in the reading curriculum. The Reading Teacher, 44(1), 28-40.

Norton, D. E. (2005). Multicultural children's literature: Though the eyes of many children. Upper Saddle River, NJ: Pearson Education, Inc.

Park, B. \& Brunkus, D. (1998). Junie B. Jones Smells Something Fishy. New York: Random House.

Patterson, C. J. (2008). Child Development. Boston: McGraw-Hill.

Patton, M. Q. (2002). Quatlitative Research and Evaluation Methods. Thousand Oaks: Sage Publications.

Rasinski, T. V., \& Padak, N. (1998). Selecting and using multicultural literature. In M. F. Opitz (Ed.), Literacy instruction for culturally and linguistically diverse students. Newark, DE: International Reading Association.

Recorvits, H., \& Swiakowska, G. (2003). My Name is Yoon. New York: Francis Foster Books.

Rigby. (2000). Yeh Shen. New York: Houghton Mifflin Harcourt. 
Rist, R. (2000). Student social class and teacher expectations: The self-fulfilling prophecy in ghetto education. Harvard Educational Review, 70(3), 257-302.

Robinson, W. C. (2007). Children's Book Publishing Retrieved November 3, 2008, from http://web.utk.edu/ - wrobinso 561 lec_child.html

Rochman, H. (1993). Against borders: Promoting books for a multicultural world. Chicago: ALA Books.

Rodosky, R. J. (2008a). Data Book. Louisville: Jefferson County Public Schools.

Rodosky, R. J. (2008b). Elementary School Profiles. Louisville: Jefferson County Public Schools.

Rogers, R., \& Christian, J. (2007). 'What could I say?' A critical discourse analysis of the construction of race in children's literature. Race Ethnicity and Education, 10(1), $21-46$.

Rogoff, B. (1990). Apprenticeship in Thinking. New York: Oxford University Press.

Rogoff, B. (2003 ). The cultural nature of human development. . Oxford: Oxford University Press.

Rollock, B. (1984). The black experience in children's books (2nd ed.). New York: New York Public Library.

Rosenblatt, L. (1978). The reader, the text, and the poem. Cambridge, MA: Harvard University Press.

Rosenblatt, L. (1982). The literary transaction: Evocation and response. Theory into Practice, 21(4), 268-277. 
Rosenblatt, L. (1994). The transactional theory of reading and writing. In M. R. R. Ruddell, \& H. Singer (Ed.), Theoretical models and processes of reading (4 ed., pp. 1057 -1092). Newark, DE: International Reading Association.

Sendak, M. (1963). Where the Wild Things Are. New York: Harper \& Row.

Seuss, D., Prelutsky, J., \& Smith, L. (1998). Hooray for Diffendoofer Day! New York: Random House.

Shannon, P. (1985). Reading instruction and social class. Language Arts, 62(6), 604-611.

Sheets, R. H. (2005). Diversity Pedagogy: Examining the role of culture in the teachinglearning process. Boston: Pearson Education, Inc.

Siegel, D. J. (1999). The Developing Mind: How relationships and the brain interact to shape who we are. New York: Guilford.

Small, M. (2000). Elementary teachers' resources for learning about, reason for reading, and responses to children's literature. Unpublished Dissertation, University of Minnesota, Twin Cities.

Snyder, B. (1973). The Hidden Curriculum. Boston: MIT Press.

Steiner, S. (2001). Promoting a global community through multicultural children's literature. Greenwood Village, CO: Greenwood Publishing Group.

Steiner, S.F., Nash, C., Chase, M. (2008, September). Multicultural Literature that Brings People Together. The Reading Teacher, 62 (1), 88-92. doi: 10.1598/RT.62.1.12

Stemle, C.G. (2009, August 19). The Kids on the Bus, LEO Weekly, 19 (38), 10-12.

Temple, C., Martinez, M., Yokota, J., \& Naylor, A. (2002). Children's Books in Children's Hands. Boston: Allyn and Bacon. 
Torres-Velasquez, D. (2000). Sociocultural Theory: Standing at the Crossroads. Remedial and Special Education, 21(2), 66-69.

United States Census Bureau. (1971). 1971 U.S. Census Report, Retrieved January 3, 2009, from http://www2.census.gov/prod2/statcomp/documents/1971-02.pdf United States Census Bureau. (1981). 1981 U.S. Census Report, Retrieved January 3, 2009, from http://www2.census.gov/prod2/statcomp/documents/1981-02.pdf United States Census Bureau. (2005). 2004 U.S. Census Population Brief. Retrieved January 3, 2009, from www.census.gov/population/www/cen2000/briefs/index.html United States Census Bureau. (2006a). American Community Survey, Retrieved January 2, 2009, from http://factfinder.census.gov/servlet

United States Census Bureau. (2006b). 2006 American Community Survey, Retrieved January 2, 2009, from http://www.census.gov/acs/www/Products/

Vygotsky, L. S. (1978). Mind in society: The development of higher psychological processes. Cambridge: Harvard University Press.

Watterson, B. (1990). Weirdos from Another Planet! Kansas City: Andrews \& McMeel. Willems, M. (2003). Don't Let the Pigeon Drive the Bus. New York: Hyperion Books for Children.

Williams, B. (2003). The face in the mirror, the person on the page Journal of Adolescent and Adult Literacy, 47(2), 178-182.

Williams, R. (1978). Marxism and Literature. Oxford: Oxford Universtity Press.

Wood, D., Bruner, J., \& , \& Ross, G. (1976). The role of tutoring in problem solving. Journal of child Psychology and Psychiatry, 17, 89-100. 
Yarrow, P. \& Lipton, L. (2007). Puff the Magic Dragon. New York: Sterling Publishing. Yokota, J. (1993). Issues in selecting multicultural children's literature. In M. F. Opitz (Ed.), Literacy instruction for culturally and linguistically diverse students. (pp. 184-197). Newark, DE: International Reading Association.

Young, T. A., Campbell, L.C., Oda, L.K. (1995). Multicultural literature for children and young adults: A rationale and resources. Reading Horizons, 35(5), 374-393.

Zhang, Y. \& Wildemuth, B.M. (2009). Qualitative analysis of content. In B. Wildemuth (Ed.), Applications of Social Research Methods to Questions in Information and Library. Retrieved from http://www.ils.unc.edu/ -yanz/Content_analysis.pdf 


\section{Appendix A}

Letter to principals

Date

Dear principals,

I am a $2^{\text {nd }}$ grade teacher in Jefferson County Public Schools and a doctoral candidate in Curriculum and Instruction at the University of Louisville. My dissertation research is directed at exploring the literature within $2^{\text {nd }}$ grade classroom libraries. I will be collecting data this spring in 12 elementary schools around the district and would like permission to do so in your school.

I would like to visit 2 classrooms in each of the selected schools. Each classroom will only be visited once, and these visits will occur after school hours, during breaks, or on professional development days. I will visit after hours to limit distractions to teachers and students. I will take notes of the literature in the classroom, using an organizational chart I devised. I will also take pictures of books displayed and those chosen by students to read. I will leave a short questionnaire for the teachers of those particular classrooms to complete and return in a supplied self-addressed and stamped envelope. These questionnaires will remain anonymous and I will not alter the classroom setting at all.

If you choose to participate, two $2^{\text {nd }}$ grade teachers will be chosen randomly from your school. If a teacher chooses not to participate, another teacher from that team will 
be asked to take part in the study. If no teachers in your school wish to participate, I will select a different school.

I would greatly appreciate your support in this endeavor. This study seeks to learn about the inclusion of literature in classroom libraries, teacher selection processes, and student preferences. Therefore, the findings could be very interesting to those of us in the field of elementary education.

If you have questions please feel free to contact me at 502-974-8688 or via email at Nancy. Hulanó jefferson.kyschools.us or you can contact Dr. Diane Kyle at 502-8520572 or diane@louisville.edu. Thank you for your attention. I look forward to working with you and your teachers.

Sincerely

Diane W. Kyle

Nancy Hulan

Professor, Dept. of

Second grade teacher

Teaching and Learning

Price Elementary School

College of Education

Doctoral Candidate

And Human Development

Curriculum and Instruction

University of Louisville

University of Louisville 
Appendix B

\section{Subject Informed Consent Document}

\section{The Nature of Representation within Literature in $2^{\text {nd }}$ Grade Classrooms}

IRB assigned number:

Investigator(s) name \& address: Diane Kyle, Nystrand Center of Excellence in

Education, Room 123A, College of Education and Human Development

Site(s) where study is to be conducted: Second grade classrooms within Jefferson County Public Schools

Phone number for subjects to call for questions: $502-974-8688$

\section{Introduction and Background Information}

You are invited to participate in a research study. The study is being conducted by Diane Kyle, EdD, Education professor and Nancy Hulan, PhD candidate and JCPS teacher. The study is sponsored by the University of Louisville, Department of Teaching and Learning. The study will take place in $2^{\text {nd }}$ grade classrooms at various elementary schools in Jefferson County Public Schools. Approximately 30 subjects will be invited to participate.

\section{Purpose}

The purpose of this study is to describe the types of literature found within $2^{\text {nd }}$ grade classroom libraries, students' literature choices, and the ways teachers select and obtain these books.

\section{Procedures}

In this study, you will be asked to complete a questionnaire. This should only take about 20 minutes to complete and will ask you questions about where and how you selected books for the classroom library. In addition, the co-investigator will inventory the books within your classroom library after school hours, and will take photographs of the walls and use of space within the classroom. You will be asked to have students put the books from your classroom library that they have in their desks on top of their desks for the observation. This is to insure that a truly representative reflection of the literature within your classroom be made. You are not required to be present during the observation, which will take one visit outside of school hours. This study will take place during the spring semester of 2009 . The questionnaire will be left for you to complete following the 
observation of your classroom library. This will be returned via postal service to the researcher's home and will only be opened and seen by that person. You may decline to answer questions that make you uncomfortable.

\section{Potential Risks}

There are no foreseeable risks other than possible discomfort in answering personal questions. There are no foreseeable risks, although there may be unforeseen risks.

\section{Benefits}

The possible benefits of this study include increased knowledge of (a) teachers' selection processes for literature for use within the classroom, (b) trends in students' book preferences, as well as (c) barriers which teachers may experience in selecting or obtaining literature. In addition, patterns and trends within classroom libraries will help teacher educators in teacher preparation courses. The information collected may not benefit you directly. The information learned in this study may be helpful to others.

\section{Confidentiality}

Total privacy cannot be guaranteed. Your privacy will be protected to the extent permitted by law. If the results from this study are published, your name will not be made public. While unlikely, the following may look at the study records: The University of Louisville Institutional Review Board and Human Subjects Protection Program Office

To ensure the security of information from this study, it will be kept in a locked file cabinet. In addition, codes will be used for teacher identity rather than their names. Data collected will also be kept within a password protected computer.

\section{Voluntary Participation}

Taking part in this study is voluntary. You may choose not to take part at all. If you decide to be in this study you may stop taking part at any time. If you decide not to be in this study or if you stop taking part at any time, you will not lose any benefits for which you may qualify.

\section{Research Subject's Rights, Questions, Concerns, and Complaints}

If you have any concerns or complaints about the study or the study staff, you have three options.

You may contact the principal investigator at 502-974-8688. 
If you have any questions about your rights as a study subject, questions, concerns or complaints, you may call the Human Subjects Protection Program Office (HSPPO) (502) 852-5188. You may discuss any questions about your rights as a subject, in secret, with a member of the Institutional Review Board (IRB) or the HSPPO staff. The IRB is an independent committee composed of members of the University community, staff of the institutions, as well as lay members of the community not connected with these institutions. The IRB has reviewed this study.

If you want to speak to a person outside the University, you may call 1877-852-1167. You will be given the chance to talk about any questions, concerns or complaints in secret. This is a 24 hour hot line answered by people who do not work at the University of Louisville.

This paper tells you what will happen during the study if you choose to take part. Your signature means that this study has been discussed with you, that your questions have been answered, and that you will take part in the study. This informed consent document is not a contract. You are not giving up any legal rights by signing this informed consent document. You will be given a signed copy of this paper to keep for your records.

Signature of Subject/Legal Representative

Date Signed

Signature of Person Explaining the Consent Form (if other than the Investigator)

Date Signed

Signature of Investigator

Date Signed

LIST OF INVESTIGATORS

PHONE NUMBERS

Diane Kyle

502-974-8688

Nancy Hulan

$502-974-8688$ 


\section{Appendix C}

Classroom library data collection chart

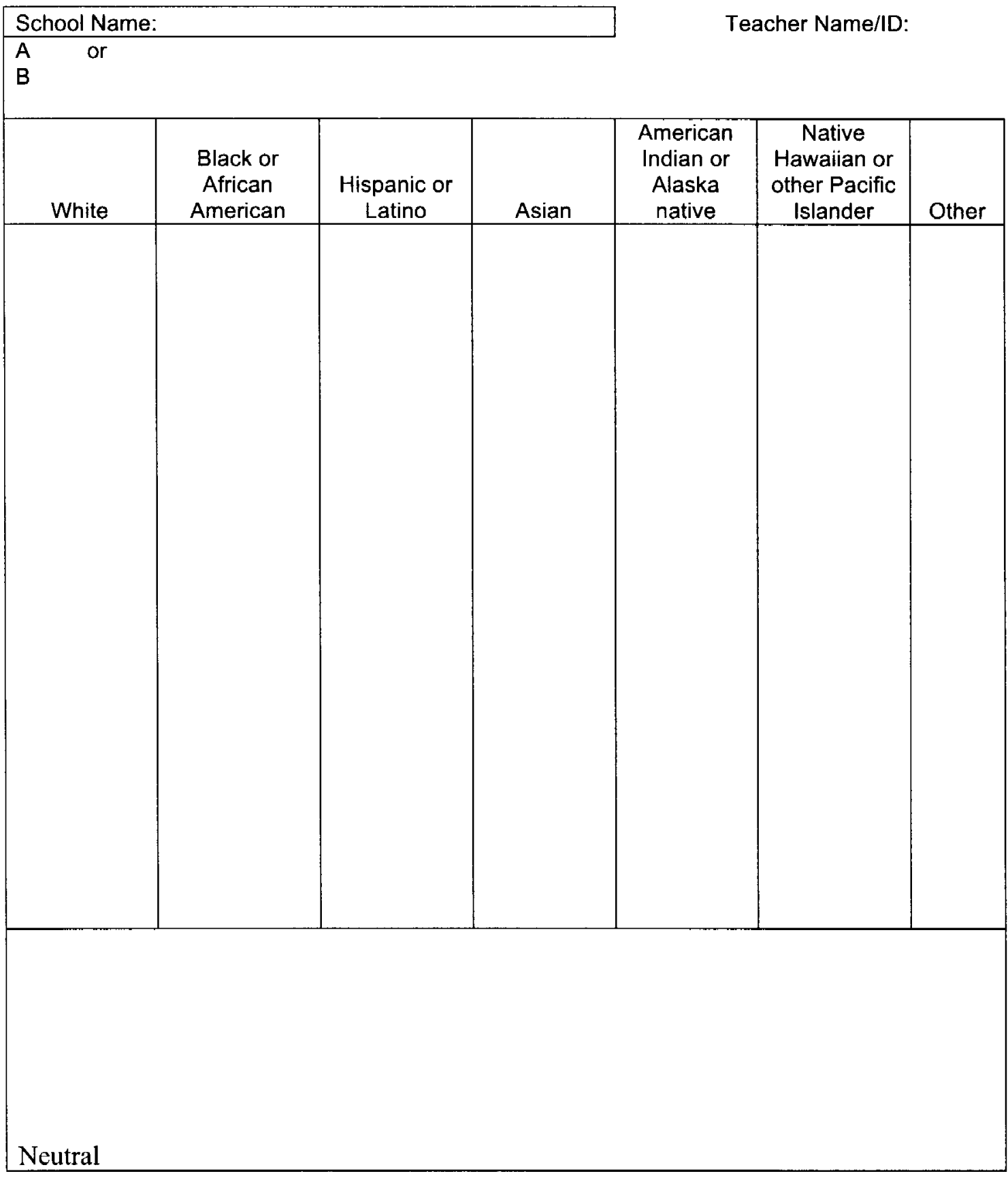




\section{Appendix D}

Teacher questionnaire

IRB Number

Subject Number

Directions: Please complete each of the following questions as they pertain to your teaching and classroom. When completed, please send it in the accompanying selfaddressed and stamped envelope. Your answers will not be viewed by anyone other than the researcher and your identity will remain anonymous. Thank you so much for your help!

1. Where did the books in your classroom library (that children read) come from (excluding Rigby books)? Please check all that apply.

(a) Hand-me-downs from past teachers

(b) My school bought them for me

(c) I bought them with my own money

(d) Grants (indicate institution granting)

(e) Borrow from The Public Library

Other (please explain)

2. What qualities do you look for when selecting books for your classroom library?

3. What do you hope your students will gain from these books?

4. Describe the typical student in your classroom. 
5. Describe the student you envision when you buy or check out books for your classroom.

6. If money was no object, what types of books would you like to add to your classroom library? Briefly explain why you would choose these.

7. Rate from the most influential- 8- to the least influential-1- how the following resources have influenced your current personal knowledge of children's literature.
a. Formal classes
b. In-services
c. Bookstores
d. Libraries/Librarians
e. Book Clubs
f. Other teachers
g. Parents
h. Internet resources

8. Please write the number of students in your class that are of each of the following backgrounds:

a. Black or African American

b. White

c. Hispanic or Latino

d. American Indian or Alaska native

e. Asian

f. Pacific Islander or Native Hawaiian

g. Other please explain

9. How long have you been teaching? 
10. What is the highest educational degree you have earned? If you are currently taking classes please describe the program/ process you are involved in.

11. Your Race:

12. Your Gender:

Would you agree to answer some follow-up questions?

If yes, please indicate how and where you would prefer to be contacted.

\section{Thank you for your participation!}




\section{Appendix E \\ Question Guide for Follow-Up/ Member Check \\ Interview Protocol \\ Date: \\ Respondent:}

What is "quality literature?"

How did the books in students' desks get there? Do they get to choose the books from the library? Do you ever assign books from the classroom library for the students to read at their seats?

What books do you think students have limited exposure to?

How do you organize the books in your classroom? Why? (by genre, size, theme, author, etc.)

How typical is your classroom library today compared to other days or years? 
Do you rotate literature in and out of your classroom library? What are your methods in selection of what should go into the library at a given time? Why do you do this (ex. space limitations)?

Share classroom library findings from the observation. Please tell me if you agree or disagree with what I have written about your classroom. What reactions do you have to these findings? Do you agree that this is a representative sample of the books in your classroom and my interpretation of your answers to the questionnaire?

How do you address the diversity of your students in the selection or inclusion of literature for your classroom library?

Would you like to change anything based on the findings? If so, what would you change and how will you go about doing that?

Would you like to receive information about specific multicultural literature that would be appropriate for the age group of your class? 


\section{Appendix F}

\section{Contact Summary}

Subject/Site ID

Contact date

What did I notice as possible themes or issues in the contact?

In regards to the research questions, what initial observations can I make from this visit? Racial diversity within the texts-

Racial diversity in the literature vs. racial diversity within the classroom-

Books students favor-

Teacher selection and inclusion criteria of literature-

Purposefully displayed books and themes relayed therein-

Do I have any new hypotheses or speculations about the literature within the classroom and selection thereof based on this observation?

Any other comments concerning this observation: 
Appendix G

\section{Adams' Classroom Data}

Mr. "Adams" (pseudonym) teaches in a B (low minority enrollment) school in a second grade classroom. Mr. Adams is White, holds his Rank 1 certification, and at the time of this study, had six years of teaching experience. During the study year, his classroom was comprised of 11 Black or African American students, 11 White students, and one Hispanic or Latino student. The children's books in his classroom library came from two sources: hand-me-downs from former teachers and himself. When looking for literature for his classroom library he reports that he looks for authors he appreciates, meaningful texts, and books that have won awards. His wish list of books includes books by Patricia Polacco, Nikki Giovani, and Nikki Grimes. He also would like more books portraying cultural diversity and real-world subjects and material. He rated sources of information concerning children's literature from most to least influential in the following way: formal classes, other teachers, Internet resources, libraries/librarians, bookstores, inservices, book clubs, parents. Mr. Adams hopes his students will gain a love of reading from the books in his classroom library. The typical student in his classroom is "eager to learn" and "quizzical." When buying or checking out books for his classroom library he admits to thinking of himself, rather than students.

Mr. Adams arranged his desks in short lines facing the chalkboard. Books in his classroom library are laid horizontally in stacks on bookshelves and in labeled and unlabeled tubs on top of the bookshelves. Whisper phones, PVC pipes put together to form phones to help kids hear themselves when they whisper read, are hidden in a box covered by books. There is limited organization. One shelf is full of sets of picture books. It is not clear if these are for guided reading groups or students' independent reading.

Table 1

Frequency of Group Representation within all Classroom Literature: Mr. Adams

Category

Frequency

White characters

Black or African American characters 
Hispanic or Latino characters

$\begin{array}{ll}\text { Asian characters } & 20\end{array}$

$\begin{array}{ll}\text { American Indian or Alaska Native characters } & 7\end{array}$

Native Hawaiian or Pacific Islander characters 0

$\begin{array}{ll}\text { Other characters } & 2\end{array}$

$\begin{array}{ll}\text { Total } & 179\end{array}$

Table G2

Classroom Library Status in Relation to the Selective Tradition

$\begin{array}{llll}\text { Category } & \text { Frequency } & \text { Percentage } & \text { Status }\end{array}$

White

$\begin{array}{llll}\text { Characters } & 98 & 54.75 \% & \text { Making progress }\end{array}$

All other

Characters $\quad 81 \quad 45.25 \%$

Note. Status reflects the difference between percentages of white and all other characters. A difference of $\leq 5 \%$ means challenging the selective tradition; a difference between of $>5 \%$ and $\leq 10 \%$ means making progress against the selective tradition; a difference $>10 \%$ means a collection is continuing the selective tradition. 
Appendix $\mathrm{H}$

\section{Burns' Classroom data}

Ms. "Burns" (pseudonym) teaches in a B school (low minority enrollment) in a second grade classroom. Ms. Burns is White, holds a Rank 1 certification, and at the time of this study, had 26 years of teaching experience. During the school year, her classroom was comprised of 10 Black or African American students and 12 White students. The children's books in her classroom library came from two sources: hand-me-downs from past teachers and herself. She added that her students like to read one another's library books in order to take Scholastic Reading Counts computer tests, which assess students' comprehension of books they have read and gives points for correct answers. When looking for literature for her classroom library she reports that she pays attention to price and reading levels, and looks for books that will interest her students. She also indicated that she looks for books that the school has Reading Counts tests for. Her wish list of books include a larger variety of chapter books and more about Junie B. Jones (although she said she already had them all). She rated sources of information concerning children's literature from most to least influential in the following way: Book clubs, other teachers, bookstores, formal classes, libraries/ librarians, in-services, parents, Internet resources. She hopes her students will ultimately gain a love of reading from the literature within her classroom. In the short term she explains that she hopes her students will improve their comprehension and get additional Reading Counts scores. The typical student in her classroom exhibits reading levels from low first grade to the end of third grade, is talkative, and easily distracted. When buying or checking out books for her classroom library she looks for selections that would appeal to young children-from picture books to chapter books.

Ms. Burns arranges her desks in clusters of seven with boxes of books in the middle of each cluster. These boxes of books take the place of a standard classroom library elsewhere in the classroom.

Table H1

Frequency of Group Representation within all Classroom Literature: Ms. Burns

Category

White characters
Frequency 
Hispanic or Latino characters

Asian characters

American Indian or Alaska Native characters

Native Hawaiian or Pacific Islander characters

Other characters

Total

Table $\mathrm{H} 2$

Classroom Library Status in Relation to the Selective Tradition

\begin{tabular}{|c|c|c|c|}
\hline Category & Frequency & Percentage & Status \\
\hline
\end{tabular}

White

$\begin{array}{llll}\text { Characters } & 112 & 70.44 \% & \text { Continuing }\end{array}$

All other

Characters 47 $29.56 \%$

Note. Status reflects the difference between percentages of white and all other characters. A difference of $\leq 5 \%$ means challenging the selective tradition; a difference between of $>5 \%$ and $\leq 10 \%$ means making progress against the selective tradition; a difference $>10 \%$ means a collection is continuing the selective tradition. 


\section{Appendix I}

\section{Caudill's Classroom Data}

Ms. "Caudill" (pseudonym) teaches in a B school (low minority enrollment) in a second grade classroom. Ms. Caudill is African American, holds her Rank 1 certification, and at the time of this study, had 14 years of teaching experience. During the study year, her classroom was comprised of 5 Black or African American students, 12 White students, and 3 Hispanic or Latino students. The children's books in her classroom library came from hand-me-downs from past teachers, were bought by her school or with her money, or were borrowed from the Public Library. When looking for literature for her classroom library she reported that she tries to pick books that have earned the Caldecott Medal or Newberry Honors. She also looks for books based on her students' interests (sports, funny books, Harry Potter, war, scary, comics, animals, Junie B. Jones, Twilight). She rated sources of information concerning children's literature from most to least influential in the following way: Internet resources, Formal classes, In-services, bookstores, libraries/ librarians, book clubs, other teachers, parents. She hopes that her students will like the books in her classroom, which will further inspire them to read more. She explained that most of the students in her classroom were great readers who loved to read and enjoyed shared and self-selected reading. Ms. Caudill said that her students' love of reading made her job easy. She said that her students often said they had read books before. She encouraged them to reread books. Her students were reading on the $3^{\text {rd }}, 4^{\text {th }}$, and $5^{\text {th }}$ grade levels - she gave credit to the students' parents for this. Ms. Caudill reported that her $2^{\text {nd }}$ graders enter her class able to comprehend what they read.

Ms. Caudill arranged her desks in groups of six or more. Books were in forwardfacing bookshelves and in regular shelves. She had many book sets and several boxes were marked with book themes (e.g., multicultural), but the contents did not match the labels. Her library contained several books depicting children with disabilities. One forward-facing bookshelf held only teacher materials and adult magazines. She did not have a designated guided reading group area.

Table Il

Frequency of Group Representation within all Classroom Literature: Ms. Caudill

$\begin{array}{ll}\text { Category } & \text { Frequency }\end{array}$

White characters 
Black or African American characters

Hispanic or Latino characters $\quad 22$

$\begin{array}{ll}\text { Asian characters } & 24\end{array}$

American Indian or Alaska Native characters 5

$\begin{array}{ll}\text { Native Hawaiian or Pacific Islander characters } & 0\end{array}$

$\begin{array}{ll}\text { Other characters } & 2\end{array}$

Total 185

Table 12

Classroom Library status in relation to the Selective Tradition

$\begin{array}{lll}\text { Category } & \text { Frequency } & \text { Percentage }\end{array}$

White
Characters
92
$49.73 \%$
Challenging

All other

Characters

93

$50.27 \%$

Note. Status reflects the difference between percentages of white and all other characters. A difference of $\leq 5 \%$ means challenging the selective tradition; a difference between of $>5 \%$ and $\leq 10 \%$ means making progress against the selective tradition; a difference $>10 \%$ means a collection is continuing the selective tradition. 
Appendix $\mathbf{J}$

Dauphin's Classroom data

Ms. "Dauphin" (pseudonym) teaches in a B school in what the principal called the Spanish speaking second grade classroom (where instruction is in Spanish). Ms. Dauphin is White, holds her Rank 1 certification, and at the time of this study, she had 14 years of teaching experience. During the study year, her classroom was comprised of 10 Black or African American students, 8 White students, and 2 Hispanic or Latino students. The children's books in her classroom library came from hand-me-downs from former teachers, were bought by her school, came from the school library, or were purchased by her. When looking for literature for her classroom library she reports that she looks for well-known authors, illustrations to support emergent readers, levels appropriate for her students and that will challenge them, fiction and nonfiction, and "various medias... used in the classroom." If money was no object she would add easy chapter books, science informational books, periodicals like "Time for Kids" and historical character books like the American doll books to her classroom library. She rated sources of information concerning children's literature from most to least influential in the following way: Formal classes, Librarians/ libraries, bookstores, book clubs, other teachers, in-services, parents, and Internet resources. Ms. Dauphin hopes the books in her classroom will help her students to gain an understanding of the various media resources and an appreciation for books. The typical student in her classroom is seven or eight years old with both parents working and comes from an average to slightly below average income family. Parents are supportive, and most children are well behaved and work hard on their studies. When buying or checking out books for her classroom library she envisions a student who will be excited about new books. She says that she doesn't have a stereotype at all, and that she thinks about how they ask to borrow her books. In addition, she thinks about their interests and what they would like to read.

Ms. Dauphin arranges her desks in groups of four with one book box on each set of desks. There are thematic groupings of books scattered around the classroom (e.g., rocks, American Girl, crafts). The one forward-facing bookshelf held multiple copies of some titles from the guided reading program (Rigby) on one side and held five random children's books (a biography of George Washington, a folktale from Texas, and three phonics readers) on the other. There were many Biblical stories in the library and many books were missing pages or covers. None of the environmental print or children's books were in Spanish.

Table J1

Frequency of Group Representation within all Classroom Literature: Ms. Dauphin 
White characters

Black or African American characters

Hispanic or Latino characters

Asian characters

American Indian or Alaska Native characters

2

Native Hawaiian or Pacific Islander characters

0

Other characters

1

Total

102

Table J2

Classroom Library Status in Relation to the Selective Tradition

Category $\quad$ Frequency $\quad$ Percentage Status

White

Characters

66

$64.71 \%$

Continuing

All other

Characters

36

$35.29 \%$

Note. Status reflects the difference between percentages of white and all other characters. A difference of $55 \%$ means challenging the selective tradition; a difference between of $>5 \%$ and $\leq 10 \%$ means making progress against the selective tradition; $a$ difference $>10 \%$ means a collection is continuing the selective tradition. 


\section{Appendix K}

\section{Evans' Classroom Data}

Ms. "Evans" (pseudonym) teaches in an A school (high minority enrollment) in a second grade classroom. Ms. Evans is White, holds her Rank 1 certification, and at the time of this study, had six years of teaching experience. During the study year, she reported that her classroom was comprised of 13 Black or African American students, 2 White students, 5 Hispanic or Latino students, 2 Asian students, and 1 she reported as "other," who was Bosnian. The children's books in her classroom library came from hand-medowns from former teachers, were purchased by her school, were paid for by grants (Reading First), or were bought by Ms. Evans. She rated sources of information concerning children's literature from most to least influential in the following way: parents, other teachers, bookstores, libraries/ librarians, Internet resources, in-services, formal classes, book clubs. When looking for literature for her classroom library she reports that she looks for what interests her students, readability, new popular books, and she also takes students' requests. Ms. Evans hopes the books in her library will lead her students to "enjoy reading and (to) love to have adventures through the excitement of books." She reports that all of the students in her classroom receive free or reduced lunch, and that they are active and sometimes hard to engage. When buying or checking out books for her classroom library Ms. Evans reports that she thinks of her students who are the hardest to reach. She imagines what will grab their interests and encourage them to read. She also thinks of her most advanced readers and tries to get books that will "push them just past their reading to keep their reading level improving." When asked what books she would like to get if money was no object, Ms. Evans asked her students what they would want. They said they would want "How to books (e.g., origami), joke books, "If I grew up when....." books, Books about presidents, chapter books (e.g., Junie B. Jones, Monster vs. Alien), I Spy (for lower level readers), books based on movies (e.g., Karate Kid, Hannah Montana), and books about sports and animals.

Ms. Evans arranged her desks in clusters of six. Her classroom library was stored in 3-drawer plastic chests. Ten of these chests lined the wall. Each drawer was labeled with a sticker explaining the contents. An additional bookshelf was filled with "Goosebumps" books. Dictionaries were lined up on top of the bookshelf. One shelf was labeled "multicultural." There seemed to be little diversity anywhere other than in this drawer. Chapter books were displayed around the room, and a class-made book was in a prominent position

\section{Table K1}

Frequency of Group Representation within all Classroom Literature: Ms. Evans 
White characters

Black or African American characters

Hispanic or Latino characters

Asian characters

American Indian or Alaska Native characters

Native Hawaiian or Pacific Islander characters

Other characters

Total

Table K2

Classroom Library Status in Relation to the Selective Tradition

$\begin{array}{lll}\text { Category } & \text { Frequency } & \text { Percentage }\end{array}$

White
Characters
170
$62.50 \%$
Continuing

All other

Characters

102

$37.50 \%$

Note. Status reflects the difference between percentages of white and all other characters. A difference of $\leq 5 \%$ means challenging the selective tradition; a difference between of $>5 \%$ and $\leq 10 \%$ means making progress against the selective tradition; a difference $>10 \%$ means a collection is continuing the selective tradition. 
Appendix L

\section{Franklin's Classroom Data}

Ms. "Franklin" (pseudonym) teaches in an A school (high minority population) in a second grade classroom. Ms. Franklin is White, is working on her masters degree, and at the time of this study, had four years of teaching experience. During the study year, she reported that her classroom was comprised of 15 Black or African American students, 3 White students, 2 Hispanic or Latino students, 1 American Indian or Alaska native student, 1 Asian student, and 1 she reported as "other," who was Indian. The children's books in her classroom library came from hand-me-downs from former teachers, were purchased by her school, or were bought by Ms. Franklin. When looking for literature for her classroom library she reports that she looks for topics that are or have been covered in class, as well as topics which would interest all of her students. She rated sources of information concerning children's literature from most to least influential in the following way: book clubs, parents, Internet resources, libraries/ librarians, bookstores, formal classes, other teachers. Ms. Franklin hopes the books in her library will help her students gain a love of reading regardless of the genre. She reports that her students read right at grade level and love fiction picture books but that they "need a little extra push to read on their own." When buying or checking out books for her classroom library Ms. Franklin reports that she thinks of her "middle of the road reader and what they would like to see in order to motivate them to pick up the book on their own." When asked what books she would like to get if money was no object, Ms. Franklin said she would like to add more chapter book series or picture book series. She explained that her kids really enjoy read alouds with the chapter books and enjoy following certain characters throughout different books.

Ms. Franklin arranged her desks in clusters of four or six. Her classroom library was in labeled bins on shelves. There were also two forward-facing bookshelves, one with big books in a shared reading area and another labeled "Ms. Franklin's Picks of the Month" which held several children's books.

Table L1

Frequency of Group Representation within all Classroom Literature: Ms. Franklin 
Hispanic or Latino characters $\quad 6$

$\begin{array}{ll}\text { Asian characters } & 21\end{array}$

American Indian or Alaska Native characters 4

Native Hawaiian or Pacific Islander characters $\quad 1$

$\begin{array}{ll}\text { Other characters } & 2\end{array}$

$\begin{array}{ll}\text { Total } & 208\end{array}$

Table L2

Classroom Library Status in Relation to the Selective Tradition

\begin{tabular}{llll}
\hline Category & Frequency & Percentage & Status \\
\hline
\end{tabular}

White

$\begin{array}{llll}\text { Characters } & 128 & 61.54 \% & \text { Continuing }\end{array}$

All other

Characters

$80 \quad 38.46 \%$

Note. Status reflects the difference between percentages of white and all other characters. A difference of $\leq 5 \%$ means challenging the selective tradition; a difference between of $>5 \%$ and $\leq 10 \%$ means making progress against the selective tradition; a difference $>10 \%$ means a collection is continuing the selective tradition. 


\section{Appendix M}

\section{Greene's Classroom Data}

Mr. "Greene" (pseudonym) teaches in a B school (low minority population) in a second grade classroom. Mr. Greene is White, was working towards his Masters degree, and at the time of this study, had three years of teaching experience. During the study year, his classroom was comprised of 6 Black or African American students, and 19 White students. The children's books in his classroom library came from hand-me-downs from former teachers, were bought by the school or by him. When looking for literature for his classroom library he reports that he looks for books that will relate to either core content or to his students. He rated sources of information concerning children's literature from most to least influential in the following way: other teachers, formal classes, in-services, parents, Internet resources, bookstores, libraries/librarians, book clubs. Mr. Greene hopes his students will gain a love for reading. He adds, "I want students to realize the possibilities reading can provide." The typical student in his classroom is on $2^{\text {nd }}$ grade reading level with basic math skills and comes from a family of average or below average socioeconomic level. When buying or checking out books for his classroom library he says he envisions "a student who can gain knowledge from and make connections to the selected book," admitting that he selects the book and then thinks about the students. His wish list of books includes more leveled books.

Mr. Greene arranged his desks in clusters of four or six desks. Books in his classroom library were divided into labeled and unlabeled boxes on bookshelves. Other children's books were in disorganized and high stacks. The library was very sparse and disorganized. A few book boxes displayed themes, but the books inside didn't match the advertised themes.

Table M1

Frequency of Group Representation within all Classroom Literature: Mr. Greene

Category

Frequency

White characters

Black or African American characters

Hispanic or Latino characters

Asian characters 
Other characters

Total 164

Table M2

Classroom Library Status in Relation to the Selective Tradition

$\begin{array}{lll}\text { Category } & \text { Frequency } & \text { Percentage }\end{array}$

White

Characters

95

$57.93 \%$

Continuing

All other

Characters

69

$42.07 \%$

Note. Status reflects the difference between percentages of white and all other characters. A difference of $55 \%$ means challenging the selective tradition; a difference between of $>5 \%$ and $\leq 10 \%$ means making progress against the selective tradition; $a$ difference $>10 \%$ means a collection is continuing the selective tradition. 


\section{Appendix N}

\section{Harper's Classroom Data}

Ms. "Harper" (pseudonym) teaches in a B school (low minority population) in a second grade classroom. Ms. Harper is African American, holds a Masters degree, and at the time of this study, had 13 years of teaching experience. During the study year, her classroom was comprised of 5 Black or African American students, 16 White students, and two Asian students. The children's books in her classroom library were bought by her school, with her own money, and were borrowed from the Public Library. Ms. Harper reports that when looking for literature for her classroom library she seeks a variety of levels and genres and books that will interest her students. She rated sources of information concerning children's literature from most to least influential in the following way: parents, formal classes, in-services, Internet resources, libraries/ librarians, bookstores, other teachers, book clubs. Ms. Harper hopes the books in her classroom library will lead her students toward "a genuine love of reading with an understanding of how essential reading is to life." She describes the typical student in her class as very talkative, with a love of reading who gets excited by books that relate to content being studied in class. When buying or checking out books for her classroom library she first thinks about whether they will enjoy reading or listening to the books. "If they listen to it, will they want to read it for themselves? I think about how they will react to reading the book. I see a student who is laughing/smiling and anxious to tell his neighbor/friend about the book and that person wanting to read." Her wish list of books includes books by her favorite author. She reports, "The kids love to read books that I like". She adds that she would also buy books that have more multicultural characters because her students are "fascinated to see different faces in books."

Ms. Harper arranged her desks in three groups of six, a line of four desks, and a few individual desks were by themselves. There were book boxes on each group of desks, and a classroom library with labeled book boxes on accessible bookshelves. The library was next to an open rug, and the area seemed very appealing, organized, and welcoming. The books were also labeled with guided reading levels. She had a round reading table, on which she had taped strategy cards at each seat for students' reference.

\section{Table N1}

Frequency of Group Representation within all Classroom Literature: Ms. Harper 
White characters

Black or African American characters

$\begin{array}{ll}\text { Hispanic or Latino characters } & 15\end{array}$

$\begin{array}{ll}\text { Asian characters } & 24\end{array}$

$\begin{array}{ll}\text { American Indian or Alaska Native characters } & 7\end{array}$

Native Hawaiian or Pacific Islander characters 2

$\begin{array}{ll}\text { Other characters } & 0\end{array}$

\begin{tabular}{ll} 
Total & 283 \\
\hline
\end{tabular}

Table N2

Classroom Library Status in Relation to the Selective Tradition

$\begin{array}{lll}\text { Category } & \text { Frequency } & \text { Percentage }\end{array}$

White

$\begin{array}{llll}\text { Characters } & 172 & 60.78 \% & \text { Continuing }\end{array}$

All other

Characters

111

$39.22 \%$

Note. Status reflects the difference between percentages of white and all other characters. A difference of $\leq 5 \%$ means challenging the selective tradition; a difference between of $>5 \%$ and $\leq 10 \%$ means making progress against the selective tradition; a difference $>10 \%$ means a collection is continuing the selective tradition. 
Appendix $\mathrm{O}$

\section{Ingram's Classroom Data}

Ms. "Ingram" (pseudonym) teaches in a B school (low minority population) in a second grade classroom. Ms. Ingram is African American, holds a Masters degree, and at the time of this study, had five years of teaching experience. During the study year, her classroom was comprised of 5 Black or African American students, 18 White students, and one Hispanic or Latino student. The children's books in her classroom library were hand-me-downs from former teachers or bought by Ms. Ingram. When looking for literature for her classroom library she reports that she looks for "books that will allow students to make a connection socially, environmentally, and academically." She rated sources of information concerning children's literature from most to least influential in the following way: formal classes, in-services, other teachers, bookstores, libraries/ librarians, book clubs, Internet resources, parents. Ms. Ingram hopes her students will gain insights from the books in her room. She describes the typical student in her as "bright, energetic, with an extremely short attention span!" When buying or checking out books for her classroom library she envisions her students helping to "mold the minds of the next generation." Her wish list of books includes picture books, and books that reflect social studies and science content.

Ms. Ingram arranged her classroom using five round tables, and one student desk was by itself. There was a book box in the center of each table for students to store their selected books. Books in her classroom library were arranged in several ways. Some books were in labeled boxes on bookshelves. Others were stacked in crates with no apparent order. Book boxes were up high on top of bookshelves, and seem like they would be hard for children to reach. Many ripped magazines and books were included in the library. There were a lot of texts about famous African Americans, and much of the displayed literature depicted diverse characters.

Table O1

Frequency of Group Representation within all Classroom Literature: Ms. Ingram

Category

White characters

Black or African American characters
Frequency 
Hispanic or Latino characters

Asian characters

American Indian or Alaska Native characters

Native Hawaiian or Pacific Islander characters

Other characters

Total

122

Table O2

Classroom Library Status in Relation to the Selective Tradition

\begin{tabular}{llll}
\hline Category & Frequency & Percentage & Status \\
\end{tabular}

White

Characters

58

$47.54 \%$

Challenging

All other

Characters

64

$52.46 \%$

Note. Status reflects the difference between percentages of white and all other characters. A difference of $\leq 5 \%$ means challenging the selective tradition; a difference between of $>5 \%$ and $\leq 10 \%$ means making progress against the selective tradition; a difference $>10 \%$ means a collection is continuing the selective tradition. 


\section{Appendix $\mathbf{P}$ \\ Jones' Classroom Data}

Ms. "Jones" (pseudonym) teaches in a B school (low minority population) in a second grade classroom. Ms. Jones is White, holds two Masters degrees (in education and psychology), and at the time of this study, had six years of teaching experience. During the study year, her classroom was comprised of 5 Black or African American students, 13 White students, and three Hispanic or Latino students. The children's books in her classroom library were hand-me-downs from past teachers, were bought by Ms. Jones, were borrowed from the Public Library, or were "earned" with book club points. When selecting literature for her classroom library she reports that she looks for well-known authors and illustrators, books that have won awards, and chapter books in sets or volumes with the same characters. She rated sources of information concerning children's literature from most to least influential in the following way: bookstores, book clubs, formal classes, libraries/ librarians, in-services, Internet resources, other teachers, parents. Ms. Jones hopes her students will find pleasure in the books in her classroom library. She hopes that through reading the books in her classroom library students will improve their reading skills, gain knowledge and understanding of other people, and find out new information. She reports that the typical student in her classroom has "limited experiences" and "limited vocabulary." When buying or checking out books for his classroom library she thinks of students' potential for growth from particular titles. Her wish list of books includes books depicting multicultural settings and characters, folktales, and biographies.

Ms. Jones arranged her desks in groups of three or four. Books in her classroom library were sorted into labeled boxes, and all were chapter books. There were what appeared to be subject area related centers around the room that had a few picture books related to the theme (e.g., insects, biographies). The book jackets from picture books were displayed on a bulletin board, but actual picture books were not evident in the room. There were many biographies displayed on the chalkboard trays, perhaps due to a biography study they were conducting. There was a round table for guided reading groups.

Table P1

Frequency of Group Representation within all Classroom Literature: Ms. Jones 
White characters

$\begin{array}{lr}\text { Black or African American characters } & 16\end{array}$

Hispanic or Latino characters 3

$\begin{array}{ll}\text { Asian characters } & 7\end{array}$

American Indian or Alaska Native characters 6

Native Hawaiian or Pacific Islander characters 1

$\begin{array}{ll}\text { Other characters } & 0\end{array}$

$\begin{array}{ll}\text { Total } & 101\end{array}$

Table P2

Classroom Library Status in Relation to the Selective Tradition

$\begin{array}{llll}\text { Category } & \text { Frequency } & \text { Percentage } & \text { Status }\end{array}$

White

$\begin{array}{llll}\text { Characters } & 68 & 67.33 \% & \text { Continuing }\end{array}$

All other

Characters $\quad 33 \quad 32.67 \%$

Note. Status reflects the difference between percentages of white and all other characters. A difference of $\leq 5 \%$ means challenging the selective tradition; a difference between of $>5 \%$ and $\leq 10 \%$ means making progress against the selective tradition; a difference $>10 \%$ means a collection is continuing the selective tradition. 


\section{Appendix Q}

\section{Klink's Classroom Data}

Ms. "Klink" (pseudonym) teaches in an A school (high minority population) in a second grade classroom. Ms. Klink is African American. She retired at the end of the study year. Ms. Klink did not return the questionnaire, so information on this teacher is limited to classroom observation and a discussion held over the phone prior to the observation.

Ms. Klink explained to me that she stopped using her own books for her classroom library several years before because students kept stealing her books. Instead, she allows students to check out books in her name from the school library, and these books are kept in a forward-facing bookshelf for access to all students. At the time of the classroom observation the class had been conducting a thematic unit on the "Three Little Pigs." Several versions had been shared.

Ms. Klink arranged her desks in groups of four. Classroom library books were displayed in a forward-facing bookshelf, and various versions of "The Three Little Pigs" were displayed on a table with miniature pigs and a house made out of candy (a student's project) that was supposed to be one of the pig's houses, A Big Book about different kinds of masks was displayed.

Table Q1

Frequency of Group Representation within all Classroom Literature: Ms. Klink

White characters

Black or African American characters

Hispanic or Latino characters

Asian characters

American Indian or Alaska Native characters

Native Hawaiian or Pacific Islander characters

Other characters 


\section{Table Q2}

Classroom Library Status in Relation to the Selective Tradition

$\begin{array}{lll}\text { Category } & \text { Frequency } & \text { Percentage }\end{array}$

White

Characters

$59.29 \%$

Continuing

All other

Characters

46

$40.71 \%$

Note. Status reflects the difference between percentages of white and all other characters. A difference of $\leq 5 \%$ means challenging the selective tradition; a difference between of $>5 \%$ and $\leq 10 \%$ means making progress against the selective tradition; $a$ difference $>10 \%$ means a collection is continuing the selective tradition. 


\section{Appendix R}

\section{Lee's Classroom Data}

Ms. "Lee" (pseudonym) teaches in as A school (high minority population) in a second grade classroom. Ms. Lee is White, holds a Masters degree, and at the time of this study, had twelve years of teaching experience. During the study year, her classroom was comprised of ten Black or African American students, four White students, and five Hispanic or Latino students. The children's books in her classroom library came from hand-me-downs from former teachers, were bought by the school, were bought by Ms. Lee, were supplied by grants, came from the school library or book room, or were borrowed from the Public Library. When looking for literature for her classroom library she reports that she tries to find books that will match students' reading levels and interests, and that she looks for books of all genre. She rated sources of information concerning children's literature from most to least influential in the following way: libraries/ librarians, other teachers, in-services, bookstores, Internet resources, formal classes, parents, and book clubs. Ms. Lee hopes her students will gain a love of reading, increased fluency, and improved comprehension skills from reading the books in her classroom library. She reports that students in her classroom are from all backgrounds and levels. His wish list of books includes chapter books, nonfiction, and more book sets to create literature circles.

Ms. Lee arranged her desks in groups of four. Each group of desks shared a book box. There was a forward-facing bookshelf displaying a lot of animal nonfiction. A round table for guided reading groups and clearly defined centers were evident around the room.

Table R1

Frequency of Group Representation within all Classroom Literature: Ms. Lee

Black or African American characters

Hispanic or Latino characters

Asian characters 
Native Hawaiian or Pacific Islander characters 1

Other characters

Table R2

Classroom Library Status in Relation to the Selective Tradition

\begin{tabular}{llll}
\hline Category & Frequency & Percentage
\end{tabular}

White

Characters

89

$64.03 \%$

Continuing

All other

Characters

50

$35.97 \%$

Note. Status reflects the difference between percentages of white and all other characters. A difference of $\leq 5 \%$ means challenging the selective tradition; a difference between of $>5 \%$ and $\leq 10 \%$ means making progress against the selective tradition; $a$ difference $>10 \%$ means a collection is continuing the selective tradition. 


\section{Appendix S}

\section{Mimms' Classroom Data}

Ms. "Mimms" (pseudonym) teaches in a B school (low minority population) in a second grade classroom. Ms. Mimms is White, holds her Masters degree, and at the time of this study, had 20 years of teaching experience. During the study year, her classroom was comprised of 6 Black or African American students, and 17 White students. The children's books in her classroom library came from hand-me-downs from former teachers, were bought by Ms. Mimms, or were "earned" using points in a book club. When looking for literature for her classroom library she reports that she looks for "quality literature." She adds that she also looks for books her students will be interested and that she can use in writing and math lessons. She rated sources of information concerning children's literature from most to least influential in the following way: Internet resources, formal classes, other teachers, book clubs, bookstores, libraries/ librarians, parents, in-services. Ms. Mimms hopes her students will gain enjoyment, knowledge, and better reading skills from the books in her classroom library. She describes the typical student in his classroom as being "bright and engertic" with "great home support." When buying or checking out books for her classroom library she tries to get books for all students - of all genre and levels. Her wish list of books includes more book sets. She explains that she prefers to use trade books for reading instruction over prescribed reading programs.

Ms. Mimms arranged her desks in groups of four and six. Her classroom library was perhaps the largest of the study. Books were organized by size of books rather than author, theme, or subject. Displayed literature was all math-related. There were class sets of dictionaries and thesauri. Ms. Mimms has small-group (six copies) or whole class sets of at least 98 books. They are organized behind her desk for use in guided reading groups. On her wall is a self-drawn poster of a little boy having something poured into his head from a pitcher. The sign says: "Knowledge provided here. Bring your own container."

\section{Table S1}

Frequency of Group Representation within all Classroom Literature: Ms. Mimms 
$\begin{array}{ll}\text { Hispanic or Latino characters } & 8\end{array}$

$\begin{array}{ll}\text { Asian characters } & 17\end{array}$

American Indian or Alaska Native characters 5

Native Hawaiian or Pacific Islander characters 5

$\begin{array}{ll}\text { Other characters } & 0\end{array}$

\begin{tabular}{ll} 
Total & 240 \\
\hline
\end{tabular}

Table S2

Classroom Library Status in Relation to the Selective Tradition

$\begin{array}{lll}\text { Category } & \text { Frequency } & \text { Percentage }\end{array}$

White

$\begin{array}{llll}\text { Characters } & 155 & 64.58 \% & \text { Continuing }\end{array}$

All other

Characters $\quad 85 \quad 35.42 \%$

Note. Status reflects the difference between percentages of white and all other characters. A difference of $55 \%$ means challenging the selective tradition; a difference between of $>5 \%$ and $\leq 10 \%$ means making progress against the selective tradition; a difference $>10 \%$ means a collection is continuing the selective tradition. 


\section{Appendix T}

\section{Napier's Classroom Data}

Ms. "Napier" (pseudonym) teaches in a B school (low minority population) in a second grade classroom. Ms. Napier is White, holds her Rank 1 certification, and at the time of this study, had 25 years of teaching experience. During the study year, her classroom was comprised of 6 Black or African American students, 17 White students, and one Asian student. The children's books in her classroom library came from hand-me-downs from former teachers, were bought by her school, were bought by Ms. Napier, or were bought by her students' parents. When obtaining books for her classroom library she pays attention to readability, storyline, and how colorful a book is. She also pays attention to what her students are checking out at the library to get ideas. She rated sources of information concerning children's literature from most to least influential in the following way: book clubs, libraries/ librarians, other teachers, bookstores, inservices, Internet resources, parents, formal classes. Ms. Napier hopes her students will find the pleasure in reading through the books in her classroom library, rather than seeing it as a means to complete an assignment. She says the typical student in her classroom is a good reader, has books at home, knows how to read silently, and enjoys working on the computer and taking Accelerated Reader tests. When buying or checking out books for her classroom library she I envisions a student "who enjoys reading and does not just look at the pictures, a child who appreciates a good book, a student who reads for pleasure not just because the teacher gave the assignment, and a student who knows how to take care of a book." Her wish list of books includes nonfiction books "because books for boys are not as plentiful and books for girls. Boys and some girls enjoy nonfiction."

Ms. Napier arranged her desks in groups of five or six. Her classroom library was very organized with stickers on bookshelves explaining where books were located. Books were organized by author. There was a separate area where she kept her class sets of books. Big books were in a bin by the door. There were additional labeled book baskets on top of the bookshelves and large tubs full of picture books on a large table.

Table T1

Frequency of Group Representation within all Classroom Literature: Ms. Napier 
Black or African American characters

$\begin{array}{ll}\text { Hispanic or Latino characters } & 18\end{array}$

$\begin{array}{ll}\text { Asian characters } & 15\end{array}$

American Indian or Alaska Native characters 3

Native Hawaiian or Pacific Islander characters 1

$\begin{array}{ll}\text { Other characters } & 0\end{array}$

$\begin{array}{ll}\text { Total } & 274\end{array}$

Table T2

Classroom Library Status in Relation to the Selective Tradition

$\begin{array}{llll}\text { Category } & \text { Frequency } & \text { Percentage } & \text { Status }\end{array}$

White

$\begin{array}{llll}\text { characters } & 170 & 62.04 \% & \text { Continuing }\end{array}$

All other

Characters

$104 \quad 37.96 \%$

Note. Status reflects the difference between percentages of white and all other characters. A difference of $\leq 5 \%$ means challenging the selective tradition; a difference between of $>5 \%$ and $\leq 10 \%$ means making progress against the selective tradition; a difference $>10 \%$ means a collection is continuing the selective tradition. 


\section{Appendix U}

\section{Osborne's Classroom Data}

Ms. "Osborne" (pseudonym) teaches in a B school (low minority population) in a second grade classroom. Ms. Osborme is African American, holds a Bachelor degree, and at the time of this study, had five years of teaching experience. During the study year, her classroom was comprised of six Black or African American students, 17 White students, and two Asian students. The children's books in her classroom library came from handme-downs from former teachers or were bought with Ms. Osborne's own money. When looking for literature for her classroom library she reports paying attention to reading and interest level, as well as looking for books that will allow students to use various reading strategies. She rated sources of information concerning children's literature from most to least influential in the following way: formal classes, in-services, libraries/ librarians, other teachers, book clubs, Internet resources, bookstores, parents. Ms. Osborne hopes the books in her classroom library will lead her students to become more knowledgeable in general and better readers and writers. The typical student in her classroom is eight years old, and loves to read and share books with others. Her wish list of books includes fiction and nonfiction chapter books.

Ms. Osborne arranged her desks in groups of six. Her classroom library was quite extensive and was held in large red tubs that were labeled with the theme of the books inside. In addition, there was one forward-facing bookshelf that displayed only Accelerated Reader books, and two others that were full of various types of books. Centers were set up around the room that were based on content areas (e.g., presidents, rocks).

\section{Table U1}

Frequency of Group Representation within all Classroom Literature: Ms. Osborne

Category

Frequency

White characters

Black or African American characters

Hispanic or Latino characters 
American Indian or Alaska Native characters

Native Hawaiian or Pacific Islander characters

Other characters

Total 376

Table U2

Classroom Library Status in Relation to the Selective Tradition

Category

Frequency

Percentage

Status

White

characters

226

$60.11 \%$

Continuing

All other

Characters

150

$39.89 \%$

Note. Status reflects the difference between percentages of white and all other characters. A difference of $55 \%$ means challenging the selective tradition; a difference between of $>5 \%$ and $\leq 10 \%$ means making progress against the selective tradition; a difference $>10 \%$ means a collection is continuing the selective tradition. 


\section{Appendix V}

\section{Preston's Classroom Data}

Ms. "Preston" (pseudonym) teaches in a B school (low minority rate) in a second grade classroom. Ms. Preston is White, has a Masters degree, and at the time of this study, had 25 years of teaching experience. During the study year, her classroom was comprised of seven Black or African American students, 14 White students, two Asian students, and 1 who Ms. Preston described as Indian. The children's books in her classroom library came from hand-me downs from former teachers, were bought by Ms. Preston, or were earned with points from book clubs. When looking for literature for her classroom library she reports that she seeks books by popular authors and depicting popular characters and animals, and that will interest her students. She rated sources of information concerning children's literature from most to least influential in the following way: book clubs, libraries/ librarians, formal classes, in-services, bookstores, other teachers, parents, Internet resources. Ms. Preston hopes the books in her classroom library will help her students gain a love of reading while also increasing their reading skills. She reports that the typical student in her classroom likes to read and has average or above average reading abilities. When buying or checking out books for his classroom library she thinks about the students in her class. Her wish list of books includes more variety, nonfiction, and more magazines.

Ms. Preston arranged her desks in groups of five or six, with a few individual desks set apart from the others. Books in her classroom library were separated into very clearly labeled book boxes. On top of the low bookshelves were boxes for magazines, such as Ranger Rick.

Table V1

Frequency of Group Representation within all Classroom Literature: Ms. Preston

Category

Frequency

White characters

Black or African American characters

Hispanic or Latino characters

Asian characters 
Native Hawaiian or Pacific Islander characters 1

$\begin{array}{ll}\text { Other characters } & 0\end{array}$

$\begin{array}{ll}\text { Total } & 183\end{array}$

Table V2

Classroom Library Status in Relation to the Selective Tradition

$\begin{array}{llll}\text { Category } & \text { Frequency } & \text { Percentage } & \text { Status }\end{array}$

White

characters

100

$54.64 \%$

Making progress

All other

Characters $\quad 83 \quad 45.36 \%$

Note. Status reflects the difference between percentages of white and all other characters. A difference of $\leq 5 \%$ means challenging the selective tradition; a difference between of $>5 \%$ and $\leq 10 \%$ means making progress against the selective tradition; a difference $>10 \%$ means a collection is continuing the selective tradition. 


\section{Appendix W}

\section{Quinn's Classroom Data}

Ms. "Quinn" (pseudonym) teaches in an A school (high minority population) in a second grade classroom. Ms. Quinn is White, has a Masters degree, and at the time of this study, had $1 \frac{1}{2}$ years of teaching experience. During the study year, her classroom was comprised of 15 Black or African American students, 6 White students, one Hispanic or Latino student, and one Asian student. The children's books in her classroom library came from hand-me-downs from former teachers, were bought by Ms. Quinn, or were borrowed from the Public Library. When looking for literature for her classroom library she reports that she seeks Caldecott award winners and variety. She rated sources of information concerning children's literature from most to least influential in the following way: book clubs, parents, Internet resources, in-services, other teachers, libraries/ librarians, bookstores, formal classes. Ms. Quinn hopes her students will gain a love of reading from the books in her classroom library. She describes the typical student in her classroom as "low-socioeconomic; minority." When buying or checking out books for her classroom library she says she thinks of all of her students. Her wish list of books includes "classic literature" and nonfiction books.

Ms. Quinn arranged her desks in lines facing the center of the room, so that students looked toward one another. Books in her classroom library were in labeled book boxes on shelves, some low and others that may have been difficult for students to reach. Additional books were displayed in forward facing bookshelves and on chalkboard trays. She had a u-shaped table for guided reading groups.

Table W1

Frequency of Group Representation within all Classroom Literature: Ms. Quinn

Category $\quad$ Frequency

White characters

Black or African American characters

Hispanic or Latino characters

Asian characters 
American Indian or Alaska Native characters

Native Hawaiian or Pacific Islander characters

Other characters

Total

Table W2

Classroom Library Status in Relation to the Selective Tradition

$\begin{array}{llll}\text { Category } & \text { Frequency } & \text { Percentage } & \text { Status }\end{array}$

White

characters

132

$53.88 \%$

Making progress

All other

Characters

113

$46.12 \%$

Note. Status reflects the difference between percentages of white and all other characters. A difference of $\leq 5 \%$ means challenging the selective tradition; a difference between of $>5 \%$ and $\leq 10 \%$ means making progress against the selective tradition; a difference $>10 \%$ means a collection is continuing the selective tradition. 


\section{Appendix X}

\section{Robin's Classroom Data}

Ms. "Robin" (pseudonym) teaches in an A school (high minority population) in a second grade classroom. Ms. Robin is White, has a Masters degree, and at the time of this study, had five years of teaching experience. During the study year, her classroom was comprised of 15 Black or African American students, 6 White students, one Hispanic or Latino student, and one Asian student. The children's books in her classroom library came from hand-me-downs from former teachers, were bought by herself or her school, or were borrowed from the Public Library. When looking for literature for her classroom library she reports that she seeks a variety of genre and levels. She adds that she looks for "good quality literature as well as some popular trendy titles." She rated sources of information concerning children's literature from most to least influential in the following way: parents, formal classes, Internet resources, bookstores, in-services, other teachers, libraries/ librarians, book clubs. Ms. Robin hopes her students will gain a love of reading, word attack skills, and fluency from the books in her classroom library. She describes the typical student in her classroom as "average second graders" who are interested in a variety of subjects "from dinosaurs to volcanoes to dancing." She explains that she tries to buy a variety of books to meet their needs. Her wish list of books includes hardback books, poetry, and sports-related books "for my boys."

Ms. Robin arranged her desks in groups of four or six. Books in her classroom library were in labeled and unlabeled book boxes on low shelves.

Table X1

Frequency of Group Representation within all Classroom Literature: Ms. Robin

White characters

Black or African American characters

Hispanic or Latino characters

Asian characters

American Indian or Alaska Native characters 
Native Hawaiian or Pacific Islander characters

Other characters

Total

91

Table X2

Classroom Library Status in Relation to the Selective Tradition

$\begin{array}{lll}\text { Category } & \text { Frequency } & \text { Percentage }\end{array}$

White

characters

56

$61.54 \%$

Continuing

All other

Characters

35

$38.46 \%$

Note. Status reflects the difference between percentages of white and all other characters. A difference of $\leq 5 \%$ means challenging the selective tradition; a difference between of $>5 \%$ and $\leq 10 \%$ means making progress against the selective tradition; a difference $>10 \%$ means a collection is continuing the selective tradition. 


\section{Appendix Y}

\section{Smith's Classroom Data}

Ms. "Smith" (pseudonym) teaches in an A school (high minority population) in a second grade classroom. Ms. Smith is African American, holds a Bachelors degree, and at the time of this study, had 31 years of teaching experience. During the study year, her classroom was comprised of 11 Black or African American students, six White students, five Hispanic or Latino students, one Asian student, and one Ms. Smith described as "biracial." The children's books in her classroom library came from hand-me-downs from former teachers, were bought by her school or with her own money, were bought with grants (Reading is Fundamental), or were borrowed from the Public Library. When looking for literature for her classroom library she reports seeking books that will relate to her students' interests, such as animals, math, science, specific authors, and nonfiction. She rated sources of information concerning children's literature from most to least influential in the following way: formal classes, libraries/ librarians, book clubs, other teachers, bookstores, parents, in-services, Internet resources. Ms. Smith hopes her students will gain a love of reading; that they will find an area of interest within the books in her classroom library. She describes the typical student in her classroom as "on task." When buying or checking out books for her classroom library she envisions "students engrossed in reading because the books are interesting and enjoyable to read." Her wish list of books includes more nonfiction because she wants her "students to be well-rounded."

Ms. Smith arranged her desks in groups of four or six. Books in her classroom library were arranged in unlabeled but neat bookshelves and in unlabeled boxes on top of the bookshelves.

Table Y1

Frequency of Group Representation within all Classroom Literature: Ms. Smith

Category

Frequency

White characters

Black or African American characters

Hispanic or Latino characters 
Asian characters

American Indian or Alaska Native characters 3

Native Hawaiian or Pacific Islander characters 0

$\begin{array}{ll}\text { Other characters } & 0\end{array}$

$\begin{array}{ll}\text { Total } & 85\end{array}$

Table Y2

Classroom Library Status in Relation to the Selective Tradition

Category $\quad$ Frequency $\quad$ Percentage Status

White

characters

53

$62.35 \%$

Continuing

All other

Characters

32

$37.65 \%$

Note. Status reflects the difference between percentages of white and all other characters. A difference of $\leq 5 \%$ means challenging the selective tradition; a difference between of $>5 \%$ and $\leq 10 \%$ means making progress against the selective tradition; $a$ difference $>10 \%$ means a collection is continuing the selective tradition. 
Appendix Z

\section{Turner's Classroom Data}

Ms. "Turner" (pseudonym) teaches in an A school (high minority population) in a second grade classroom. Ms. Turner is White, has a Masters degree, and at the time of this study, had 16 years of teaching experience. During the study year, her classroom was comprised of nine Black or African American students, 11 White students, and four Hispanic or Latino students. The children's books in her classroom library came from hand-me-downs from former teachers, were bought with her money, or were donated by her friends. When seeking literature for her classroom library she looks for books on her students' different reading levels, nonfiction, fiction, and books her students "may not have much exposure to." She rated sources of information concerning children's literature from most to least influential in the following way: Internet resources, inservices, bookstores, other teachers, formal classes, libraries/ librarians, book clubs, parents. Ms. Turner hopes the books in her classroom library will help her students gain a love of reading and will help them learn more information about various subjects. She also hopes her students will gain the "realization of how much can be gained from reading and if you can't read how much is lost on you." She reports that the typical student in her classroom has "average to lower intelligence," with " one parent in jail, split household," or a "child living with a foster parent or other family member." When buying or checking out books for her classroom library thinks of a "child craving knowledge who has little exposure to books outside of school." Her wish list of books includes more big books, oversized hardback books, and paperbacks.

Ms. Turner arranged her desks in groups of four, five, or six. Books in her classroom library were in unlabeled bookcases. Several titles depicted characters with disabilities.

Table Z1

Frequency of Group Representation within all Classroom Literature: Ms. Turner

Category

Frequency

White characters

Black or African American characters

Hispanic or Latino characters 
Asian characters

American Indian or Alaska Native characters 6

Native Hawaiian or Pacific Islander characters 2

$\begin{array}{ll}\text { Other characters } & 0\end{array}$

$\begin{array}{ll}\text { Total } & 188\end{array}$

Table Z2

Classroom Library Status in Relation to the Selective Tradition

\begin{tabular}{llll}
\hline Category & Frequency & Percentage & Status
\end{tabular}

White

$\begin{array}{llll}\text { characters } & 93 & 49.47 \% & \text { Challenging }\end{array}$

All other

Characters $\quad 95 \quad 50.53 \%$

Note. Status reflects the difference between percentages of white and all other characters. A difference of $\leq 5 \%$ means challenging the selective tradition; a difference between of $>5 \%$ and $\leq 10 \%$ means making progress against the selective tradition; a difference $>10 \%$ means a collection is continuing the selective tradition. 
Appendix AA

\section{Usher' Classroom Data}

Ms. "Usher" (pseudonym) teaches in an A school (high minority population) in a second grade classroom. Ms. Usher is Africa American, and holds her Rank 1 certification. She did not report the number of years experience she has. During the study year, her classroom was comprised of ten Black or African American students, nine White students, one Hispanic or Latino student, and three other-one she described as Arabic and two she described as biracial. The children's books in her classroom library came from hand-me-downs from former teachers or were bought by her school or herself. When looking for literature for her classroom library she reports paying attention to reading levels, series books, and books that involve TV characters. She rated sources of information concerning children's literature from most to least influential in the following way: formal classes, in-services, Internet resources, bookstores, libraries/ librarians, other teachers, book clubs, parents. Ms. Usher hopes her students will learn life lessons and see relatable situations within the books in her classroom. She describes the typical student in her classroom as someone who loves to read, is excited about learning, and need to be challenged. When buying or checking out books for her classroom library she pictures students that love reading various topics and genres in the kindergarten through third grade range. Her wish list of books includes more chapter books for the advanced readers and more book sets. She explains that, "The children love reading the chapter books. The text is richer than just a short story book."

Ms. Usher arranged her desks in groups of four or six. Books in his classroom library were organized into labeled boxes on bookshelves. In addition, there were three forward-facing bookshelves full of books.

Table AA1

Frequency of Group Representation within all Classroom Literature: Ms. Usher

Category

Frequency

White characters

Black or African American characters

Hispanic or Latino characters

Asian characters 
Native Hawaiian or Pacific Islander characters

Other characters

Total

181

Table AA2

Classroom Library Status in Relation to the Selective Tradition

$\begin{array}{lll}\text { Category } & \text { Frequency } & \text { Percentage }\end{array}$

White

$\begin{array}{llll}\text { Characters } & 120 & 66.30 \% & \text { Continuing }\end{array}$

All other

Characters

61

$33.70 \%$

Note. Status reflects the difference between percentages of white and all other characters. A difference of $\leq 5 \%$ means challenging the selective tradition; a difference between of $>5 \%$ and $\leq 10 \%$ means making progress against the selective tradition; $a$ difference $>10 \%$ means a collection is continuing the selective tradition. 


\section{Appendix AB}

\section{Vogel's Classroom Data}

Mr. "Vogel" (pseudonym) teaches in an A school (high minority population) in a second grade classroom. Mr. Vogel is White, holds a Masters degree, and at the time of this study, had nine years of teaching experience. During the study year, his classroom was comprised of eight Black or African American students, eight White students, one Asian student, and seven students Mr. Vogel described as biracial. The children's books in his classroom library came from hand-me-downs from former teachers or were bought by his school or himself. When looking for literature for his classroom library he reports that he looks for books that are age appropriate, offer a variety of genres, and are written and illustrated to stimulate a desire to read. He rated sources of information concerning children's literature from most to least influential in the following way: formal classes, bookstores, libraries/ librarians, in-services, other teachers, Internet resources, book clubs, parents. Mr. Vogel hopes the books in his classroom library will help his students discover opportunities to explore through reading. He describes the students in his classroom as eight and nine year olds; some are non-readers and others read on the $4^{\text {th }}$ grade level; from low socioeconomic background with some support at home for academic success. He adds that his students have a desire to learn. When buying or checking out books for his classroom library he thinks about a student who is eager to learn about new people, places and stories, and who is motivated to read for fun. His wish list of books includes books of all genres and levels. His main criteria would be "quality plots, strong vocabulary, and stimulating art."

Mr. Vogel had his desks arranged in a few clusters of four or five desks and several individually placed desks. Books were arranged in unmarked buckets on easily accessible bookshelves and in a forward-facing bookshelf.

Table AB1

Frequency of Group Representation within all Classroom Literature: Mr. Vogel

Category

White characters

Black or African American characters

Hispanic or Latino characters
Frequency 
American Indian or Alaska Native characters 6

Native Hawaiian or Pacific Islander characters 0

$\begin{array}{ll}\text { Other characters } & 8\end{array}$

$\begin{array}{ll}\text { Total } & 140\end{array}$

Table AB2

Classroom Library Status in Relation to the Selective Tradition

$\begin{array}{lll}\text { Category } & \text { Frequency } & \text { Percentage }\end{array}$

White

$\begin{array}{llll}\text { Characters } & 82 & 58.57 \% & \text { Continuing }\end{array}$

All other

Characters $\quad 58 \quad 41.43 \%$

Note. Status reflects the difference between percentages of white and all other characters. A difference of $\leq 5 \%$ means challenging the selective tradition; a difference between of $>5 \%$ and $\leq 10 \%$ means making progress against the selective tradition; a difference $>10 \%$ means a collection is continuing the selective tradition. 


\section{Appendix AC}

\section{Table AC1}

Diversity of Literature and Students in Individual Classrooms

\begin{tabular}{cccc} 
& & \multicolumn{2}{c}{ Racial Groups Represented } \\
\cline { 3 - 4 } Subject & A or & In Classroom Libraries & $\begin{array}{c}\text { Among students in the } \\
\text { classroom }\end{array}$ \\
\hline
\end{tabular}

\begin{tabular}{|c|c|c|c|}
\hline Adams & B & $\begin{array}{l}54.75 \% \mathrm{~W} ; 26.82 \% \mathrm{~B} ; 2.23 \% \mathrm{HL} \\
11.17 \% \mathrm{~A} ; 3.91 \% \mathrm{AI} \text { or } \mathrm{Al} ; 0 \% \mathrm{NH} \text { or } \\
\mathrm{PI} ; 1.11 \% \text { other }\end{array}$ & $48 \% \mathrm{~W} ; 48 \% \mathrm{~B} ; 4 \% \mathrm{HL}$ \\
\hline Burns & B & $\begin{array}{l}70.44 \% \mathrm{~W} ; 15.72 \% \mathrm{~B} ; 1.26 \% \mathrm{HL} ; \\
6.92 \% \mathrm{~A} ; 3.14 \% \mathrm{AI} \text { or } \mathrm{Al} ; 0.63 \% \mathrm{NH} \\
\text { or PI; } 1.89 \% \text { other }\end{array}$ & $55 \% \mathrm{~W} ; 45 \% \mathrm{~B}$ \\
\hline Caudill & B & $\begin{array}{l}49.73 \% \mathrm{~W} ; 21.62 \% \mathrm{~B} ; 11.89 \% \mathrm{HL} ; \\
12.97 \% \mathrm{~A} ; 2.7 \% \mathrm{AI} \text { or } \mathrm{Al} ; 0 \% \mathrm{NH} \text { or } \\
\mathrm{PI} ; 1.08 \% \text { other }\end{array}$ & $60 \% \mathrm{~W} ; 25 \% \mathrm{~B} ; 15 \% \mathrm{HL}$ \\
\hline Dauphin & B & $\begin{array}{l}64.7 \% \mathrm{~W} ; 14.7 \% \mathrm{~B} ; 8.8 \% \mathrm{HL} ; 8.8 \% \mathrm{~A} ; \\
2 \% \mathrm{AI} \text { or } \mathrm{Al} ; 0 \% \mathrm{NH} \text { or } \mathrm{PI} ; 1 \% \text { other }\end{array}$ & $40 \% \mathrm{~W} ; 50 \% \mathrm{~B} ; 10 \% \mathrm{HL}$ \\
\hline Evans & A & $\begin{array}{l}62.5 \% \mathrm{~W} ; 18.38 \% \mathrm{~B} ; 7 \% \mathrm{HL} ; 9.56 \% \\
\mathrm{~A} ; 1.47 \% \mathrm{AI} \text { or } \mathrm{Al} ; 0.71 \% \mathrm{NH} \text { or PI; } \\
0.37 \% \text { other }\end{array}$ & $\begin{array}{c}13 \% \mathrm{~W} ; 56 \% \mathrm{~B} ; 22 \% \mathrm{HL} ; 9 \% \\
\mathrm{~A}\end{array}$ \\
\hline Franklin & A & $\begin{array}{l}61.54 \% \mathrm{~W} ; 22.12 \% \mathrm{~B} ; 2.88 \mathrm{HL} ; 10.1 \% \\
\mathrm{~A} ; 1.92 \% \mathrm{AI} \text { or } \mathrm{AI} ; 0.48 \% \mathrm{NH} \text { or } \mathrm{PI} \\
0.96 \% \text { other }\end{array}$ & $\begin{array}{c}13 \% \mathrm{~W} ; 65 \% \mathrm{~B} ; 9 \% \mathrm{HL} ; 4 \% \\
\mathrm{~A} ; 4 \% \mathrm{AI} \text { or } \mathrm{Al} ; 4 \% \text { other }\end{array}$ \\
\hline Greene & B & $\begin{array}{l}57.93 \% \mathrm{~W} ; 23.17 \% \mathrm{~B} ; 4.88 \% \mathrm{HL} ; \\
10.37 \% \mathrm{~A} ; 3.66 \% \mathrm{AI} \text { or } \mathrm{Al} ; 0 \% \mathrm{NH} \text { or } \\
\mathrm{PI} ; 0 \% \text { other }\end{array}$ & $76 \% \mathrm{~W} ; 24 \% \mathrm{~B}$ \\
\hline Harper & B & $\begin{array}{l}60.73 \% \mathrm{~W} ; 22.36 \% \mathrm{~B} ; 5.3 \% \mathrm{HL} ; \\
8.48 \% \mathrm{~A} ; 2.47 \% \mathrm{Al} \text { or } \mathrm{Al} ; 0.71 \% \mathrm{NH} \\
\text { or PI; } 0 \% \text { other }\end{array}$ & $70 \% \mathrm{~W} ; 22 \% \mathrm{~B} ; 8 \% \mathrm{~A}$ \\
\hline Ingram & B & $\begin{array}{l}47.54 \% \mathrm{~W} ; 27.87 \% \mathrm{~B} ; 13.11 \% \mathrm{HL} ; \\
5.71 \% \mathrm{~A} ; 5.71 \% \mathrm{AI} \text { or } \mathrm{Al} ; 0 \% \mathrm{NH} \text { or } \\
\mathrm{PI} ; 0 \% \text { other }\end{array}$ & $75 \% \mathrm{~W} ; 21 \% \mathrm{~B} ; 4 \% \mathrm{HL}$ \\
\hline Jones & B & $\begin{array}{l}67.33 \% \mathrm{~W} ; 15.84 \% \mathrm{~B} ; 2.97 \% \mathrm{HL} ; \\
6.93 \% \mathrm{~A} ; 5.94 \% \mathrm{AI} \text { or } \mathrm{Al} ; 99 \% \mathrm{NH} \text { or } \\
\mathrm{PI} ; 0 \% \text { other }\end{array}$ & $62 \% \mathrm{~W} ; 24 \% \mathrm{~B} ; 14 \% \mathrm{HL}$ \\
\hline
\end{tabular}


$59.29 \% \mathrm{~W} ; 25.66 \% \mathrm{~B} ; 2.65 \% \mathrm{HL}$

$11.5 \% \mathrm{~A} ; 0 \% \mathrm{AI}$ or $\mathrm{Al} ; 0.88 \% \mathrm{NH}$ or

Klinck

Lee

Mimms

Napier

Osborne

Robin

Smith

Turner

Usher

Vogel

Note. $\mathrm{W}=$ White, $\mathrm{B}=$ Black or African American, $\mathrm{HL}=$ Hispanic or Latino, Asian= Asian, $\mathrm{AI}$ or $\mathrm{Al}=$ American Indian or Alaska native, $\mathrm{NH}$ or $\mathrm{PI}=$ Native Hawaiian or Pacific Islander

Results not reported

$21 \% \mathrm{~W} ; 53 \% \mathrm{~B} ; 26 \% \mathrm{H}$

$7.91 \% \mathrm{~A} ; 2.88 \% \mathrm{AI}$ or $\mathrm{Al} ; 0.72 \% \mathrm{NH}$

or PI; $0 \%$ other

$64.58 \% \mathrm{~W} ; 20.83 \% \mathrm{~B} ; 3.33 \% \mathrm{HL}$;

$74 \% \mathrm{~W} ; 26 \% \mathrm{~B}$

$7.08 \% \mathrm{~A} ; 2.08 \% \mathrm{AI}$ or $\mathrm{Al} ; 2.08 \% \mathrm{NH}$

B or PI; $0 \%$ other

$62.04 \% \mathrm{~W} ; 24.45 \% \mathrm{~B} ; 6.57 \% \mathrm{HL}$;

$71 \% \mathrm{~W} ; 25 \% \mathrm{~B} ; 4 \% \mathrm{~A}$

$5.47 \% \mathrm{~A} ; 1.09 \% \mathrm{Al}$ or $\mathrm{Al} ; 0.36 \% \mathrm{NH}$

$\mathrm{B}$ or PI; $0 \%$ other

$60.11 \% \mathrm{~W} ; 22.61 \% \mathrm{~B} ; 3.99 \% \mathrm{HL}$;

$68 \% \mathrm{~W} ; 24 \% \mathrm{~B} ; 8 \% \mathrm{~A}$

$10.37 \% \mathrm{~A} ; 2.92 \% \mathrm{AI}$ or $\mathrm{Al} ; 0 \% \mathrm{NH}$ or

B PI; $0 \%$ other

$54.64 \% \mathrm{~W} ; 20.77 \% \mathrm{~B} ; 8.74 \% \mathrm{HL}$;

$58 \% \mathrm{~W} ; 29 \% \mathrm{~B} ; 8 \% \mathrm{~A}$

$13.11 \% \mathrm{~A} ; 2.19 \% \mathrm{AI}$ or $\mathrm{Al} ; 0.55 \% \mathrm{NH}$

B or PI; $0 \%$ other

$53.88 \% \mathrm{~W} ; 24.9 \% \mathrm{~B} ; 11.43 \% \mathrm{HL}$;

$33 \% \mathrm{~W} ; 63 \% \mathrm{~B} ; 4 \% \mathrm{HL}$

$7.76 \% \mathrm{~A} ; 1.63 \% \mathrm{AI}$ or $\mathrm{Al} ; 0 \% \mathrm{NH}$ or

A PI; $0.41 \%$ other

$61.54 \% \mathrm{~W} ; 20.88 \% \mathrm{~B} ; 4.4 \% \mathrm{HL} ; 5.5 \%$

$26 \% \mathrm{~W} ; 65 \%$ B $4 \% \mathrm{H} ; 4 \% \mathrm{~A}$

$\mathrm{A} ; 4.4 \% \mathrm{AI}$ or $\mathrm{Al} ; 2.2 \% \mathrm{NH}$ or PI;

A $\quad 1.1 \%$ other

$62.35 \% \mathrm{~W} ; 25.88 \% \mathrm{~B} ; 2.35 \% \mathrm{HL}$; $5.88 \% \mathrm{~A} ; 3.51 \% \mathrm{Al}$ or $\mathrm{Al} ; 0 \% \mathrm{NH}$ or A PI; $0 \%$ other

$49.47 \% \mathrm{~W} ; 23.4 \% \mathrm{~B} ; 11.7 \% \mathrm{HL}$;

$11.17 \% \mathrm{~A} 3.19 \% \mathrm{AI}$ or $\mathrm{Al} ; 1.06 \% \mathrm{NH}$

A

or PI; $0 \%$ other

$66.30 \% \mathrm{~W} ; 18.23 \% \mathrm{~B} ; 3.31 \% \mathrm{HL}$;

$8.29 \% \mathrm{~A} ; 2.76 \% \mathrm{Al}$ or $\mathrm{Al} ; 0 \% \mathrm{NH}$ or

A PI; $1.1 \%$ other

$58.57 \% \mathrm{~W} ; 21.43 \% \mathrm{~B} ; 5 \% \mathrm{HL} ; 5 \% \mathrm{~A}$ $4.29 \% \mathrm{AI}$ or $\mathrm{Al} ; 0 \% \mathrm{NH}$ or PI $5.71 \%$

$4.29 \%$
$46 \% \mathrm{~W} ; 38 \% \mathrm{~B} ; 16 \% \mathrm{HL}$

$33 \% \mathrm{~W} ; 33 \% \mathrm{~B} ; 4 \% \mathrm{~A} ; 29 \%$

other

$25 \% \mathrm{~W} ; 46 \% \mathrm{~B} ; 21 \% \mathrm{HL} ; 4 \%$ A; $4 \%$ other

other 
Appendix AD

Table AD1

Representations within Classroom Library and Student-selected Literature

\begin{tabular}{|c|c|c|c|c|}
\hline & School & Racial Groups in the Classroom & Racial Groups in & \\
\hline Teacher & Group & Libraries & Student selected & 1. \\
\hline
\end{tabular}

Adams
B

$70.44 \% \mathrm{~W} ; 15.72 \% \mathrm{~B} ; 1.26 \% \quad 70.7 \% \mathrm{~W} ; 17.1 \% \mathrm{~B}$

Burns B $\quad B \quad H=6.92 \% A ; 3.14 \%$ AI or Al;

$\mathrm{HL} ; 6.92 \% \mathrm{~A} ; 3.14 \% \mathrm{AI}$ or $\mathrm{Al} ; \quad 9.8 \% \mathrm{~A} ; 2.4 \%$ other

Comparable $0.63 \% \mathrm{NH}$ or PI; $1.89 \%$ other

Caudill

$49.73 \% \mathrm{~W} ; 21.62 \% \mathrm{~B} ; 11.89 \%$

B

$\mathrm{HL} ; 12.97 \% \mathrm{~A} ; 2.7 \% \mathrm{AI}$ or $\mathrm{Al}$;

$60.4 \% \mathrm{~W} ; 20.8 \% \mathrm{~B}$

$0.0 \% \mathrm{NH}$ or PI; $1.08 \%$ other

$$
5.7 \% \mathrm{HL} ; 3.8 \% \mathrm{~A}
$$

Teacher more inclusive

$64.7 \% \mathrm{~W} ; 14.7 \% \mathrm{~B} ; 8.8 \% \mathrm{HL}$;

Dauphin

B

$8.8 \% \mathrm{~A} ; 2 \% \mathrm{AI}$ or $\mathrm{Al} ; 0.0 \% \mathrm{NH}$

$100 \% \mathrm{~W}$

Teachers more

or PI; $1 \%$ other

\begin{tabular}{|c|c|c|c|c|}
\hline Evans & A & $62.5 \% \mathrm{~W} ; 18.38 \% \mathrm{~B} ; 7 \% \mathrm{HL} ;$ & $70 \% \mathrm{~W} ; 12.5 \% \mathrm{~B} ; 10 \%$ & Teachers and \\
\hline & & $9.56 \% \mathrm{~A} ; 1.47 \% \mathrm{AI}$ or $\mathrm{Al}$ & $\mathrm{HL} ; 7.9 \% \mathrm{~A}$ & students more \\
\hline
\end{tabular}


$0.71 \% \mathrm{NH}$ or $\mathrm{PI} ; 0.37 \%$ other

$61.54 \% \mathrm{~W} ; 22.12 \% \mathrm{~B} ; 2.88 \%$

Franklin

A $\mathrm{HL} ; 10.1 \% \mathrm{~A} ; 1.92 \% \mathrm{AI}$ or Al;

$0.48 \% \mathrm{NH}$ or PI; $0.96 \%$ other

$57.93 \% \mathrm{~W} ; 23.17 \% \mathrm{~B} ; 4.88 \%$

Greene

B

$\mathrm{HL} ; 10.37 \% \mathrm{~A} ; 3.66 \% \mathrm{AI}$ or $\mathrm{Al}$;

$0.0 \% \mathrm{NH}$ or PI; $0.0 \%$ other

$60.78 \% \mathrm{~W} ; 22.36 \% \mathrm{~B} ; 5.3 \%$

Harper

$\mathrm{HL} ; 8.48 \% \mathrm{~A} ; 2.47 \% \mathrm{Al}$ or $\mathrm{Al}$;

$0.71 \% \mathrm{NH}$ or PI; $0.0 \%$ other

$47.54 \% \mathrm{~W} ; 27.87 \% \mathrm{~B} ; 13.11 \%$

Ingram

B

$\mathrm{HL} ; 5.71 \% \mathrm{~A} ; 5.71 \% \mathrm{Al}$ or $\mathrm{Al}$;

$0.0 \% \mathrm{NH}$ or PI; $0.0 \%$ other

$67.33 \% \mathrm{~W} ; 15.84 \% \mathrm{~B} ; 2.97 \%$

Jones
$\mathrm{HL} ; 6.93 \% \mathrm{~A} ; 5.94 \% \mathrm{Al}$ or $\mathrm{Al}$

$0.99 \%$ NH or PI; $0.0 \%$ other
$62.5 \% \mathrm{~W} ; 14.3 \% \mathrm{~B}$

$3.6 \% \mathrm{H} ; 12.5 \% \mathrm{~A}$;

Comparable

$1.8 \% \mathrm{Al}$ or $\mathrm{Al} ; 1.8 \%$

NH or PI; $3.6 \%$ other

$82.9 \% \mathrm{~W} ; 12.2 \% \mathrm{~B} ; \quad$ Teachers more

$4.9 \% \mathrm{~A}$

inclusive.

$85.7 \% \mathrm{~W} ; 9.5 \% \mathrm{~B}$

$4.8 \% \mathrm{~A}$

Teachers more

inclusive.
$62.1 \% \mathrm{~W} ; 20.7 \% \mathrm{~B}$

$6.9 \% \mathrm{HL} ; 3.4 \% \mathrm{~A}$

$6.9 \% \mathrm{AI}$ or $\mathrm{Al}$

Teachers and

$61.9 \% \mathrm{~W} ; 28.6 \% \mathrm{~B}$

$2.4 \% \mathrm{H} ; 7.1 \% \mathrm{~A}$
Teacher more

inclusive students more

inclusive of

different groups 
$59.29 \% \mathrm{~W} ; 25.66 \% \mathrm{~B} ; 2.65 \%$

Klink

A

$\mathrm{HL} ; 11.5 \% \mathrm{~A} ; 0.0 \% \mathrm{AI}$ or $\mathrm{Al}$;

$0.88 \% \mathrm{NH}$ or PI; $0.0 \%$ other

$64.03 \% \mathrm{~W} ; 19.42 \% \mathrm{~B} ; 5.04 \%$

Lee

A

$\mathrm{HL} ; 7.91 \% \mathrm{~A} ; 2.88 \% \mathrm{AI}$ or $\mathrm{Al}$;

$0.72 \% \mathrm{NH}$ or PI; $0.0 \%$ other

$64.58 \% \mathrm{~W} ; 20.83 \% \mathrm{~B} ; 3.33 \%$

Mimms

B

$\mathrm{HL} ; 7.08 \% \mathrm{~A} ; 2.08 \% \mathrm{AI}$ or $\mathrm{Al}$; $2.08 \% \mathrm{NH}$ or $\mathrm{PI} ; 0.0 \%$ other

$62.04 \% \mathrm{~W} ; 24.45 \% \mathrm{~B} ; 6.57 \%$

Napier

$\mathrm{HL} ; 5.47 \% \mathrm{~A} ; 1.09 \% \mathrm{AI}$ or $\mathrm{Al}$;

$0.36 \% \mathrm{NH}$ or PI; $0.0 \%$ other

$60.11 \% \mathrm{~W} ; 22.61 \% \mathrm{~B} ; 3.99 \%$ $\mathrm{HL} ; 10.37 \% \mathrm{~A} ; 2.92 \% \mathrm{AI}$ or $\mathrm{Al}$; $0.0 \% \mathrm{NH}$ or PI; $0.0 \%$ other

$54.64 \% \mathrm{~W} ; 20.77 \% \mathrm{~B} ; 8.74 \%$

$\mathrm{HL} ; 13.11 \% \mathrm{~A} ; 2.19 \% \mathrm{AI}$ or $\mathrm{Al}$;

$0.55 \% \mathrm{NH}$ or PI; $0.0 \%$ other
$61.90 \% \mathrm{~W} ; 28.57 \% \mathrm{~B}$

$2.38 \% \mathrm{HL} ; 7.14 \% \mathrm{~A} ; \quad$ Comparable

$0.0 \% \mathrm{AI}$ or $\mathrm{Al} ; 0.0 \%$

NH or PI; $0.0 \%$ other

$73.3 \% \mathrm{~W} ; 20 \% \mathrm{~B}$;

$6.7 \% \mathrm{~A}$

Teacher more

inclusive

Teachers more

inclusive.

$74.3 \% \mathrm{~W} ; 20 \% \mathrm{~B}$; $2.9 \% \mathrm{HL} ; 2.9 \% \mathrm{~A}$

Teachers more inclușive.

$75.5 \% \mathrm{~W} ; 12.2 \% \mathrm{~B}$; $4.1 \% \mathrm{HL} ; 8.2 \% \mathrm{~A}$

Teachers more inclusive.

$41.7 \% \mathrm{~W} ; 16.7 \% \mathrm{~B}$

$12.5 \% \mathrm{HL} ; 25 \% \mathrm{~A}$;

$4.2 \% \mathrm{AI}$ or $\mathrm{Al}$
Students more

inclusive 


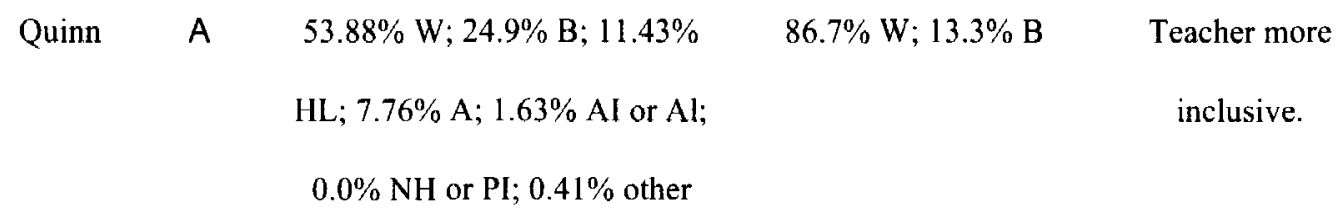

$61.54 \% \mathrm{~W} ; 20.88 \% \mathrm{~B} ; 4.4 \%$

$\begin{array}{llll}\text { Robin } & \mathrm{HL} & \mathrm{H} & \text { Teacher more } \\ \end{array}$

$2.2 \% \mathrm{NH}$ or PI; $1.1 \%$ other

$62.35 \% \mathrm{~W} ; 25.88 \% \mathrm{~B} ; 2.35 \%$

Smith A HL; $5.88 \% \mathrm{~A} ; 3.51 \% \mathrm{AI}$ or $\mathrm{Al}$;

$80 \% \mathrm{~W} ; 15 \% \mathrm{~B} ; 5 \% \quad$ Teacher more

$0.0 \% \mathrm{NH}$ or $\mathrm{Pl} ; 0.0 \%$ other

$$
\text { AI or } \mathrm{Al} \quad \text { inclusive }
$$

Turner

A

$49.47 \% \mathrm{~W} ; 23.4 \% \mathrm{~B} ; 11.7 \% \quad 56.3 \% \mathrm{~W} ; 23.3 \% \mathrm{~B}$

$\mathrm{HL} ; 11.17 \% \mathrm{~A} ; 3.19 \% \mathrm{Al}$ or $\mathrm{Al}$

$10.7 \% \mathrm{HL} ; 8.7 \% \mathrm{~A}$;

Comparable

$1.06 \% \mathrm{NH}$ or $\mathrm{PI} ; 0.0 \%$ other

$1 \% \mathrm{AI}$ or $\mathrm{Al}$

$66.3 \% \mathrm{~W} ; 18.23 \% \mathrm{~B} ; 3.31 \%$

Usher

A

$\mathrm{HL} ; 8.29 \% \mathrm{~A} ; 2.76 \% \mathrm{AI}$ or $\mathrm{Al}$;

$84 \% \mathrm{~W} ; 4 \% \mathrm{~B} ; 12 \% \mathrm{~A}$

Teachers more

$0.0 \% \mathrm{NH}$ or PI; $1.1 \%$ other

inclusive

Vogel

A

$58.57 \% \mathrm{~W} ; 21.43 \% \mathrm{~B} ; 5.0 \%$

$\mathrm{HL} ; 5.0 \% \mathrm{~A} ; 4.29 \% \mathrm{AI}$ or $\mathrm{Al}$;

$67.5 \% \mathrm{~W} ; 20 \% \mathrm{~B} ; 5 \%$

$\mathrm{HL} ; 5 \% \mathrm{~A} ; 2.5 \%$ other

Comparable

$0.0 \% \mathrm{NH}$ or $\mathrm{PI} ; 5.71 \%$ other

Note. $\mathrm{W}=$ White, $\mathrm{B}=$ Black or African American, $\mathrm{HL}=$ Hispanic or Latino, $\mathrm{A}=\mathrm{A}$ sian, $\mathrm{AI}$ or $\mathrm{Al}=$ American Indian or Alaska Native, $\mathrm{NH}$ or $\mathrm{PI}=$ Native Hawaiian or Pacific Islander 


\title{
CURRICULUM VITAE
}

\section{Nancy Franklin Hulan}

\author{
105 Iola Road \\ Louisville, Kentucky 40207 \\ Phone: (502) 974-8688 \\ nancyfranklin@gmail.com
}

\section{EDUCATION}

2010 Doctoral Candidate, Curriculum and Instruction: Literacy Education

Department of Teaching and Learning, University of Louisville

Expected completion date: Fall 2010

2003

M.Ed., Elementary Education with a specialization in Reading Education

Vanderbilt University

$1999 \quad$ B.A., Linguistics and Spanish

University of Kentucky

Study Abroad through the Kentucky Institute for International Studies:

1997

1996

Morelia, Mexico

Segovia, Spain

\section{RESEARCH EXPERIENCE}

2007-2008 Research Assistant, North Carolina State University, Funded by National Council for Teachers of English

$\square$ Videotaped and transcribed teachers' lessons using equity pedagogy lens

$\square$ Analyzed transcriptions, student data, and teacher surveys qualitatively

$\square$ Presented findings at AERA, NCTE, IRA, and NRC

2007-2008 Program Evaluation Intern, Jefferson County Public Schools, Department of Accountability, Research, and Planning

0 Participated in implementation of qualitative and quantitative research

$\square$ Evaluated district-wide educational intervention programs

$\square$ Utilized SPSS in data analysis

2006-2007 Graduate Research Assistant, University of Louisville, 


\section{Department of Teaching and Learning}

1] Assisted faculty member with research and publication process

$\square$ Collected and analyzed data relating to literacy development

- Taught graduate-level classes as needed

$\square$ Interviewed applicants to the M.Ed. program

2001-2003 Graduate Research Assistant, Vanderbilt University,

Department of Special Education

$\square$ Worked in a variety of schools and classrooms implementing PeerAssisted Learning Strategies

Administered and analyzed reading assessments

- Monitored Computer-Assisted Instruction in classrooms

$\square$ Collected and analyzed data for studies involving reading interventions and their effectiveness

\section{TEACHING EXPERIENCE}

2010-2011 Instructor: University of Louisville

Louisville, KY

C EDTP 311: Introduction to Reading/ Language Arts, P-5

C EDTP 320: Methods for Teaching Reading/Language Arts, P-5

2007-2009 Second Grade Teacher: All subjects, Jefferson County Public Schools, Louisville, KY

Instructed classes of 24 students, with a large population of special needs students and English Language Learners, in Kentucky Core Content for second grade.

[- Participated in Student Support Team, Math Cadre, and Literacy Cadre.

(1) Served as school's second grade team leader, math lead teacher and environmental education liaison.

2005-2006 Second Grade Teacher: All subjects, Clark County Public Schools, Las Vegas, NV

[] Instructed class of 18 students in all areas of the Nevada Curriculum for second grade

(] Brought all students onto grade level in reading through focused instruction

[- Participated in Student Intervention Program, Budget Committee, and Thinking Map instruction

(] Facilitated in the planning of Parents and Kids Reading Together (PAKRAT), a Family Literacy program

2003-2005 Reading Resource/Title I Lead Teacher, Fayette County Public Schools, Lexington, $\mathrm{KY}$ 
] Instructed groups of struggling readers in kindergarten - fifth grade, significantly increasing reading ability in $99 \%$ of students

[] Ensured school adherence to Title 1 regulations and practices

0 Co-wrote Reading First grant, resulting in powerful new reading initiative for primary grades

(1) Served as school liaison and translator to Hispanic families, encouraging increased participation

Implemented school-wide initiatives, increasing parental involvement and student motivation, associated with the Kentucky Reading Project

2000-2001 International Mission Coordinator, Puentes de Cristo, Presbyterian Church, U.S.A., Reynosa, Mexico

C Created and taught basic literacy curriculum in Spanish to preliterate students from ages 6 to 15 .

Planned and implemented children's activities and lessons

( Interpreted and translated for volunteers and community members

1999-2000 Project Coordinator, United Way Grant, Western Kentucky Refugee M.A.A., Bowling Green, KY

Implemented United Way Unanticipated Arrivals grant, encouraging participation in local community

Initiated, trained, and monitored English tutors and mentors, encouraging relationships among participants

C Created and taught English language curriculum to adults

$\square$ Assisted refugee students and their families with school concerns and the job search

Planned Community Education conference with the Center for Multicultural Human Services

\section{PUBLICATIONS}

\section{Books:}

McIntyre, E., Hulan, N., \& Layne, V. (2010). Reading instruction for Diverse Classrooms: A Research-Based, Culturally Responsive Approach. New York: Guilford Press.

\section{Published Manuscripts:}

McIntyre, E., \& Hulan, N. (in press). Teachers' developing understandings about race and achievement in a graduate course on literacy learning. Teacher Education and Practice.

Hulan, N. (2010). What the students will say while the teacher is away: An investigation into student and teacher led discussion within guided reading groups. Literacy Teaching and Learning, $14(1 / 2)$. 
McIntyre, E., Hulan, N., \& Maher, M. (2010). The relationship between literacy learning and cultural differences: A study of teachers' dispositions. Journal of Reading Education, 35 (3).

\section{Manuscripts Submitted for Review:}

McIntyre, E., \& Hulan, N. (under review). Blending instructional paradigms: Elementary teachers' implementation of research-based, culturally responsive reading practice.

\section{Manuscripts in progress:}

Hulan, N. Finding similarities in experiences through multicultural literature: An investigation of second graders' views toward literature from around the world. Manuscript in progress.

\section{Evaluation Reports:}

Dossett, D., \& Hulan, N.F. (2007). LifeSkills Program. Louisville, KY: Jefferson County Public School District.

Dossett, D., \& Hulan, N. F. (2007). Jefferson County Public Schools Reading First Case Study Report: Hartstern Elementary Year 1: 2004-2005. Louisville, KY: Jefferson County Public School District.

Dossett, D., \& Hulan, N. F. (2007). Jefferson County Public Schools Reading First Case Study Report: Hartstern Elementary Year 2: 2005-2006. Louisville, KY: Jefferson County Public School District.

Dossett, D., \& Hulan, N. F. (2007). Jefferson County Public Schools Reading First Case Study Report: Dixie Elementary Year 1: 2004-2005. Louisville, KY: Jefferson County Public School District.

Dossett, D., \& Hulan, N. F. (2007). Jefferson County Public Schools Reading First Case Study Report: Dixie Elementary Year 2: 2005-2006. Louisville, KY: Jefferson County Public School District.

\section{CURRICULAR RESOURCES}

Hulan, N. (2007). Equity lesson sequence: Heifer International and cultural awareness. Louisville, KY: University of Louisville.

Franklin, N. (2004). PACT time for family literacy. Lexington, KY: Breckinridge Elementary School. 
Franklin, N. (2003). Ancient civilizations of Latin America: A curricular resource.

Nashville, TN: Vanderbilt University.

Franklin, N. (2000). Early literacy for Spanish speakers. Reynosa, Mexico: Puentes de Cristo, Presbyterian Church, U.S.A.

Franklin, N. (1999). ESL curriculum for adults. Bowling Green, KY: Western Kentucky Refugee, M.A.A.

\section{PROFESSIONAL DEVELOPMENT (created and led)}

Engaging Kids in Vocabulary Development

Sarah J. Price Elementary School, Louisville, KY, 2008.

Working with English Language Learners in the General Education Classroom. Breckinridge Elementary School, Lexington, KY, 2003.

R. Guild Gray Elementary School, Las Vegas, NV, 2005.

The Literacy Block: What does it look like?

Breckinridge Elementary School, Lexington, KY, 2003 and 2004.

Literacy Centers

Breckinridge Elementary School, Lexington, KY, 2004.

\section{PRESENTATIONS}

McIntyre, E. \& Hulan, N. (2010, December). Can Research-Based Reading Instruction be Culturally Responsive? The Development and Feasibility of a Hybrid Model of Elementary Reading Instruction. To be presented at the annual meeting of the Literacy Research Association, Ft. Worth, TX.

McIntyre, E., \& Hulan, N. (2009, April). Can research-based reading instruction be culturally responsive? Using hybridity as a concept for a model of elementary teachers' literacy practices. Presented at the annual meeting of the American Educational Research Association. San Diego, CA.

McIntyre, E. \& Hulan, N. (2008, December). Teachers' Developing Understandings and Practices of Equity Pedagogy in Reading Instruction. Paper presented at the 58th National Reading Conference, Orlando, FL.

Hulan, N. (2008, May). What the Students will say while the Teacher is away: Encouraging student-led discussions. Paper presentation at 53rd Annual Convention of the International Reading Association, Atlanta, GA. 
McIntyre, E. \& Hulan, N. (2008, May). Moving from traditional discussion toward instructional conversation: Five elementary teachers' development. Poster presentation at the 53rd Annual Convention of the International Reading Association, Atlanta, GA.

McIntyre, E. \& Hulan, N. (2007, November). Teachers' and Researchers' Analyses of Equitable Discourse in Literacy Teaching. Paper presentation at the 57th National Reading Conference, Austin, TX.

McIntyre, E. \& Hulan, N. (2007, November). Teachers' Understandings about the Effects of Class Capital on Student Achievement. Paper presentation at the annual conference of the National Council of Teachers of English, New York City.

Hulan, N., Vanderhaar, J., Ardasheva, Y. (2007, November). Culturally Responsive Teaching in your Classroom. Presentation at the Bienniel Convocation of Kappa Delta $\mathrm{Pi}$, Louisville, $\mathrm{KY}$.

Hulan, N. (2007, April). How do students respond to Rigby's literature? Poster presentation at the Spring Research Conference, jointly sponsored by the University of Louisville, the University of Cincinnati, and the University of Kentucky, Lexington, KY.

Franklin, N. \& Routt, M. K. (2004, May). Parent involvement and student motivation in increasing comprehension. Paper presented at the Kentucky Reading Project Conference, Louisville, KY.

Franklin, N. (2000, February). Puentes de Cristo: Funding goals and directions. Presentation at the Presbyterian Church, Bowling Green, KY.

\section{PROFESSIONAL SERVICE}

2010

2010

2009

2008-2009

2008-2009

2008

2008

2007-2008
Journal of Curriculum Studies, Reviewer

Literacy Research Association (LRA) Proposal Reviewer

Early and Elementary Literacy Processes (Area 5)

Social, Cultural, and Political issues and practices in literacy (Area 7)

Literacy Learning and practice in Multilingual and Multicultural

Settings (Area 8)

National Reading Conference (NRC) Proposal Reviewer

Early and Elementary Literacy Processes (Area 5)

Social, Cultural, and Political issues and practices in literacy (Area 7)

Literacy Learning and practice in Multilingual and Multicultural

Settings (Area 8)

Second grade team leader, Price Elementary School.

Environmental education lead teacher, Price Elementary School

National Reading Conference (NRC) Proposal Reviewer, Section 8.

International Reading Association (IRA) Proposal Reviewer, IRA's

54th Annual Convention West

Math Lead Teacher, Price Elementary School 
2007-2008

2007

2007

2007-2008

2007-2008

2006- 2007

2006- 2007

2005-2006

2003-2005

1997-1999
Student Support Team member, Price Elementary School

Serials review project participant, University of Louisville Champion for Children, Jefferson County Public School District Culturally Responsive Teaching Discussion Board, Creator, Moderator Kappa Delta Pi Education Society, University of Louisville Chapter Historian

Graduate Student Association: Departmental Representative, University of Louisville, College of Education Everyl Reads Reading Mentor, Semple Elementary School Student Intervention Planning Team, R. Gray Elementary School Literacy Team Member, Breckinridge Elementary School Carnegie Center ESL tutor, Lexington, KY

\section{PROFESSIONAL AFFILIATIONS}

National Council of Teachers of English

Literacy Research Association, formerly the National Reading Conference

International Reading Association

American Educational Research Association

\section{GRANT EXPERIENCE AND AWARDS}

Recipient, Samuels Family Scholarship Fund, University of Louisville, 2010, $\$ 350$.

Author, Kappa Delta Pi Educational Foundation, Classroom Teacher Grant, Louisville, $\mathrm{KY}, 2008, \$ 150.00$.

Research Assistant, National Council of Teachers of English grant: Teaching the science of reading through equity pedagogy (Ellen McIntyre, PI). 2007-2009. $\$ 15,000$.

Louisville, KY/Raleigh, NC.

Co-author, Reading First grant, Breckinridge Elementary School, Lexington, KY, 2004$2010, \$ 170,000$.

Project Coordinator, United Way Grant for Unanticipated Arrivals to Western Kentucky Refugee Relocation Services, Bowling Green, KY, 1999-2000.

\section{TEACHING CERTIFICATIONS}

Kentucky Teaching Certificate for teaching Primary to Grade 5 Kentucky Teaching Endorsement for teaching Reading and Writing in all grades National Center for Family Literacy: Certification in "Working with Families"

\section{LANGUAGES}

Spanish 